National Toxicology Program

NTP DEVELOPMENTAL AND

REPRODUCTIVE TOXICITY

TECHNICAL REPORT ON THE

PRENATAL DEVELOPMENT

STUDIES OF

VINPOCETINE

(CASRN 42971-09-5) IN

Sprague DaWley

(HSD:SPRAGUe DAWLEY ${ }^{\circledR}$ SD $^{\circledR}$ )

Rats and NeW Zealand

White (Hra:NzW SpF)

Rabbits (Gavage Studies)

NTP DART 03

JUNE 2020 


\title{
NTP Developmental and Reproductive Toxicity Technical Report on the Prenatal Development Studies of Vinpocetine (CASRN 42971-09-5) in Sprague Dawley (Hsd:Sprague Dawley ${ }^{\circledR}$ SD $^{\circledR}$ ) Rats and New Zealand White (Hra:Nzw Spf) Rabbits (Gavage Studies)
}

DART Report 03

June 2020

\author{
National Toxicology Program \\ Public Health Service \\ U.S. Department of Health and Human Services
}

ISSN: 2690-2052

Research Triangle Park, North Carolina, USA 


\section{Foreword}

The National Toxicology Program (NTP), established in 1978, is an interagency program within the Public Health Service of the U.S. Department of Health and Human Services. Its activities are executed through a partnership of the National Institute for Occupational Safety and Health (part of the Centers for Disease Control and Prevention), the Food and Drug Administration (primarily at the National Center for Toxicological Research), and the National Institute of Environmental Health Sciences (part of the National Institutes of Health), where the program is administratively located. NTP offers a unique venue for the testing, research, and analysis of agents of concern to identify toxic and biological effects, provide information that strengthens the science base, and inform decisions by health regulatory and research agencies to safeguard public health. NTP also works to develop and apply new and improved methods and approaches that advance toxicology and better assess health effects from environmental exposures.

The NTP Technical Report series for developmental and reproductive toxicity studies began in 2019. The studies described in this NTP Technical Report series (i.e., the NTP DART Report series) are designed and conducted to characterize and evaluate the developmental or reproductive toxicity of selected substances in laboratory animals. Substances (e.g., chemicals, physical agents, and mixtures) selected for NTP reproductive and developmental studies are chosen primarily on the basis of human exposure, level of commercial production, and chemical structure. The interpretive conclusions presented in NTP DART Reports are based only on the results of these NTP studies, and extrapolation of these results to other species, including characterization of hazards and risks to humans, requires analyses beyond the intent of these reports. Selection for study per se is not an indicator of a substance's developmental or reproductive toxicity potential.

NTP conducts its studies in compliance with its laboratory health and safety guidelines and the Food and Drug Administration Good Laboratory Practice Regulations and meets or exceeds all applicable federal, state, and local health and safety regulations. Animal care and use are in accordance with the Public Health Service Policy on Humane Care and Use of Laboratory Animals. Studies are subjected to retrospective quality assurance audits before they are presented for public review. Draft reports undergo external peer review before they are finalized and published.

The NTP DART Reports are available free of charge on the NTP website and cataloged in PubMed, a free resource developed and maintained by the National Library of Medicine (part of the National Institutes of Health). Data for these studies are included in NTP's Chemical Effects in Biological Systems database.

For questions about the reports and studies, please email NTP or call 984-287-3211. 


\section{Table of Contents}

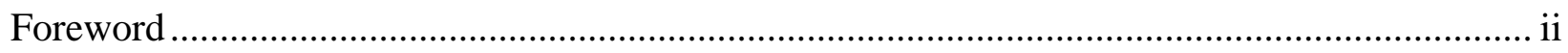

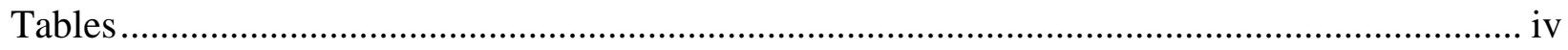

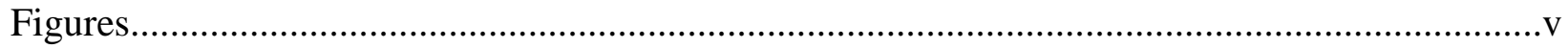

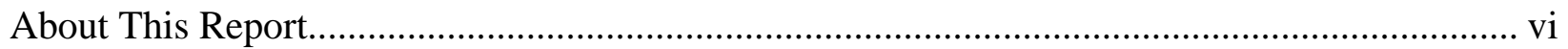

Explanation of Levels of Evidence for Developmental Toxicity ................................................. ix

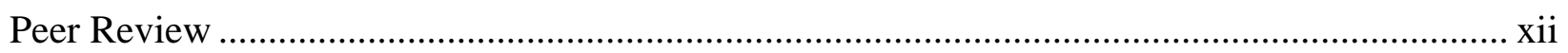

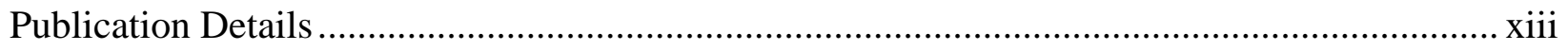

Acknowledgments............................................................................................................ xii

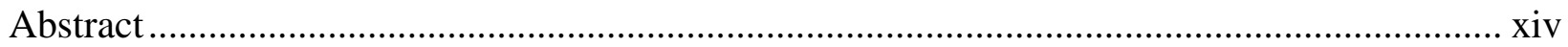

Dose Range-finding Prenatal Developmental Toxicity Study in Rats................................... xiv

Prenatal Developmental Toxicity Study in Rats ................................................................ xiv

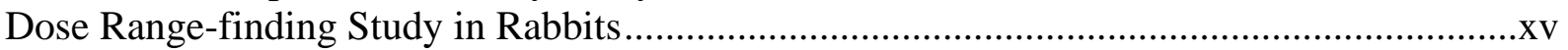

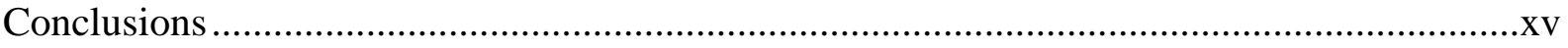

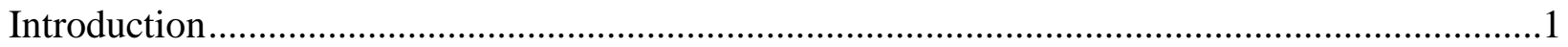

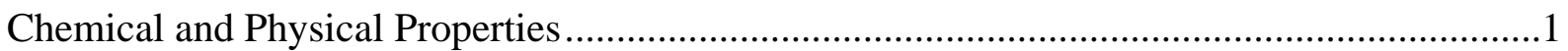

Production, Use, and Human Exposure …………….......................................................

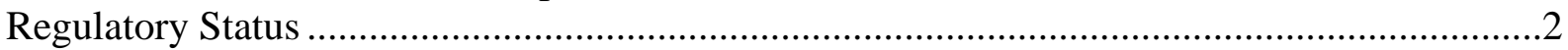

Absorption, Distribution, Metabolism, and Excretion ...............................................................2

Experimental Animals ........................................................................................2

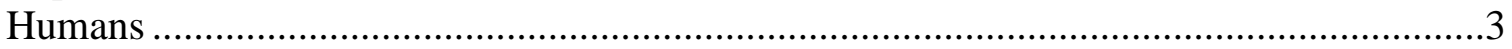

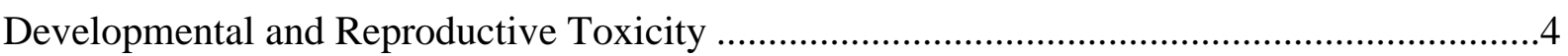

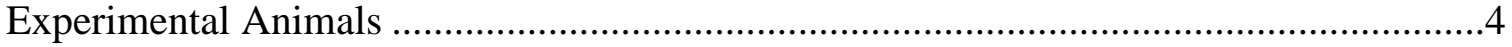

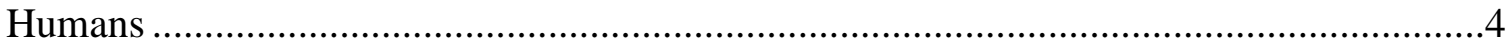

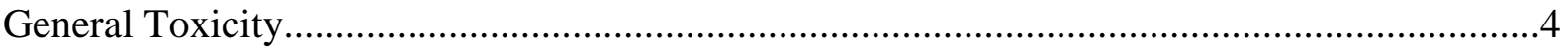

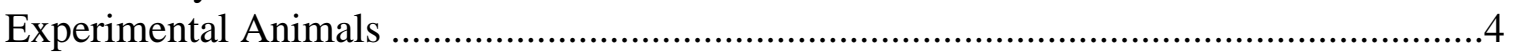

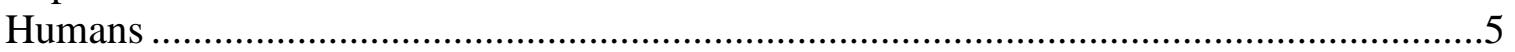

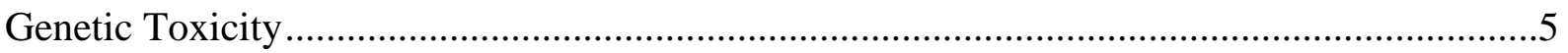

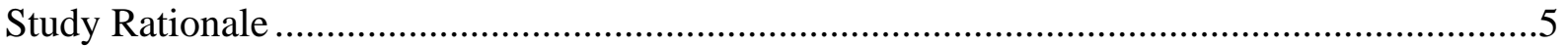

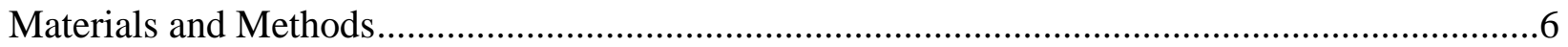

Overview of Prenatal Developmental Toxicity Study Designs ...................................................6

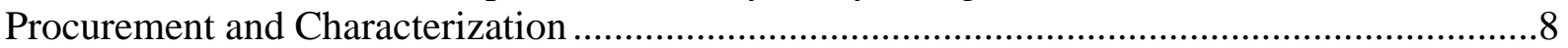

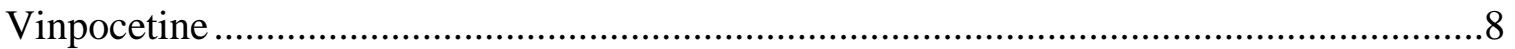

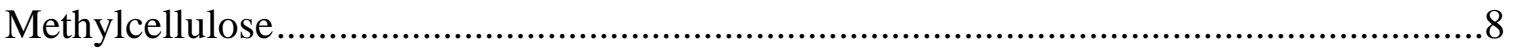

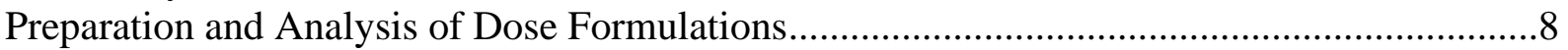

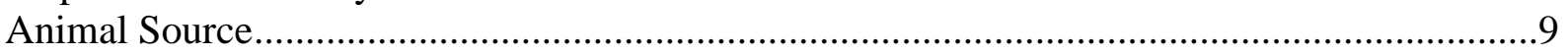

Animal Health Surveillance ...........................................................................................

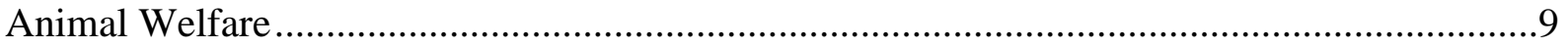

Experimental Design ...............................................................................................10

Dose Range-finding Study in Rats.............................................................................11

Prenatal Developmental Toxicity Study in Rats ...............................................................11 
Dose Range-finding Study in Rabbits.............................................................................12

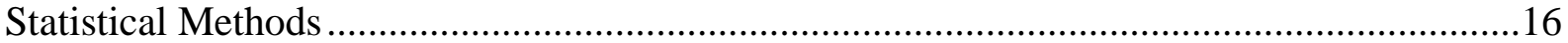

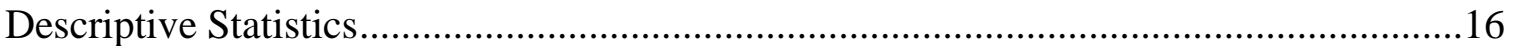

Analysis of Maternal Parameters and Uterine Contents .....................................................17

Analysis of Incidences of Gross Pathology and Morphology Findings .............................17

Historical Control Data ..............................................................................................18

Quality Assurance Methods …………………………....................................................18

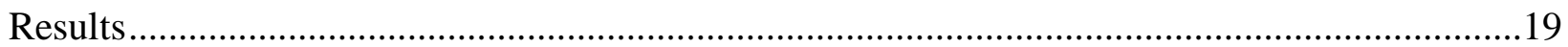

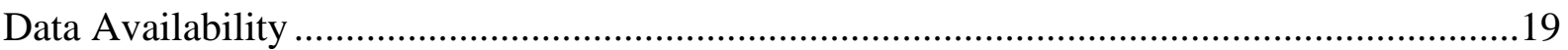

Dose Range-finding Study in Rats .................................................................................19

Maternal Findings ...............................................................................................19

Fetal Findings..........................................................................................................24

Dose Selection Rationale for the Prenatal Development Toxicity Study in Rats ......................24

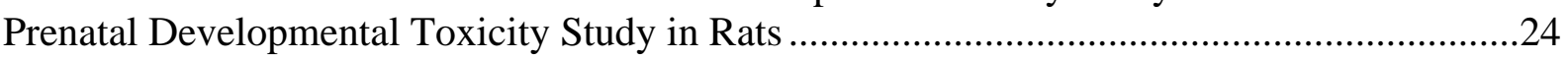

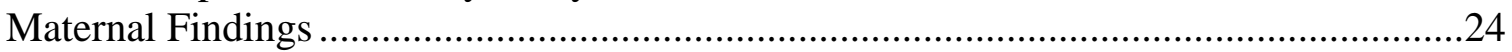

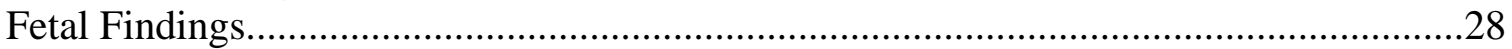

Dose Selection Rationale for the Dose Range-finding Study in Rabbits...................................33

Dose Range-finding Study in Rabbits...................................................................................33

Maternal Findings ..........................................................................................................33

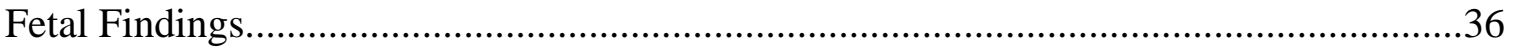

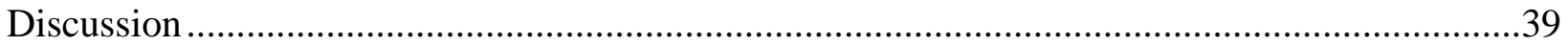

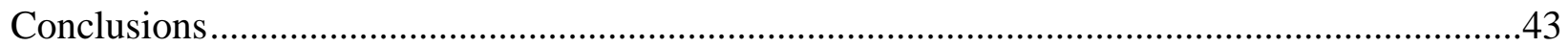

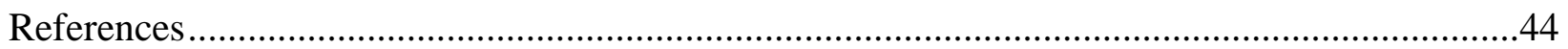

Appendix A. Chemical Characterization and Dose Formulation Studies.................................... A-1

Appendix B. Ingredients, Nutrient Composition, and Contaminant Levels in NIH-07 Rat and Mouse Ration...............................................................................................

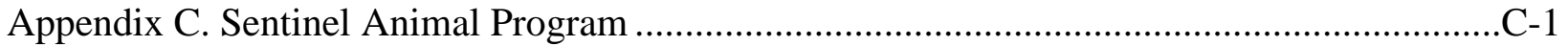

Appendix D. Summary of Peer Review Panel Comments ........................................................ D-1

Appendix E. Supplemental Files...............................................................................................

\section{Tables}

Summary of Exposure-related Findings in Rats in the Prenatal Developmental Toxicity Gavage Study of Vinpocetine.................................................................................... xvi

Summary of Exposure-related Findings in Rabbits in the Dose Range-finding Gavage Study of Vinpocetine ................................................................................................ xviii

Table 1. Experimental Design and Materials and Methods in the Dose Range-finding and Prenatal Developmental Toxicity Gavage Studies of Vinpocetine in Rats ......................12

Table 2. Experimental Design and Materials and Methods in the Dose Range-finding Gavage Study of Vinpocetine in Rabbits.

Table 3. Maternal Disposition of Rats in the Dose Range-finding Gavage Study of Vinpocetine. 
Table 4. Summary of Maternal Body Weight Gains of Rats in the Dose Range-finding Gavage Study of Vinpocetine

Table 5. Summary of Maternal Feed Consumption of Rats in the Dose Range-finding Gavage Study of Vinpocetine

Table 6. Summary of Uterine Content Data for Rats in the Dose Range-finding Gavage Study of Vinpocetine

Table 7. Maternal Disposition of Rats in the Prenatal Developmental Toxicity Gavage Study of Vinpocetine

Table 8. Summary of Maternal Body Weight Gains of Rats in the Prenatal

Developmental Toxicity Gavage Study of Vinpocetine....

Table 9. Summary of Maternal Feed Consumption of Rats in the Prenatal Developmental Toxicity Gavage Study of Vinpocetine

Table 10. Summary of Uterine Content Data for Rats in the Prenatal Developmental Toxicity Gavage Study of Vinpocetine

Table 11. Summary of Selected Fetal Visceral Findings in Rats in the Prenatal Developmental Toxicity Gavage Study of Vinpocetine.

Table 12. Summary of Selected Fetal Skeletal Findings in Rats in the Prenatal Developmental Toxicity Gavage Study of Vinpocetine.

Table 13. Maternal Disposition of Rabbits in the Dose Range-finding Gavage Study of Vinpocetine.

Table 14. Summary of Maternal Body Weight Gains of Rabbits in the Dose Rangefinding Gavage Study of Vinpocetine

Table 15. Summary of Maternal Feed Consumption of Rabbits in the Dose Range-finding Gavage Study of Vinpocetine.

Table 16. Summary of Uterine Content Data for Rabbits in the Dose Range-finding Gavage Study of Vinpocetine

\section{Figures}

Figure 1. Vinpocetine (CASRN 42971-09-5; Chemical Formula: $\mathrm{C}_{22} \mathrm{H}_{26} \mathrm{~N}_{2} \mathrm{O}_{2}$; Molecular Weight: 350.46) 1

Figure 2. Design of Dose Range-finding and Prenatal Developmental Toxicity Studies in Rats....

Figure 3. Design of Dose Range-finding Prenatal Developmental Toxicity Study in Rabbits

Figure 4. Maternal Growth Curves for Pregnant Rats Administered Vinpocetine by Gavage in the Dose Range-finding Study

Figure 5. Maternal Growth Curves for Pregnant Rats Administered Vinpocetine by Gavage in the Prenatal Developmental Toxicity Study .25

Figure 6. Maternal Growth Curves for Pregnant Rabbits Administered Vinpocetine by Gavage in the Dose Range-finding Study 


\section{About This Report}

National Toxicology Program ${ }^{1}$

${ }^{1}$ Division of the National Toxicology Program, National Institute of Environmental Health Sciences, Research Triangle Park, North Carolina, USA

\section{Collaborators}

N.R. Catlin, V.L. Sutherland, L.J. Betz, C.R. Blystone, B. Burback, H.C. Cunny, J.M. Fostel, P.M. Foster, S.F. Harris, C.D. Hébert, M.J. Hooth, A.P. King-Herbert, G.E. Kissling, B.S. McIntyre, L. Miller, E. Mylchreest, J. Peirfelice, K.R. Ryan, K.A. Shipkowski, K.R. Shockley, M.V. Smith, N. South, M.K. Vallant, S. Waidyanatha, N.J. Walker, A.T.D. Watson

Division of the National Toxicology Program, National Institute of Environmental Health Sciences, Research Triangle Park, North Carolina, USA

Evaluated and interpreted results and reported findings

N.R. Catlin, Ph.D., Co-Study Scientist

V.L. Sutherland, Ph.D., Co-Study Scientist

C.R. Blystone, Ph.D.

H.C. Cunny, Ph.D.

J.M. Fostel, Ph.D.

P.M. Foster, Ph.D. (Retired)

M.J. Hooth, Ph.D.

A.P. King-Herbert, D.V.M.

G.E. Kissling, Ph.D. (Retired)

B.S. McIntyre, Ph.D.

K.R. Ryan, Ph.D.

K.A. Shipkowski, Ph.D.

K.R. Shockley, Ph.D.

M.K. Vallant, M.S., M.T. (Retired)

S. Waidyanatha, Ph.D.

N.J. Walker, Ph.D.

A.T.D. Watson, Ph.D.

Southern Research, Birmingham, Alabama, USA

Conducted studies and evaluated findings

C.D. Hébert, Ph.D., Principal Investigator and Study Director

L. Miller, Ph.D., Study Director

E. Mylchreest, Ph.D., Study Director

Social \& Scientific Systems, Inc., Research Triangle Park, North Carolina, USA

Provided statistical analyses

M.V. Smith, Ph.D., Principal Investigator

L.J. Betz, M.S.

S.F. Harris, M.S. 
Battelle Memorial Institute, Columbus, Ohio, USA

Conducted pre-test chemistry activities, dose formulations, and maternal dose measurements

B. Burback, Ph.D.

N. South, B.S.

J. Peirfelice, B.S.

\section{Contributors}

Division of the National Toxicology Program, National Institute of Environmental Health Sciences, Research Triangle Park, North Carolina, USA

Provided oversight of report audit and preparation

G.K. Roberts, Ph.D.

Provided oversight of external peer review

E. A. Maull, Ph.D.

M.S. Wolfe, Ph.D.

Vistronix, Research Triangle Park, North Carolina, USA

Prepared data for report

P. Brown, B.S.

H. Gong, M.S.

C. Myers, M.S.

N. Sayers, B.S.

M. Shaw, B.S.

R. Whittlesey, M.S.

CSS Corporation, Research Triangle Park, North Carolina, USA

Prepared quality assessment audits

S. Brecher, Ph.D., Principal Investigator

S. Iyer, B.S.

V.S. Tharakan, D.V.M.

Biotechnical Services, Inc., Little Rock, Arkansas, USA

Prepared draft report

S.R. Gunnels, M.A., Principal Investigator

K.K. Coker, Ph.D.

B.F. Hall, M.S.

L.M. Harper, B.S.

D.C. Serbus, Ph.D. 


\section{ICF, Durham, North Carolina, USA}

Provided contract oversight, edited and formatted report, and supported peer review D.F. Burch, M.E.M., Contract Manager

S.E. Blaine, B.A.

T.W. Cromer, M.P.S.

L.M. Green, M.P.H.

T. Hamilton, M.S.

K.R. Helmick, M.P.H.

M.E. McVey, Ph.D.

A.A. Murphy, B.S.

B.C. Riley, B.S. 


\section{Explanation of Levels of Evidence for Developmental Toxicity}

The National Toxicology Program (NTP) describes the results of individual studies of chemical agents and other test articles and notes the strength of the evidence for conclusions regarding each study. Generally, each study is confined to a single laboratory animal species, although in some instances, multiple species may be investigated under the purview of a single study report. Negative results, in which the study animals do not exhibit evidence of developmental toxicity, do not necessarily imply that a test article is not a developmental toxicant, but only that the test article is not a developmental toxicant under the specific conditions of the study. Positive results demonstrating that a test article causes developmental toxicity in laboratory animals under the conditions of the study are assumed to be relevant to humans, unless data are available that demonstrate otherwise. In addition, such positive effects should be assumed to be primary effects, unless there is clear evidence that they are secondary consequences of excessive maternal toxicity. Given that developmental events are intertwined in the reproductive process, effects on developmental toxicity may be detected in reproductive studies. Evaluation of such developmental effects should be based on the NTP Criteria for Levels of Evidence for Developmental Toxicity.

It is critical to recognize that the "levels of evidence" statements described herein describe only developmental hazard. The actual determination of risk to humans requires exposure data that are not considered in these summary statements.

Five categories of evidence of developmental toxicity are used to summarize the strength of the evidence observed in each experiment: two categories for positive results (clear evidence and some evidence); one category for uncertain findings (equivocal evidence); one category for no observable effects (no evidence); and one category for experiments that cannot be evaluated because of major design or performance flaws (inadequate study). Application of these criteria requires professional judgment by individuals with ample experience and an understanding of the animal models and study designs employed. For each study, conclusion statements are made using one of the following five categories to describe the findings. These categories refer to the strength of the evidence of the experimental results and not to potency or mechanism.

\section{Levels of Evidence for Evaluating Developmental System Toxicity}

- Clear evidence of developmental toxicity is demonstrated by data that indicate a dose-related effect on one or more of its four elements (embryo-fetal death, structural malformations, growth retardation, or functional deficits) that is not secondary to overt maternal toxicity.

- Some evidence of developmental toxicity is demonstrated by dose-related effects on one or more of its four elements (embryo-fetal death, structural malformations, growth retardation, or functional deficits), but where there are greater uncertainties or weaker relationships with regard to dose, severity, magnitude, incidence, persistence, and/or decreased concordance among affected endpoints.

- Equivocal evidence of developmental toxicity is demonstrated by marginal or discordant effects on developmental parameters that may or may not be related to the test article. 
- No evidence of developmental toxicity is demonstrated by data from a study with appropriate experimental design and conduct that are interpreted as showing no biologically relevant effects on developmental parameters that are related to the test article.

- Inadequate study of developmental toxicity is demonstrated by a study that, because of major design or performance flaws, cannot be used to determine the occurrence of developmental toxicity.

When a conclusion statement for a particular study is selected, consideration must be given to key factors that would support the selection of an individual category of evidence. Such consideration should allow for incorporation of scientific experience and current understanding of developmental toxicity studies in laboratory animals, particularly with respect to interrelationships between endpoints, impact of the change on development, relative sensitivity of endpoints, normal background incidence, and specificity of the effect. For those evaluations that may be on the borderline between two adjacent levels, some factors to consider in selecting the level of evidence of developmental toxicity are given below:

- Increases in severity and/or prevalence (more individuals and/or more affected litters) as a function of dose generally strengthen the level of evidence, keeping in mind that the specific manifestation may be different with increasing dose. For example, malformations may be observed at a lower dose level, but higher doses may produce embryo-fetal death.

- Effects seen in many litters may provide stronger evidence than effects confined to one or a few litters, even if the incidence within those litters is high.

- Because of the complex relationship between maternal physiology and development, evidence for developmental toxicity may be greater for a selective effect on the embryo-fetus or pup.

- Concordant effects (syndromic) may strengthen the evidence of developmental toxicity. Single endpoint changes by themselves may be weaker indicators of effect than concordant effects on multiple endpoints related by a common process or mechanism.

- In order to be assigned a level of "clear evidence” the endpoint(s) evaluated should normally show a statistical increase in the deficit, or syndrome, on a litter basis.

- In general, the more animals affected, the stronger the evidence; however, effects in a small number of animals across multiple, related endpoints should not be discounted, even in the absence of statistical significance for the individual endpoint(s). In addition, rare malformations with low incidence, when interpreted in the context of historical controls, may be biologically important.

- Consistency of effects across generations in a multigenerational study may strengthen the level of evidence. However, if effects are observed in the $\mathrm{F}_{1}$ generation but not in the $F_{2}$ generation (or the effects occur at a lesser frequency in the $F_{2}$ generation), this may be due to survivor selection for resistance to the effect (i.e., if the effect is incompatible with successful reproduction, then the affected individuals will not produce offspring). 
- Transient changes (e.g., pup weight decrements, reduced ossification in fetuses) by themselves may be weaker indicators of an effect than persistent changes.

- Uncertainty about the occurrence of developmental toxicity in one study may be lessened by effects (even if not identical) that are observed in a second species.

- Insights from supportive studies (e.g., toxicokinetics, ADME, computational models, structure-activity relationships) and developmental findings from other in vivo animal studies (NTP or otherwise) should be drawn upon when interpreting the biological plausibility of an effect.

- New assays and techniques need to be appropriately characterized to build confidence in their utility: their usefulness as indicators of effect is increased if they can be associated with changes in traditional endpoints.

For more information visit: http://ntp.niehs.nih.gov/go/10003. 


\section{Peer Review}

An external ad hoc panel was convened at the National Institute of Environmental Health Sciences, Research Triangle Park, NC on July 31, 2019, to peer review the draft NTP Developmental and Reproductive Toxicity Technical Report on the Prenatal Developmental Studies of Vinpocetine (CASRN 42971-09-5) in Sprague Dawley (Hsd:Sprague Dawley ${ }^{\circledR} S D^{\circledR}$ ) Rats and New Zealand White (Hra:Nzw Spf) Rabbits (Gavage Studies). The public could view the proceedings via webcast and there was opportunity for presentation of oral public comment. The selection of panel members and conduct of the peer review were in accordance with Federal policies and regulations. The panel was charged to:

1. Review and evaluate the scientific and technical elements of each study and its presentation.

2. Determine whether each study's experimental design, conduct, and findings support the NTP's conclusion regarding the prenatal developmental toxicity of the substance tested.

NTP carefully considered the panel's recommendations in finalizing the technical report. The peer review report is provided in Appendix D. Other meeting materials are available on the NTP website (https://ntp.niehs.nih.gov/go/meeting).

\section{Peer Reviewers}

George Daston, Ph.D., Chairperson

The Procter and Gamble Company

Cincinnati, Ohio, USA

Cheryl Broussard, Ph.D.

Centers for Disease Control and Prevention

Atlanta, Georgia, USA

Alan Hoberman, Ph.D.

Charles River Laboratories Preclinical Services

Horsham, Pennsylvania, USA

Linda Roberts, Ph.D.

NapaTox Consulting LLC

San Francisco, California, USA

Mary Alice Smith, Ph.D.

University of Georgia

Athens, Georgia, USA

Kimberley Treinen, Ph.D.

Sunovion Pharmaceuticals, Inc.

Marlborough, Massachusetts, USA 


\section{Publication Details}

Publisher: National Toxicology Program

Publishing Location: Research Triangle Park, NC

ISSN: 2690-2052

DOI: https://doi.org/10.22427/NTP-DART-03

Report Series: NTP Developmental and Reproductive Toxicity Report Series

Report Series Number: 03

Official citation: National Toxicology Program (NTP). 2020. NTP developmental and reproductive toxicity technical report on the prenatal development studies of vinpocetine (CASRN 42971-09-5) in Sprague Dawley (Hsd:Sprague Dawley ${ }^{\circledR}$ SD ${ }^{\circledR}$ ) rats and New Zealand White (Hra:Nzw Spf) rabbits (gavage studies). Research Triangle Park, NC: National Toxicology Program. DART Report 03.

\section{Acknowledgments}

This work was supported by the Intramural Research Program (ES103316, ES103318, and ES103319) at the National Institute of Environmental Health Sciences, National Institutes of Health and performed for the National Toxicology Program, Public Health Service, U.S. Department of Health and Human Services under contracts HHSN273201800006C, HHSN273201600020C, HHSN273201400027C, HHSN273201300012C, HHSN273201000016C, HHSN273201300009C, HHSN316201200054W, and HHSN273201300004C. 


\section{Abstract}

Vinpocetine is mainly marketed as a dietary supplement for cognitive enhancement, Alzheimer's, dementia, and ischemic stroke; however, several products are marketed toward students as brain supplements for increased cognitive performance. Additionally, vinpocetine is used by bodybuilders to enhance visual acuity, memory, and focus and to rapidly reduce body fat. Human exposure to vinpocetine typically occurs through oral consumption. Marketed as a dietary supplement in the United States, vinpocetine is regulated by the Food and Drug Administration (FDA) under the Dietary Supplement Health and Education Act of 1994. Analysis of vinpocetine supplements have shown that in a significant number of products, the actual vinpocetine content varied from what was stated on the label, which could result in higher doses than what is recommended by the product labels. Because of the limited literature indicating that vinpocetine may not be safe for use during pregnancy and the possibility for widespread exposure to women of childbearing age, the National Toxicology Program (NTP) conducted prenatal developmental toxicology studies. In these studies, time-mated Sprague Dawley (Hsd:Sprague Dawley ${ }^{\circledR} \mathrm{SD}^{\circledR}$ ) rats and New Zealand White (Hra:NZW SPF) rabbits received vinpocetine (99.3\% pure) in $0.5 \%$ methylcellulose by gavage from implantation on gestation day (GD) 6 (rats) or 7 (rabbits) to the day before expected parturition (GD 20 for rats; GD 28 for rabbits). Evidence of vinpocetine-related maternal and fetal toxicity was examined in the dose range-finding study in rats followed by the standard prenatal developmental toxicity study in rats. A dose range-finding study in rabbits was conducted to see if effects occurred in a second species and which species might be more sensitive, but a standard prenatal developmental toxicity study was not performed in rabbits.

\section{Dose Range-finding Prenatal Developmental Toxicity Study in Rats}

Groups of 10 time-mated female rats were administered 0, 20, 40, 80, 160, or $320 \mathrm{mg}$ vinpocetine/kg body weight per day (mg/kg/day) (based on the most recent body weight) in $0.5 \%$ aqueous methylcellulose by gavage from GD 6 to GD 20. Vehicle control (0 mg/kg) animals received aqueous methylcellulose.

All animals survived to the end of the study. Clinical observations were limited to red or brown vaginal discharge, discoloration of the nares, and piloerection. Dose-related decreases were observed in mean maternal body weight and mean body weight gains from GD 6 to GD 21 in groups administered $40 \mathrm{mg} / \mathrm{kg}$ or greater. When adjusted for gravid uterine weight, maternal body weights of the 160 and $320 \mathrm{mg} / \mathrm{kg}$ groups were significantly lower than those of the vehicle control group. Concomitant treatment-related, dose-dependent decreases in maternal feed consumption in groups receiving $40 \mathrm{mg} / \mathrm{kg}$ or greater was also noted. There was a significant, treatment-related effect on percent postimplantation loss in all dose groups. At doses of $80 \mathrm{mg} / \mathrm{kg}$ or greater, dams exhibited total resorption of their litters except for one dam in the $160 \mathrm{mg} / \mathrm{kg}$ group with live fetuses. No external malformation or variations attributed to vinpocetine administration in fetuses were observed.

\section{Prenatal Developmental Toxicity Study in Rats}

Due to the postimplantation loss observed at doses of $80 \mathrm{mg} / \mathrm{kg}$ and greater in the dose rangefinding study, $60 \mathrm{mg} / \mathrm{kg}$ was chosen as the high dose for the prenatal developmental toxicity study. Groups of 25 time-mated female rats were administered 0, 5, 20, or $60 \mathrm{mg} / \mathrm{kg} /$ day (based on the most recent body weight) in 0.5\% aqueous methylcellulose by gavage from GD 6 to GD 20. Vehicle control (0 mg/kg) animals received aqueous methylcellulose. 
All animals survived to the end of the study. Treatment-related clinical findings were red or brown vaginal discharge in the 20 and $60 \mathrm{mg} / \mathrm{kg}$ groups. Significantly decreased mean maternal body weights and mean body weight gains were found in the $60 \mathrm{mg} / \mathrm{kg}$ group that were associated with a significant increase in postimplantation loss, including total litter resorption in 12 dams. A treatment-related decrease in feed consumption was found also in the $60 \mathrm{mg} / \mathrm{kg}$ group. Because of the increased postimplantation loss in the $60 \mathrm{mg} / \mathrm{kg}$ group, a significant decrease was found in the number of live fetuses per litter and in gravid uterine weight.

A small number of litters and fetuses were viable for evaluation at $60 \mathrm{mg} / \mathrm{kg}$. In the viscera, treatment-related increased incidences of ventricular septum defect were in all exposed groups. In the skeleton, treatment-related findings included significantly increased incidences of incomplete ossification of the thoracic centrum in the 20 and $60 \mathrm{mg} / \mathrm{kg}$ groups and full supernumerary thoracolumbar ribs in the $60 \mathrm{mg} / \mathrm{kg}$ group.

\section{Dose Range-finding Study in Rabbits}

Groups of eight time-mated female rabbits were administered $0,25,75,150$, or $300 \mathrm{mg} / \mathrm{kg} / \mathrm{day}$ (based on the most recent body weight) in $0.5 \%$ aqueous methylcellulose by gavage from GD 7 to GD 28. Vehicle control ( $0 \mathrm{mg} / \mathrm{kg})$ animals received aqueous methylcellulose.

All rabbits survived until the end of the study except one $150 \mathrm{mg} / \mathrm{kg}$ female that was removed on GD 25 due to abortion. There were no clinical observations related to vinpocetine treatment. Significant decreases in mean maternal body weight gains were observed in the 150 and $300 \mathrm{mg} / \mathrm{kg}$ groups and a treatment-related decrease in feed consumption in these groups.

An exposure-related effect was observed on embryo-fetal survival in the $300 \mathrm{mg} / \mathrm{kg}$ group with an increase in early resorptions per litter resulting in an increase in percent postimplantation loss and a significant decrease in the number of live fetuses per litter. These findings in the $300 \mathrm{mg} / \mathrm{kg}$ group were also associated with a significant decrease in mean gravid uterine weight. No exposure-related effects were observed on embryo-fetal survival in any group administered $150 \mathrm{mg} / \mathrm{kg}$ or less. There were no external malformations or variations attributed to vinpocetine exposure.

Data from this rabbit dose range-finding study supported findings observed in the rat dose rangefinding study and rat prenatal developmental toxicity studies (increase in postimplantation loss) with exposure to vinpocetine.

\section{Conclusions}

Under the conditions of the rat prenatal study, there was clear evidence ${ }^{\dagger}$ of developmental toxicity of vinpocetine in Hsd:Sprague Dawley ${ }^{\circledR} \mathrm{SD}^{\circledR}$ rats attributable to increased postimplantation loss and increased incidences of ventricular septum defects, thoracolumbar ribs (full), and incomplete ossification of the thoracic centrum in the absence of overt maternal toxicity.

Synonyms: Apovincaminic acid ethyl ester; cis-apovincaminic acid ethyl ester; ethyl (+)apovincaminate; ethyl apovincamin-22-oate; ethyl (+)-cis-apovincaminate; ethyl $(3 \alpha, 16 \alpha)$ eburnamenine-14-carboxylate

Trade names: Bravinton, Cavinton, Ceractin, Intelectol, RGH-4405, TCV-3B, Vinporal

${ }^{\dagger}$ See Explanation of Levels of Evidence for Developmental Toxicity. 
Summary of Exposure-related Findings in Rats in the Prenatal Developmental Toxicity Gavage Study of Vinpocetine

\begin{tabular}{|c|c|c|c|c|}
\hline & $0 \mathrm{mg} / \mathrm{kg}$ & $5 \mathrm{mg} / \mathrm{kg}$ & $20 \mathrm{mg} / \mathrm{kg}$ & $60 \mathrm{mg} / \mathrm{kg}$ \\
\hline \multicolumn{5}{|l|}{ Maternal Parameters } \\
\hline Animals on Study & 25 & 25 & 25 & 25 \\
\hline Number Pregnant & 21 & 20 & 22 & 20 \\
\hline Number Died or Euthanized Moribund & 0 & 0 & 0 & 0 \\
\hline Clinical Observations & None & None & $\begin{array}{l}\text { Red or brown } \\
\text { vaginal discharge }\end{array}$ & $\begin{array}{l}\text { Red or brown } \\
\text { vaginal } \\
\text { discharge }\end{array}$ \\
\hline \multicolumn{5}{|l|}{ Body Weight and Feed Consumption ${ }^{\mathrm{a}}$} \\
\hline Terminal Body Weight & $385.7 \pm 4.2^{* *}$ & $368.5 \pm 8.2$ & $370.0 \pm 5.5$ & $296.1 \pm 8.2^{* *}$ \\
\hline Body Weight Change GD 6 to 21 & $142.8 \pm 3.4^{* *}$ & $128.7 \pm 7.4$ & $130.0 \pm 5.1$ & $55.3 \pm 7.9^{* *}$ \\
\hline Feed Consumption GD 6 to 21 & $22.0 \pm 0.3^{* *}$ & $21.6 \pm 0.4$ & $22.2 \pm 0.3$ & $19.9 \pm 0.4^{* *}$ \\
\hline Necropsy Observations & None & None & None & None \\
\hline \multicolumn{5}{|l|}{ Developmental/Fetal Parameters } \\
\hline Number of Litters Examined & 21 & 19 & 21 & 8 \\
\hline Number of Live Fetuses Evaluated & 293 & 239 & 261 & 51 \\
\hline Number of Live Fetuses per Litter ${ }^{b}$ & $13.95 \pm 0.55^{* *}$ & $11.95 \pm 1.06$ & $11.86 \pm 0.88$ & $2.5 \pm 1.00^{* *}$ \\
\hline Number of Early Resorptions ${ }^{\mathrm{c}}$ & 7 & 12 & 19 & 208 \\
\hline Number of Late Resorptions ${ }^{c}$ & 1 & 0 & 2 & 0 \\
\hline Number of Dead Fetuses ${ }^{c}$ & 1 & 0 & 0 & 0 \\
\hline Number of Whole Litter Resorption & $0 * *$ & 1 & 1 & $12^{* *}$ \\
\hline Percent Postimplantation Loss ${ }^{\mathrm{b}}$ & $3.29 \pm 1.33^{* *}$ & $10.67 \pm 5.29$ & $11.13 \pm 4.65$ & $83.13 \pm 6.47^{* *}$ \\
\hline Fetal Body Weight per Litter ${ }^{a}$ & $5.15 \pm 0.07$ & $5.29 \pm 0.16$ & $5.21 \pm 0.12$ & $5.11 \pm 0.10$ \\
\hline Male Fetal Weight per Litter ${ }^{\mathrm{a}}$ & $5.28 \pm 0.06$ & $5.49 \pm 0.21$ & $5.35 \pm 0.12$ & $5.18 \pm 0.08$ \\
\hline Female Fetal Weight per Litter ${ }^{\mathrm{a}}$ & $5.03 \pm 0.07$ & $5.10 \pm 0.10$ & $5.09 \pm 0.12$ & $4.63 \pm 0.06$ \\
\hline Gravid Uterine Weight ${ }^{\mathrm{a}}$ & $97.79 \pm 3.11^{* *}$ & $83.89 \pm 6.59$ & $85.07 \pm 5.28$ & $19.52 \pm 6.53^{* *}$ \\
\hline External Findings & None & None & None & None \\
\hline \multicolumn{5}{|l|}{ Visceral Findings $^{d}$} \\
\hline \multicolumn{5}{|l|}{ Heart } \\
\hline \multicolumn{5}{|c|}{ Ventricle, ventricular septum defect - $[\mathrm{M}]$} \\
\hline Fetuses & $0(0.00)$ & $3(1.26)$ & $8(3.07)$ & $2(3.92)$ \\
\hline Litters & $0(0.00)$ & $3(15.79)$ & $7(33.33)^{* *}$ & $2(25.00)$ \\
\hline \multicolumn{5}{|l|}{ Skeletal Findings ${ }^{\mathrm{d}, \mathrm{e}}$} \\
\hline \multicolumn{5}{|l|}{ Thoracic Centrum } \\
\hline \multicolumn{5}{|l|}{ Incomplete ossification, total - [V] } \\
\hline Fetuses & $1(0.34)^{\# \#}$ & $1(0.42)$ & $6(2.31)^{\#}$ & $8(17.02)^{\# \#}$ \\
\hline
\end{tabular}


Vinpocetine, NTP DART 03

\begin{tabular}{|c|c|c|c|c|}
\hline & $0 \mathrm{mg} / \mathrm{kg}$ & $5 \mathrm{mg} / \mathrm{kg}$ & 20 mg/kg & $60 \mathrm{mg} / \mathrm{kg}$ \\
\hline Litters & $1(4.76)^{* *}$ & $1(5.26)$ & $5(23.81)$ & $3(42.86)^{*}$ \\
\hline \multicolumn{5}{|c|}{ Supernumerary Rib } \\
\hline \multicolumn{5}{|c|}{ Thoracolumbar, full, total - [M] } \\
\hline Fetuses & $1(0.34)^{\# \#}$ & 5 (2.09) & $12(4.62)$ & $12(25.53)^{\# \#}$ \\
\hline Litters & $1(4.76)^{*}$ & 3 (15.79) & $4(19.05)$ & 3 (42.86)* \\
\hline
\end{tabular}

Level of Evidence of Developmental Toxicity: Clear Evidence

*Statistically significant $(\mathrm{p} \leq 0.05)$ trend (denoted in vehicle control column) or pairwise comparison (denoted in dose group column).

$* * \mathrm{p} \leq 0.01$.

\#Statistically significant $(\mathrm{p} \leq 0.05)$ trend (denoted in vehicle control column) or pairwise comparison (denoted in dose group column) for fetuses.

${ }^{\# \prime} \mathrm{p} \leq 0.01$.

$\mathrm{GD}=$ gestation day; $[\mathrm{M}]$ = malformation; $[\mathrm{V}]$ = variation .

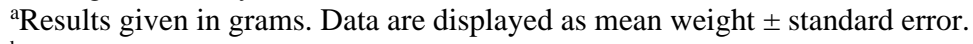

bata are displayed as mean number \pm standard error.

'No statistical analyses were performed on number of early resorptions, number of late resorptions, or number of dead fetuses.

${ }^{\mathrm{d} U p p e r ~ r o w ~ d e n o t e s ~ t h e ~ n u m b e r ~ o f ~ a f f e c t e d ~ f e t u s e s ~ a n d ~(\%) ~ a n d ~ l o w e r ~ r o w ~ t h e ~ n u m b e r ~ o f ~ a f f e c t e d ~ l i t t e r s ~ a n d ~(\%) . ~}$

eFor skeletal findings, only 47 fetuses from 7 litters were evaluated for skeletal alterations. 
Summary of Exposure-related Findings in Rabbits in the Dose Range-finding Gavage Study of Vinpocetine

\begin{tabular}{|c|c|c|c|c|c|}
\hline & 0 mg/kg & $25 \mathrm{mg} / \mathrm{kg}$ & $75 \mathrm{mg} / \mathrm{kg}$ & $150 \mathrm{mg} / \mathrm{kg}$ & $300 \mathrm{mg} / \mathrm{kg}$ \\
\hline \multicolumn{6}{|l|}{ Maternal Parameters } \\
\hline Animals on Study & 8 & 8 & 8 & 8 & 8 \\
\hline Number Pregnant & 8 & 7 & 8 & 8 & 8 \\
\hline $\begin{array}{l}\text { Number Died or Euthanized } \\
\text { Moribund }\end{array}$ & 0 & 0 & 0 & 0 & 0 \\
\hline Number Euthanized - Abortion & 0 & 0 & 0 & 1 & 0 \\
\hline Clinical Observations & None & None & None & $\begin{array}{l}\text { Red vaginal } \\
\text { discharge }\end{array}$ & $\begin{array}{l}\text { Red vaginal } \\
\text { discharge }\end{array}$ \\
\hline \multicolumn{6}{|c|}{ Body Weight and Feed Consumption ${ }^{\mathrm{a}}$} \\
\hline Necropsy Body Weight & $3,499.4 \pm 64.6^{*}$ & $3,406.5 \pm 58.0$ & $3,467.7 \pm 95.0$ & $3,358.4 \pm 105.6$ & $3,271.4 \pm 34.2$ \\
\hline Body Weight Change GD 7 to 29 & $460.2 \pm 33.8^{* *}$ & $458.2 \pm 46.2$ & $399.3 \pm 58.4$ & $256.7 \pm 40.9 * *$ & $304.1 \pm 33.2^{* *}$ \\
\hline Feed Consumption GD 7 to 29 & $137.6 \pm 4.3$ & $131.8 \pm 5.7$ & $125.2 \pm 4.0$ & $101.3 \pm 11.4^{* *}$ & $113.8 \pm 8.9 *$ \\
\hline Necropsy Observations & None & None & None & None & None \\
\hline \multicolumn{6}{|l|}{ Developmental/Fetal Parameters } \\
\hline Number of Litters Examined & 8 & 7 & 8 & 7 & 8 \\
\hline $\begin{array}{l}\text { Number of Live Fetuses } \\
\text { Evaluated }\end{array}$ & 73 & 54 & 72 & 53 & 52 \\
\hline Number of Live Fetuses/Litter ${ }^{\mathrm{b}}$ & $9.13 \pm 0.44^{*}$ & $7.71 \pm 0.42$ & $9.00 \pm 0.53$ & $7.57 \pm 0.81$ & $6.50 \pm 0.73^{*}$ \\
\hline Number of Early Resorptions ${ }^{\mathrm{c}}$ & 1 & 0 & 0 & 1 & 13 \\
\hline Number of Late Resorptions ${ }^{c}$ & 0 & 1 & 2 & 0 & 2 \\
\hline Dead Fetuses $^{\mathrm{c}}$ & 0 & 1 & 0 & 0 & 0 \\
\hline $\begin{array}{l}\text { Number of Whole Litter } \\
\text { Resorption }\end{array}$ & 0 & 0 & 0 & 0 & 0 \\
\hline Percent Postimplantation Loss ${ }^{\mathrm{b}}$ & $1.39 \pm 1.39$ & $3.37 \pm 2.18$ & $2.53 \pm 1.66$ & $3.57 \pm 3.57$ & $20.42 \pm 9.05$ \\
\hline Fetal Body Weight per Litter ${ }^{\mathrm{a}}$ & $39.72 \pm 1.33^{* *}$ & $41.47 \pm 0.95$ & $37.53 \pm 0.90$ & $39.36 \pm 1.74$ & $35.78 \pm 1.15$ \\
\hline Male Fetal Weight per Litter ${ }^{\mathrm{a}}$ & $40.87 \pm 1.59 * *$ & $42.70 \pm 0.97$ & $38.50 \pm 1.15$ & $38.06 \pm 1.62$ & $36.49 \pm 2.00$ \\
\hline Female Fetal Weight per Litter ${ }^{\mathrm{a}}$ & $38.76 \pm 1.57^{*}$ & $40.37 \pm 1.12$ & $36.35 \pm 1.01$ & $39.29 \pm 1.75$ & $34.65 \pm 0.95$ \\
\hline Gravid Uterine Weight ${ }^{\mathrm{a}}$ & $515.25 \pm 14.70 * *$ & $470.05 \pm 20.66$ & $483.91 \pm 32.24$ & $421.86 \pm 39.25 *$ & $340.94 \pm 27.73^{* *}$ \\
\hline External Findings & None & None & None & None & None \\
\hline
\end{tabular}

*Statistically significant $(\mathrm{p} \leq 0.05)$ trend (denoted in vehicle control column) or pairwise comparison (denoted in dose group column).

$* * \mathrm{p} \leq 0.01$.

$\mathrm{GD}=$ gestation day.

${ }^{a}$ Results given in grams. Data are displayed as mean weight \pm standard error.

${ }^{\mathrm{b}}$ Data are displayed as mean number \pm standard error.

${ }^{\mathrm{c}}$ No statistical analyses were performed on number of early resorptions, number of late resorptions, or number of dead fetuses. 


\section{Introduction}<smiles>CCOC(=O)C1=C[C@]2(CC)CCCN3CCc4c(n1c1ccccc41)[C@]32C</smiles>

Figure 1. Vinpocetine (CASRN 42971-09-5; Chemical Formula: $\mathrm{C}_{22} \mathrm{H}_{26} \mathrm{~N}_{2} \mathrm{O}_{2}$; Molecular Weight: 350.46)

Synonyms: Apovincaminic acid ethyl ester; cis-apovincaminic acid ethyl ester; ethyl (+)-apovincaminate; ethyl apovincamin-22oate; ethyl (+)-cis-apovincaminate; ethyl $(3 \alpha, 16 \alpha)$-eburnamenine-14-carboxylate.

Trade names: Bravinton, Cavinton, Ceractin, Intelectol, RGH-4405, TCV-3B, Vinporal.

\section{Chemical and Physical Properties}

Vinpocetine is a white crystalline solid with a molecular mass of $350.45 \mathrm{~g} / \mathrm{mol}$. It has an estimated boiling point of $420^{\circ} \mathrm{C}$, melting point of $147-153^{\circ} \mathrm{C}$, a log Kow of $4.3^{1}$ and vapor pressure of $3.02 \times 10^{-7} \mathrm{~mm} \mathrm{Hg}$ at $25^{\circ} \mathrm{C}$.

\section{Production, Use, and Human Exposure}

Vinpocetine can be synthesized in several ways from vincamine, an alkaloid extract from the periwinkle plant. One method described by Szabó et al. ${ }^{2}$ involves heating (+)-14-oxo-15hydroxyimino-E-homo-eburnane with ethanol and sulfuric acid. The resulting solution is cooled and brought to a $\mathrm{pH}$ of 9 with ammonium hydroxide. The organic phase is extracted with methylene chloride, then dried, filtered, and evaporated. The residual oil is recrystallized in ethanol, which yields 67.6\% vinpocetine. A "one-pot" synthesis method describes two synthesis pathways for vinpocetine production from vincamine. ${ }^{3}$ With this method, vinpocetine is produced (80\% product yield) through either transesterification or dehydration of vincamine in ethanol using Lewis acids; ferric chloride catalyzed both processes. Tabersonine, an alkaloid extract from voacanga seeds found mostly in West Africa, can also serve as a source from which vinpocetine can be derived. ${ }^{4}$ Additionally, there are patents for synthetic methods of vinpocetine production that can result in higher yields ( 90\%) than the semisynthetic methods described above. For example, one method described the reaction of apovincaminic acid with ethanol in the presence of 2-fluoro-1,3,5-trinitrobenzene and 4-dimethylaminopyridine. ${ }^{5}$

Since the late 1970s, vinpocetine has been widely available as a pharmaceutical agent in Hungary, Germany, Poland, Russia, China, and Japan for use in cerebrovascular and cognitive disorders. ${ }^{6}$ In the United States, vinpocetine is mainly marketed as a dietary supplement with the primary purported indication of cognitive enhancement, including use for Alzheimer's, dementia, and ischemic stroke. ${ }^{6-11}$ Though original indications for vinpocetine promoted its use in the elderly, several products are currently available that are specifically marketed toward students as brain supplements for increasing cognitive performance. ${ }^{12}$ Additionally, vinpocetine is used among healthy athletes within the bodybuilding community for reported enhancement of visual acuity, memory, and focus in addition to rapid reductions in body fat. ${ }^{13}$ Other reported 
uses are for vertigo, urinary incontinence, tinnitus, Meniere’s disease, visual impairment, menopause symptoms, chronic fatigue syndrome, seizure disorders, and prevention of motion sickness. ${ }^{14-18}$ Several patents claim additional applications for vinpocetine, including topical use for enhanced female sexual response, ${ }^{19 ;} 20$ as a primary ingredient in a supplement for the improvement of sleep and lucid dreaming, ${ }^{21}$ and as an ingredient (either alone or in combination with stimulants, anti-motion drugs, or nootropics) for intranasal administration to treat dyslexia in children. ${ }^{22}$

Human exposure to vinpocetine typically occurs through oral consumption. As reported by the Physicians' Desk Reference for Nutritional Supplements, vinpocetine doses can range from 5 to $20 \mathrm{mg}$ per day. ${ }^{23}$ In the United States, vinpocetine products are available in dosages ranging from 5 to $30 \mathrm{mg}$, with recommended uses of one to three times daily, equaling daily doses of 5 to $90 \mathrm{mg}$. However, a recent analysis of vinpocetine supplements demonstrated a common problem with botanical dietary supplements, where 6 of the 23 (17\%) sampled supplements contained no vinpocetine and, in those that did contain vinpocetine, the actual vinpocetine content varied from what was stated on the label. ${ }^{24}$ Thus, actual daily consumption rates could differ from the target dose and potentially be higher than recommended by the product labels.

\section{Regulatory Status}

Vinpocetine is often marketed as a dietary supplement in the United States and, therefore, regulated by the Food and Drug Administration (FDA) under the Dietary Supplement Health and Education Act of 1994. Vinpocetine was submitted in several notifications to the FDA as a new dietary ingredient by manufacturers beginning in 1997. However, the FDA has recently published a notice in the Federal Register requesting comment as to the regulatory status of vinpocetine as a dietary ingredient. Specifically, FDA tentatively concluded that vinpocetine does not meet the definition of a dietary ingredient and is excluded from the definition of a dietary supplement in the Food, Drug, and Cosmetic Act. ${ }^{25}$ This administrative proceeding has not been finalized.

\section{Absorption, Distribution, Metabolism, and Excretion}

\section{Experimental Animals}

In rats, vinpocetine was rapidly absorbed following a single oral administration with peak plasma and tissue concentrations occurring within 2 hours. ${ }^{26-28}$ Following administration of $[3 \mathrm{H}]$ vinpocetine, approximately $47 \%$ and $34 \%$ of the dose was recovered in the urine and feces, respectively, at 48 hours; less than $5 \%$ was recovered in bile within 9 hours of administration. ${ }^{29}$ The highest radioactivity was recovered in the liver and small intestine, followed by the lung, stomach, kidney, and adrenal glands. Except for the liver and kidneys, residual radioactivity in tissues returned to minimal levels within 48 hours of administration. Urinary and fecal excretion of vinpocetine were similar, following a 5-day repeated oral exposure. The plasma elimination half-life of vinpocetine after a single gavage administration of $10 \mathrm{mg}^{30}$ or $1-2 \mathrm{mg} / \mathrm{kg}^{27 ;} 28$ was $\leq 3$ hours. The maximum plasma concentration $\left(\mathrm{C}_{\max }\right)$ and area under the concentration-versustime curve (AUC) after a single gavage administration of $2 \mathrm{mg} / \mathrm{kg}$ were $135.33 \mathrm{ng} / \mathrm{mL}$ and $504.03 \mathrm{ng} . \mathrm{h} / \mathrm{mL},{ }^{28}$ respectively; after $1 \mathrm{mg} / \mathrm{kg}$ gavage, the $\mathrm{C}_{\max }$ and AUC were $23.8 \mathrm{ng} / \mathrm{mL}$ and $57.4 \mathrm{ng} . \mathrm{h} / \mathrm{mL},{ }^{31}$ respectively. Oral bioavailability of vinpocetine in rats was $52 \%$, suggesting extensive first pass metabolism. ${ }^{30}$ The main metabolite of vinpocetine identified in rat urine was 
apovincaminic acid (approximately 75\% of urinary excretion), arising from de-esterification of vinpocetine. ${ }^{29 ;} 30$ Formation of apovincaminic acid following oral administration of vinpocetine in rats was rapid, with the highest plasma concentration observed approximately 1 hour after administration with an elimination half-life of 3-10 hours. ${ }^{27 ;} 30$

The National Toxicology Program (NTP) conducted a study to investigate the toxicokinetics of vinpocetine and apovincaminic acid in pregnant rats and to estimate gestational transfer following gavage administration of 5 and $20 \mathrm{mg} / \mathrm{kg}$ vinpocetine to dams from gestational days (GD) 6 through GD $18{ }^{32}$ Both vinpocetine and apovincaminic acid were detected in dam plasma. Vinpocetine was absorbed rapidly in dams with the $\mathrm{C}_{\max }$ occurring $\leq 1.4$ hours after dosing. The predicted $\mathrm{C}_{\max }$ and AUC increased less than proportionally to the dose. Vinpocetine was rapidly distributed to the peripheral compartment. More importantly, a significant transfer of vinpocetine from dams to fetuses was observed with fetal $\mathrm{Cmax}$ and AUC $\geq 55 \%$ of that of dams. Vinpocetine was rapidly cleared from dam plasma with a half-life of $\leq 4.02$ hours with no apparent dose-related effect. Vinpocetine was rapidly and highly metabolized to apovincaminic acid with apovincaminic acid $\mathrm{C}_{\max }$ reached $\leq 1.5$ hours. The $\mathrm{C}_{\max }$ and AUC values indicate that the apovincaminic acid levels were $\geq 2.7$-fold higher than vinpocetine levels in dams, although in the fetuses, apovincaminic acid levels were much lower than those of vinpocetine.

Absorption of vinpocetine was also rapid in New Zealand White rabbits following oral administration, with peak plasma concentration reached within 2 hours; maximum plasma concentrations varied with $209 \mathrm{ng} / \mathrm{mL}, 163 \mathrm{ng} / \mathrm{mL}$, and $61.5 \mathrm{ng} / \mathrm{mL}$ reported for $10 \mathrm{mg}$, $10 \mathrm{mg} / \mathrm{kg}$, and $40 \mathrm{mg}$, respectively. ${ }^{33-35}$ The plasma elimination half-life was 2-6.5 hours, depending on the study. In dogs, the elimination half-life was longer (approximately 9 hours). ${ }^{26}$

NTP investigated systemic exposure to vinpocetine and apovincaminic acid in pregnant New Zealand White rabbits, using plasma samples collected in the current study. Doses of 0, 20, 40, 80,160 , or $320 \mathrm{mg} / \mathrm{kg}$ vinpocetine were administered by gavage from GD 7 through GD 19, and doe plasma was collected 1 and 2 hours following the last dose. ${ }^{36}$ Vinpocetine and apovincaminic acid were detected at both time points, and the concentrations of both increased less than proportionally to the dose. Unlike in rats, the plasma concentration of apovincaminic acid was much higher than that of vinpocetine, suggesting significant species difference in metabolism, which is a conclusion reached in previous metabolism studies, both in vivo ${ }^{26}$ and in vitro. ${ }^{37}$ In addition to apovincaminic acid, hydroxyvinpocetine, hydroxyl-apovincaminic acid, and dihydroxy-vinpocetine-glycinate are other minor metabolites that have been identified in dogs and humans. ${ }^{26}$

\section{Humans}

In humans, similar to animals, absorption of vinpocetine following ingestion was fast with a maximum plasma concentration reached within 2 hours after ingestion and a plasma elimination half-life of $\leq 2$ hours. ${ }^{38-42}$ The reported oral bioavailability in humans varies from $6.7 \%$ to $57 \%{ }^{38 \text {; }}$

${ }^{39}$ Vinpocetine bioavailability differs if administered with or without food: relative bioavailability was $60-100 \%$ higher in individuals who were administered vinpocetine under non-fasting conditions compared with fasting conditions ${ }^{41}$ In the same study, food intake did not affect the rate of absorption, with maximum serum concentrations observed at 1 hour following vinpocetine administration, similar to other observed peak plasma levels. Gulyás et al. ${ }^{43} ; 44$ examined the tissue distribution of orally administered ${ }^{11} \mathrm{C}$-vinpocetine in humans through the 
use of positron emission tomography and found that vinpocetine rapidly enters the blood stream and liver through the stomach and gastrointestinal tract. These studies also demonstrated radioactivity uptake and distribution of vinpocetine in the brain, indicating that the compound can cross the blood brain barrier.

Metabolism of vinpocetine is extensive in humans similar to animals, with undetectable levels of unchanged vinpocetine in the urine 24 hours after administration. ${ }^{38}$ In vitro studies with human hepatocytes have demonstrated that human metabolism of vinpocetine is similar to that in dogs, in that metabolism occurs almost exclusively in the liver. ${ }^{37}$ The main metabolite measured in humans is apovincaminic acid. ${ }^{40 ; 45 ; 46}$

\section{Developmental and Reproductive Toxicity}

\section{Experimental Animals}

Data in the publicly available literature regarding the developmental and reproductive toxicity of vinpocetine are limited to one publication that summarized 14 safety studies. ${ }^{47}$ Vinpocetine was tested in multiple animal species (rats, dogs, and rabbits) at doses ranging from 2 to $150 \mathrm{mg} / \mathrm{kg}$, depending on the route of exposure (oral, intraperitoneal, intravenous, or intramuscular).

Maternal findings observed in these studies were limited to decreased maternal body weight gain and uterine bleeding. Fetal findings ranged from no adverse fetal outcomes (noted in the litters that survived to term) to fetal growth retardation and malformations; however, few details were reported on the types of malformations. Fetal loss, including whole litter resorptions, was noted in all studies. The publication included few study findings and details were minimal, but the authors concluded, on the basis of the data presented, that vinpocetine was safe for use in adults but recommended avoidance for pregnant women.

\section{Humans}

No studies examined vinpocetine exposure and adverse reproductive (or prenatal) outcomes in humans in the literature.

\section{General Toxicity}

\section{Experimental Animals}

The oral $\mathrm{LD}_{50}$ (lethal dose for $50 \%$ of exposed animals) value for vinpocetine is approximately $500 \mathrm{mg} / \mathrm{kg}$ in rats and mice, the intravenous $\mathrm{LD}_{50}$ is approximately $50 \mathrm{mg} / \mathrm{kg}$ in rats and mice, and the intraperitoneal $\mathrm{LD}_{50}$ ranges from 134 to $240 \mathrm{mg} / \mathrm{kg}$ in rats and mice. ${ }^{47 ;} 48$ Rodents that were administered lethal doses displayed the clinical observations of ataxia and clonic convulsions. ${ }^{47}$

Summary data from subchronic toxicity tests of vinpocetine in animals were published with limited details by Cholnoky and Dömök. ${ }^{47}$ Rats exposed orally to $100 \mathrm{mg} / \mathrm{kg} /$ day for 4 weeks displayed increased liver and thyroid gland weights and clinical observations of increased salivation. Contrary to these findings, no vinpocetine-related toxicity was noted in a separate rat study with doses up to $100 \mathrm{mg} / \mathrm{kg}$ by oral gavage. A 3-month intraperitoneal injection study in rats resulted in mortality (38\% of the males, $25 \%$ of the females) due to severe confluent 
fibroblastic peritonitis and ascites with vinpocetine doses of $25 \mathrm{mg} / \mathrm{kg} /$ day. No general toxicities were noted in a study performed in dogs with vinpocetine doses up to $25 \mathrm{mg} / \mathrm{kg} / \mathrm{day}$ administered orally through capsules for six months.

\section{Humans}

Vinpocetine exposure in humans has been associated with nausea, dizziness, insomnia, drowsiness, dry mouth, transient hypotension and tachycardia, pressure-type headache, and facial flushing. ${ }^{23 ;} 49$ Long-term use of vinpocetine has also been associated with slight reductions in systolic and diastolic blood pressure, as well as slight reductions in blood glucose. ${ }^{23}$

\section{Genetic Toxicity}

No studies on the genetic toxicity of vinpocetine were found in the published literature. However, the NTP conducted a bacterial mutation assay with vinpocetine, which produced negative results in all three bacterial strains tested, and a combined in vivo micronucleus/comet assay in female mice. Results of the micronucleus test were negative, and results of the comet assay, which evaluates potential for DNA damage, were judged to be equivocal in liver and negative in blood leukocytes and stomach epithelial cells. Results of an in vitro micronucleus test with vinpocetine in TK6 cells were judged to be positive. Data from all NTP genetic toxicity tests with vinpocetine are available in the NTP Chemical Effects in Biological Systems database: https://doi.org/10.22427/NTP-DATA-002-03277-0000-0000-1. ${ }^{50}$

\section{Study Rationale}

The dietary supplement vincamine was nominated by the National Cancer Institute for genotoxicity, subchronic toxicity, and toxicokinetic studies due to a lack of information on potential toxicity. However, vincamine is no longer widely marketed as a dietary supplement in the United States and has been replaced by its semisynthetic derivative, vinpocetine. Due to limited literature indicating that vinpocetine might not be safe for use during pregnancy and the possibility for widespread exposure to women of childbearing age, the developmental toxicity of vinpocetine in rats was investigated. Given the adverse responses on prenatal development that were observed in the rat, a dose range-finding rabbit study was included to provide information on vinpocetine in a second species and to assess species-specific developmental effects. 


\section{Materials and Methods}

\section{Overview of Prenatal Developmental Toxicity Study Designs}

Prenatal developmental toxicity studies are conducted to ascertain if in utero exposure to a test agent results in embryo-fetal death, structural malformations/variations, growth retardation, or functional deficits not secondary to overt maternal toxicity. Overt maternal toxicity has been shown to affect normal embryo-fetal growth and development (e.g., excessively lower maternal body weight gains and lower fetal weights, increased maternal stress in mice, and cleft palate). ${ }^{51-53}$ The presence of maternal toxicity, however, should not negate a priori an apparent fetal response. Rather, given the maternal/embryo-fetal interrelationship, maternal responses should be considered when interpreting fetal findings. Pregnant animals should be administered the highest feasible dose levels of test agent (or the limit dose) to achieve maximal dam and fetal exposure and sufficiently challenge the test system to identify potential developmental hazards. ${ }^{54}$

The conduct of a dose range-finding study helps determine dose selection when the potential for test agent-induced maternal toxicity is unknown and can provide preliminary information on embryo-fetal outcomes (e.g., postimplantation loss, changes in fetal weight, external defects) and informs the design for a prenatal developmental toxicity study. In the prenatal developmental toxicity study, fetal examination is expanded to include examination of the fetal viscera, head (soft tissue and skeletal components), and the skeleton for osseous and cartilaginous defects. Abnormalities are categorized in one of two groups: (1) malformations that are permanent structural changes that could adversely affect survival, development, or function; and (2) variations that are a divergence beyond the usual range of structural constitution but might not adversely affect survival or health, ${ }^{52}$ consistent with the descriptions by Makris et al. ${ }^{55}$ The general study design for the dose range-finding and prenatal developmental toxicity studies in the rat is presented in Figure 2, and the general study design for a dose range-finding rabbit study is presented in Figure 3. 


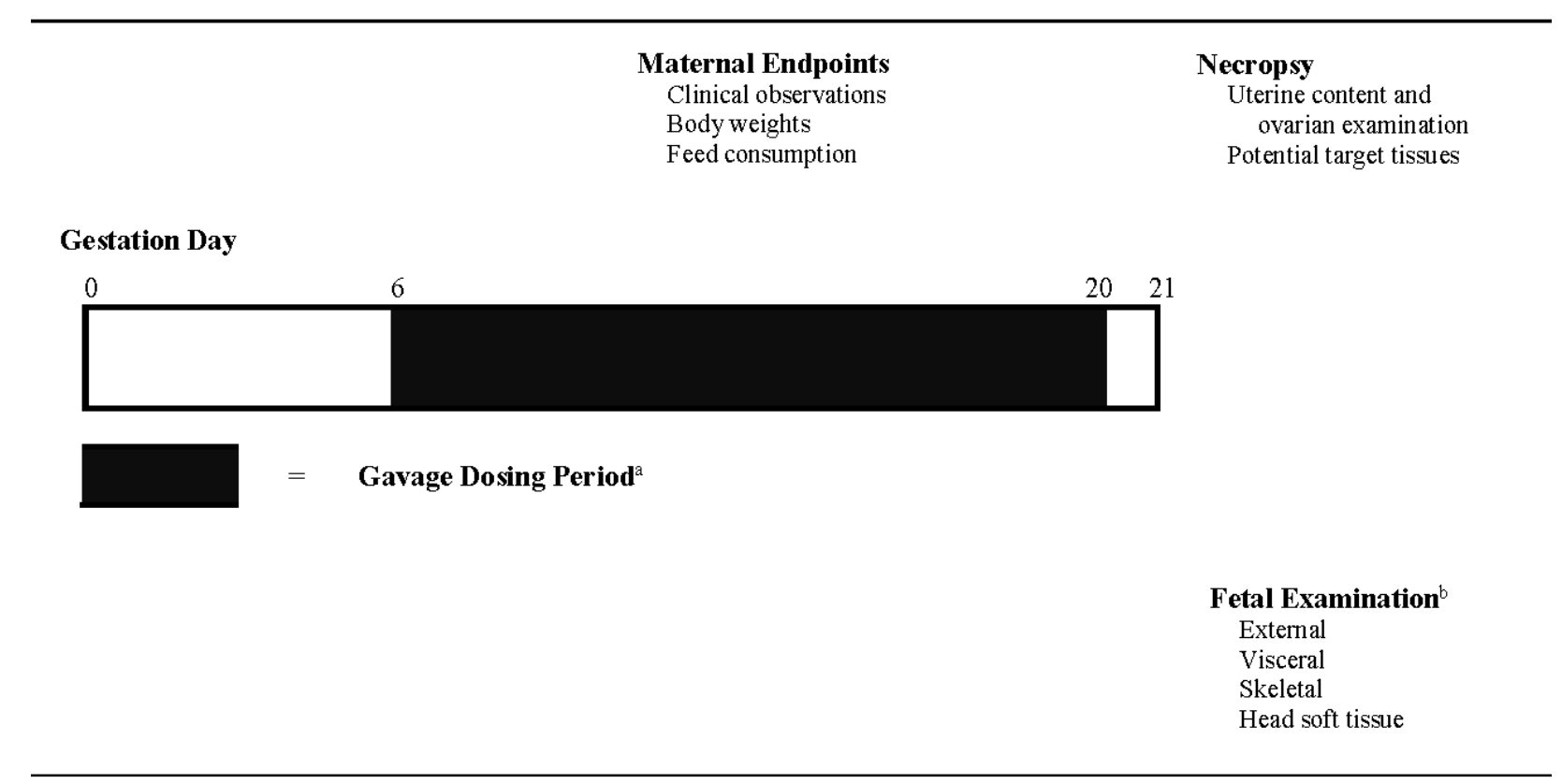

Figure 2. Design of Dose Range-finding and Prenatal Developmental Toxicity Studies in Rats

${ }^{\text {a} A n i m a l s ~ a r e ~ e x p o s e d ~ o n c e ~ d a i l y ~ f r o m ~ g e s t a t i o n ~ d a y ~(G D) ~} 6$ to GD 20 and necropsied on GD 21.

${ }^{b}$ All fetuses are examined externally (including inspection of the oral cavity). Fetuses in the prenatal developmental toxicity study also are also examined for visceral and skeletal effects with approximately $50 \%$ of the heads examined for soft tissue alterations.

\begin{tabular}{ccc}
\hline & Maternal Endpoints & Necropsy \\
Uterine content and \\
Clinical observations & Body weights & Potential target tissues \\
& Feed consumption & Potion \\
\end{tabular}

\section{Gestation Day}
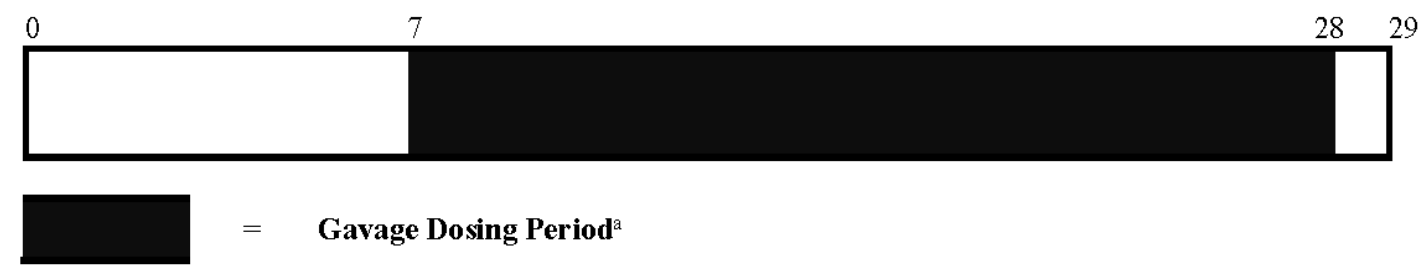

Fetal Examination $^{b}$ External

Figure 3. Design of Dose Range-finding Prenatal Developmental Toxicity Study in Rabbits

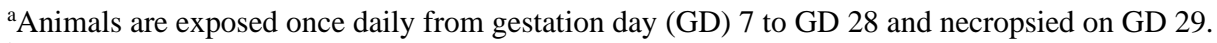

${ }^{b}$ All fetuses are examined externally (including inspection of the oral cavity). 


\section{Procurement and Characterization}

\section{Vinpocetine}

Vinpocetine was obtained from Maypro Industries, LLC (Purchase, NY) in one lot (VA201211001). Identity, purity, and stability analyses were conducted by the analytical chemistry laboratory at Battelle (Columbus, OH) (Appendix A). The chemical, a white crystalline powder, was identified as vinpocetine using Fourier transform infrared (FTIR) and proton and carbon-13 nuclear magnetic resonance spectroscopy and gas chromatography (GC) with mass spectrometry detection. The optical activity analysis indicated an average rotation of $+131.6^{\circ}$, which is consistent with the optical rotation of vinpocetine. Purity of the test article was determined by elemental analyses, proton-induced X-ray emission (PIXE) spectroscopy, differential scanning calorimetry, melting point analysis, high-performance liquid chromatography (HPLC) with ultraviolet (UV) detection, and GC with flame ionization detection (FID).

Karl Fischer titration indicated less than $0.07 \%$ water. Elemental analyses for carbon, hydrogen, nitrogen, and oxygen agreed with the theoretical values for vinpocetine; PIXE analyses indicated no inorganic impurities greater than $0.1 \%$. Melting point analysis averaged $149.88^{\circ} \mathrm{C}$ and differential scanning calorimetry indicated a purity of 99.9\%. HPLC/UV indicated one major peak (99.5\% of the total peak area) and two impurities greater than $0.1 \%$ of the total peak area $(0.17 \%$ and $0.28 \%)$. The larger impurity peak was tentatively identified as apovincamine. GC/FID indicated one major peak (99.3\% of the total peak area) and one reportable impurity $(0.67 \%$ of the total peak area), which was tentatively identified as apovincamine. Screening for volatiles using a second GC/FID system indicated the presence of $0.018 \%$ methylene chloride. The overall purity of lot VA201211001 was determined to be greater than $99.3 \%$.

Stability studies of the bulk chemical were performed using GC/FID. These studies indicated that vinpocetine was stable as a bulk chemical for at least 14 days when stored in sealed amber glass vials at temperatures up to $60^{\circ} \mathrm{C}$. To ensure stability, the bulk chemical was stored at room temperature and protected from light in sealed double plastic bags in a plastic bucket. Reanalysis of the bulk chemical was performed twice during the studies with GC/FID, and no degradation was detected.

\section{Methylcellulose}

Methylcellulose was obtained from Spectrum Chemical Manufacturing Corporation (Gardena, CA) in two lots (2CB0045 and 2DH0326); lot 2CB0045 was used in the dose range-finding study in rats, and lot 2DH0326 was used in the prenatal developmental toxicity study in rats and the dose range-finding study in rabbits. Lot 2DH0326 was identified as methylcellulose using FTIR spectroscopy. Duplicate determinations of the methoxy content (30.9\% and 31.1\%) were within the acceptance limits of $26.0-33.0 \%$.

\section{Preparation and Analysis of Dose Formulations}

The dose formulations were prepared once for each study by mixing vinpocetine with $0.5 \%$ aqueous methylcellulose solution. The analytical chemistry laboratory used GC/FID to evaluate the homogeneity of 0.1 and $200 \mathrm{mg} / \mathrm{mL}$ formulations, syringeability for 18- and 22-gauge gavage needles using the $200 \mathrm{mg} / \mathrm{mL}$ formulation, resuspendability of the $200 \mathrm{mg} / \mathrm{mL}$ 
formulation, and stability of the $0.1 \mathrm{mg} / \mathrm{mL}$ formulation. Homogeneity, syringeability, and resuspendability were confirmed. Stability was confirmed for 42 days for dose formulations stored in clear glass bottles with Teflon ${ }^{\circledR}$-lined lids packaged in sealed amber plastic bags at room temperature and for 3 hours under simulated animal room conditions.

Periodic analyses of the dose formulations of vinpocetine were conducted by the analytical chemistry laboratory using GC/FID. During the dose range-finding study in rats, dose formulations were analyzed once: all five dose formulations analyzed and used were within $10 \%$ of the target concentrations (Table A-3). Animal room samples of these dose formulations were also analyzed; four of five were within $10 \%$ of the target concentrations. During the prenatal developmental toxicity study in rats, the dose formulations were analyzed once; animal room samples of these dose formulations were also analyzed (Table A-4). All three dose formulations and all three animal room samples were within $10 \%$ of the target concentrations. During the dose range-finding study in rabbits, the dose formulations were analyzed once (Table A-5). Of the dose formulations analyzed during the study, all eight were within $10 \%$ of the target concentrations; two of four animal room samples were within $10 \%$ of the target concentrations.

\section{Animal Source}

Female Sprague Dawley (Hsd:Sprague Dawley ${ }^{\circledR} \mathrm{SD}^{\circledR}$ ) rats for use in the dose range-finding and prenatal developmental toxicity studies were obtained from Envigo (formerly Harlan Laboratories, Inc., Indianapolis, IN) (Table 1). This stock is routinely used in NTP studies for toxicity evaluation. Sexually mature (12-13 weeks old) females were time-mated overnight at the vendor and were received on gestation day (GD) 1 or 2 for both the dose range-finding and prenatal developmental toxicity studies. GD 0 was defined as the day that positive evidence of mating was observed.

Female New Zealand White (Hra:NZW SPF) rabbits for use in the dose range-finding study were obtained from Covance Research Products (Greenfield, IN) (Table 2). Sexually mature females (5 months old) were time-mated at the vendor and were received on GD 1 or 2.

\section{Animal Health Surveillance}

In accordance with the NTP Sentinel Animal Program (Appendix C), 10 female rabbits randomly selected from among the study groups were evaluated at the end of the dose range-finding study. Antibodies to rotavirus were detected in several samples. Rotavirus is a common virus in rabbits that was not considered to have impacted the current study. ${ }^{56}$ All other test results were negative. Disease screening was not conducted in the rats; however, rats were obtained from a commercial colony free of the following rat pathogens: Sendai virus, pneumonia virus of mice, sialodacryoadenitis virus, Kilham rat virus, Toolan's $\mathrm{H} 1$ virus, rat minute virus, reovirus, rat theilovirus, lymphocytic choriomeningitis virus, hantavirus, mouse adenovirus, rat parvovirus, Mycoplasma pulmonis, and Pneumocystis carinii.

\section{Animal Welfare}

Animal care and use were in accordance with the Public Health Service Policy on Humane Care and Use of Animals and the U.S. Animal Welfare Act and Regulations. All animal studies were conducted in an animal facility accredited by AAALAC International. Studies were approved by 
the Southern Research Animal Care and Use Committee and conducted in accordance with all relevant NIH and NTP animal care and use policies and applicable federal, state, and local regulations and guidelines.

\section{Experimental Design}

In the dose range-finding and prenatal developmental toxicity studies, time-mated rats were housed individually, provided NIH-07 feed and water ad libitum, and observed at least twice daily for viability (morning and afternoon). Clinical observations were performed on GD 3 (prenatal developmental toxicity study only) and on GD 6 through 21 until removal, typically twice daily (at the time of dose administration and cage-side post dose). Females in the dose range-finding study were weighed daily from GD 3 through GD 21, and those in the prenatal developmental study were weighed on the day of arrival, on GD 3, and daily from GD 6 through GD 21. Feed consumption was recorded for GDs 3 to 6, GD 6 to 9, GD 9 to 12, GD 12 to 15, GD 15 to 18, and GD 18 to 21. Details of the study design-including animal source and identification, diet, water, husbandry, environmental conditions, euthanasia, necropsy, and fetal evaluations - are summarized in Table 1. Information on feed composition and contaminants is provided in Appendix B and Appendix C.

In the vinpocetine rabbit dose range-finding study, time-mated animals were housed individually, provided Purina 5322 5LMO or Teklad 2031C feeds and water ad libitum, and observed at least twice daily for viability (morning and afternoon). Clinical observations were recorded on GD 3 and on GD 7 through GD 29 until removal, typically twice daily (at the time of dose administration and cage-side post dose). Females were weighed daily on GD 3 through GD 29. Feed consumption was recorded for GD 3 to 7, GD 7 to 9, GD 9 to 12, GD 12 to 15, GD 15 to 18, GD 18 to 21, GD 21 to 24, GD 24 to 27, and GD 27 to 29. Details of the rabbit study design - including animal source and identification, diet, water, husbandry, environmental conditions, euthanasia, necropsy, and fetal evaluations-are summarized in Table 2.

On GD 21, rats were weighed, euthanized by $\mathrm{CO}_{2}$ inhalation, and examined for gross lesions of the thoracic and abdominal cavities. On GD 29, rabbits were weighed, euthanized with intravenous injection of sodium pentobarbital-containing solution, and examined for gross lesions of the thoracic and abdominal cavities. The ovaries and gravid uterus of both species were excised and weighed (ovaries for prenatal developmental toxicology study only) and placental findings were recorded. The numbers of uterine implantation sites and corpora lutea visible on the surface of each ovary were recorded. Uterine contents were examined for pregnancy status and the number and location of all live and dead fetuses (a live fetus is defined as one that responds to stimuli; a dead fetus is defined as a term fetus that does not respond to stimuli and is not markedly autolyzed) and resorptions were recorded.

Resorptions were classified as early or late. Early resorptions included a conceptus characterized by a grossly necrotic mass that had no recognizable fetal form or presence of nidation sites (“pregnant by stain”). Late resorptions were characterized by grossly necrotic but recognizable fetal form with placental remnants visible. ${ }^{57 ;} 58$ Postimplantation loss was calculated as the number of dead plus resorbed conceptuses divided by the total number of implantations (multiplied by 100). For each uterus with no macroscopic evidence of implantation, the uterus was stained with $10 \%(\mathrm{v} / \mathrm{v})$ ammonium sulfide to visualize any possible early implantation sites. ${ }^{59}$ 
Adult females that were euthanized moribund, delivered early, or found dead received a gross necropsy that included an examination of the thoracic and abdominal viscera for evidence of dosing trauma or toxicity. The uterus of each female was examined and stained, if necessary, to determine pregnancy status. Females were not retained for further examination.

All rabbits that aborted (defined as delivering before GD 29), were euthanized moribund, or found dead received a gross necropsy that included examination of the thoracic and abdominal viscera for evidence of dosing trauma, toxicity, and gross lesions. The uterus of each female was examined and stained, as necessary, to determine pregnancy status. Females were not retained for further examination.

\section{Dose Range-finding Study in Rats}

Time-mated rats were individually identified by tail marking and randomized by GD 3 body weight stratification into six groups (vehicle control, low, low-mid, mid, mid-high, or high) using Southern Research’s Instem ${ }^{\mathrm{TM}}$ Provantis $^{\circledR}$ (version 8) electronic data collection system.

Groups of 10 time-mated female rats were administered 0 (vehicle control), 20, 40, 80, 160, or $320 \mathrm{mg}$ vinpocetine/kg body weight/day (mg/kg/day), calculated from the most recent body weight, in $0.5 \%$ aqueous methylcellulose by gavage from GD 6 to GD 20. Vehicle control animals received aqueous methylcellulose alone; the dosing volume was $5 \mathrm{~mL} / \mathrm{kg} / \mathrm{day}$. Given the limited data in one publication and potential strain differences, the high dose of $320 \mathrm{mg} / \mathrm{kg}$ was chosen to ensure that the animals were sufficiently challenged even though excessive maternal toxicity might result. Data from this study were used to inform the prenatal developmental toxicity study.

On GD 21, rat fetuses were removed from the uterus, individually weighed (live fetuses only), and examined externally for alterations, including inspection of the oral cavity for cleft palate. Live fetuses were euthanized by decapitation or with intraperitoneal injection of a commercially available solution containing sodium pentobarbital followed by bilateral pneumothorax or decapitation. Fetuses were not retained following completion of the external examination.

\section{Prenatal Developmental Toxicity Study in Rats}

On receipt (GD 1 or 2), time-mated rats were individually identified by tail marking and were randomized by GD 3 body weight stratification into four groups (vehicle control, low, mid, or high) using Southern Research's Instem ${ }^{\mathrm{TM}}$ Provantis $^{\circledR}$ (version 9) electronic data collection system. Dams were received over a 4-day period to allow for a staggered study start.

Groups of 25 time-mated female rats were administered 0 (vehicle control), 5, 20, or $60 \mathrm{mg}$ vinpocetine $/ \mathrm{kg} /$ day, calculated from the most recent body weight, in $0.5 \%$ aqueous methylcellulose by gavage from GD 6 to GD 20 (15 days). Vehicle control animals received the aqueous methylcellulose vehicle alone; the dosing volume was $5 \mathrm{~mL} / \mathrm{kg}$.

On GD 21, fetuses were removed from the uterus, and live fetuses individually weighed. The uteri of animals that did not appear pregnant were examined for nidations (implantation sites) by staining with $0.5 \%$ ammonium sulfide. ${ }^{59}{ }^{60}$ All fetuses were examined externally for alterations, including inspection of the oral cavity for cleft palate. Live fetuses were subsequently euthanized by intraperitoneal injection of sodium pentobarbital. Fetal sex was confirmed by inspection of 
gonads in situ. All fetuses were examined for soft tissue alterations under a stereomicroscope. ${ }^{61}$

62 The heads were removed from approximately half of the fetuses in each litter and fixed in Bouin's solution and subsequently examined by free-hand sectioning. ${ }^{63}$ This technique precludes skeletal evaluations of the skull; therefore, remaining heads and all fetuses were eviscerated, fixed in ethanol, macerated in potassium hydroxide, stained with alcian blue and alizarin red, and examined for subsequent cartilage and osseous alterations. ${ }^{60 ; 64}$ External, visceral, and skeletal fetal alterations were recorded as developmental variations or malformations.

\section{Dose Range-finding Study in Rabbits}

Groups of eight time-mated female rabbits were administered 0 (vehicle control), 25, 75, 150, or $300 \mathrm{mg}$ vinpocetine/kg/day (based on the most recent body weight) in $0.5 \%$ aqueous methylcellulose by gavage from GD 7 to GD 28. Vehicle control animals received aqueous methylcellulose alone; the dosing volume was $5 \mathrm{~mL} / \mathrm{kg}$. The high dose of $300 \mathrm{mg} / \mathrm{kg}$ was chosen informed by data from the rat range-finding study and the limited toxicokinetic data in the literature on rabbits, suggesting similar disposition of vinpocetine between rats and rabbits. ${ }^{27 ; 28 \text {; }}$ 30; 33-35

On GD 29, fetuses were removed from the uterus, individually weighed (live fetuses only), and examined externally for alterations, including inspection of the oral cavity for cleft palate. Live fetuses were euthanized by intraperitoneal injection of a commercially available solution containing sodium pentobarbital. Fetuses were not retained following completion of the external examination.

Table 1. Experimental Design and Materials and Methods in the Dose Range-finding and Prenatal Developmental Toxicity Gavage Studies of Vinpocetine in Rats

\begin{tabular}{|c|c|}
\hline Dose Range-finding Study & Prenatal Developmental Toxicity Study \\
\hline \multicolumn{2}{|l|}{ Study Laboratory } \\
\hline Southern Research (Birmingham, AL) & Southern Research (Birmingham, AL) \\
\hline \multicolumn{2}{|l|}{ Strain and Species } \\
\hline Sprague Dawley (Hsd:Sprague Dawley ${ }^{\circledR} \mathrm{SD}^{\circledR}$ ) rats & Sprague Dawley (Hsd:Sprague Dawley ${ }^{\circledR} \mathrm{SD}^{\circledR}$ ) rats \\
\hline \multicolumn{2}{|l|}{ Animal Source } \\
\hline $\begin{array}{l}\text { Envigo (formerly Harlan Laboratories, Inc., } \\
\text { Indianapolis, IN) }\end{array}$ & $\begin{array}{l}\text { Envigo (formerly Harlan Laboratories, Inc., } \\
\text { Indianapolis, IN) }\end{array}$ \\
\hline \multicolumn{2}{|l|}{ Day of Arrival } \\
\hline February 19, 2014 (GD 1 or 2) & January 14 or 16,2015 (GD 1 or 2 ) \\
\hline \multicolumn{2}{|l|}{ Average Age on Arrival } \\
\hline 12 weeks & 12 to 13 weeks \\
\hline \multicolumn{2}{|l|}{ Weight Range at Randomization } \\
\hline $201.7 \mathrm{~g}$ to $256.4 \mathrm{~g}$ on GD 3 & $190.4 \mathrm{~g}$ to $260.2 \mathrm{~g}$ on GD 3 \\
\hline \multicolumn{2}{|l|}{ Calendar Day of First Dose and Last Dose } \\
\hline $\begin{array}{l}\text { GD } 6 \text { (February } 23 \text { or 24, 2014) and GD } 20 \text { (March } 9 \text { or } \\
\text { 10, 2014); staggered start }\end{array}$ & $\begin{array}{l}\text { GD } 6 \text { (January } 18 \text { to 21, 2015) and GD } 20 \text { (February } 1 \\
\text { to 4, 2015); staggered start }\end{array}$ \\
\hline
\end{tabular}




\section{Duration of Dosing}

GD 6 to 20, once daily

GD 6 to 20, once daily

\section{Size of Study Groups}

10 time-mated females

25 time-mated females

\section{Method of Randomization and Identification}

Time-mated animals were uniquely identified on day of receipt by tail marking. Animals were assigned to one of six exposure groups by stratified randomization of GD 3 Same as dose range-finding study; animals assigned to body weights using Instem Provantis ${ }^{\circledR}$ (version 8) electronic data collection system. Each animal was assigned a unique animal number in Provantis ${ }^{\circledR}$. This number was linked to the respective tattoo and all data collected during the study was associated with the Provantis ${ }^{\circledR}$ animal number.

\section{Animals per Cage}

Diet

Irradiated NIH-07 0.5-inch Certified Rodent Diet pellets Same as dose range-finding study or wafer diet (Zeigler Brothers, Inc., Gardners, PA), available ad libitum

\section{Water}

Tap water (Birmingham Water Works Co., Birmingham, Same as dose range-finding study AL, municipal supply) via automatic watering system, available ad libitum

\section{Cages}

Solid bottom polycarbonate cages (Lab Products, Seaford, DE), changed weekly

\section{Bedding}

Certified irradiated Sani-Chips ${ }^{\circledR}$ hardwood cage bedding (P.J. Murphy Forest Products Corporation, Montville, NJ), changed weekly

\section{Cage Filters}

Spunbonded Remay (Andico, Birmingham, AL), changed every 2 weeks

\section{Racks}

Stainless steel (Lab Products, Inc., Seaford, DE), changed every 2 weeks

\section{Animal Room Environment}

Temperature: $72^{\circ} \mathrm{F} \pm 3^{\circ} \mathrm{F}$

Relative humidity: $50 \% \pm 15 \%$

Room fluorescent light: 12 hours/day

Room air changes: at least 10 /hour
Same as dose range-finding study

Same as dose range-finding study

Same as dose range-finding study

Same as dose range-finding study

Same as dose range-finding study 


\section{Doses}

$0,20,40,80,160$, or $320 \mathrm{mg} / \mathrm{kg}$ in $0.5 \%$

methylcellulose (dosing volume $5 \mathrm{~mL} / \mathrm{kg}$ )

\section{Type and Frequency of Observation of Dams}

Observed for viability (cageside) twice daily from GD 3 through GD 20. Clinical observations (out of cage) were performed at least once during the prestudy period and at least once daily while on study (1 to 3 hours postdose). Animals were weighed daily beginning on GD 3 . Feed consumption was recorded at 3-day intervals from GD 3 through GD 21.

\section{Primary Method of Euthanasia}

$100 \% \mathrm{CO}_{2}$ (adults) or intraperitoneal injection of a solution containing sodium pentobarbital followed by bilateral pneumothorax or decapitation (fetuses)

\section{Necropsy and Postmortem Evaluation of Females}

On GD 21, terminal body and gravid uterine weights were recorded and the uterine contents examined. The number of corpora lutea on each ovary was recorded. The number and location of all fetuses (live or dead) and resorptions (early or late) and the total number of implantation sites were recorded; if no macroscopic evidence of pregnancy, the uterus was stained to visualize potential evidence of implantation sites. For animals removed early, gross necropsy including an examination of the thoracic and abdominal viscera was performed. The uterus of each female was examined to determine pregnancy status or, if no evidence of pregnancy, stained to visualize possible early implantation sites.

\section{Fetal Evaluation}

Live fetuses were counted, sexed, weighed, and examined for external morphologic abnormalities that included inspection of the oral cavity for cleft palate.
$0,5,20$, or $60 \mathrm{mg} / \mathrm{kg}$ in $0.5 \%$ aqueous methylcellulose (dosing volume $5 \mathrm{~mL} / \mathrm{kg}$ )

Observed for viability (cageside) at least twice daily from GD 3 through GD 20. Clinical observations (out of cage) were performed at least once during the prestudy period and at least once daily while on study (1 to 3 hours post-dose). Animals were weighed on the day of arrival, on GD 3, and on GD 6 through 21. Feed consumption was recorded at 3-day intervals from GD 3 through GD 21.

Same as dose range-finding study

On GD 21, terminal body, ovarian, and gravid uterine weights were recorded. Uterine contents were examined. The number of corpora lutea on each ovary was recorded. The number and location of all fetuses (live or dead) and resorptions (early or late) and the total number of implantation sites were recorded; if no macroscopic evidence of pregnancy, the uterus was stained to visualize potential evidence of implantation sites. For animals removed early, gross necropsy including an examination of the thoracic and abdominal viscera was performed. The uterus of each female was examined to determine pregnancy status or, if no evidence of pregnancy, stained to visualize possible early implantation sites.

Live fetuses were counted, sexed, weighed, and examined for external morphologic abnormalities including inspection of the oral cavity for cleft palate. Placental morphology was also evaluated.

Live fetuses were euthanized and then examined for visceral morphologic abnormalities by fresh dissection. The sex of each fetus was confirmed by internal examination. The heads from approximately one half of the fetuses in each litter were fixed, sectioned, and examined. All fetuses were eviscerated, fixed, stained, and examined for skeletal developmental variations, malformations, or other morphologic findings.

GD = gestation day. 
Table 2. Experimental Design and Materials and Methods in the Dose Range-finding Gavage Study of Vinpocetine in Rabbits

\section{Dose Range-finding Study in Rabbits}

\section{Study Laboratory}

Southern Research (Birmingham, AL)

\section{Strain and Species}

New Zealand White (Hra:NZW SPF) rabbits

\section{Animal Source}

Covance Research Products (Greenfield, IN)

\section{Day of Arrival}

April 24, 2015 (GD 1 or 2)

\section{Average Age on Arrival}

5 to 6 months

\section{Weight Range at Randomization}

2,676.0 g to 3,561.6 g on GD 3

\section{Calendar Day of First Dose (GD 7) and Last Dose (GD 28)}

GD 7 (April 29 or 30, 2015) and GD 28 (May 20 or 21, 2015); staggered start

\section{Duration of Dosing}

GD 7 to 28, once daily

\section{Size of Study Groups}

8 time-mated females

\section{Method of Randomization and Identification}

Time-mated animals were individually identified by ear marking and randomized by GD 3 body weight stratification into five groups using Instem Provantis ${ }^{\circledR}$ (version 9) electronic data collection system.

\section{Animals per Cage}

1

Diet

Irradiated Purina 53225 LMO (Purina, Richmond, IN) and Teklad 2031 C (Harlan, Madison, WI) Certified Rabbit Diets, available ad libitum; timothy hay (BioServe, Flemington, NJ) once daily as consumable enrichment

\section{Water}

Tap water (Birmingham Water Works Co., Birmingham, AL, municipal supply) via automatic watering system, available ad libitum

\section{Cages}

Perforated-bottom stainless steel cages (Allentown Caging Equipment Co, Allentown, PA), changed every 2 weeks

\section{Bedding}

Paper cage liners (Manufacturer, City, ST), changed 3 times per week

\section{Racks}

Stainless steel (Allentown Caging Equipment Co, Allentown, PA), changed every 2 weeks 


\section{Dose Range-finding Study in Rabbits}

\section{Animal Room Environment}

Temperature: $61^{\circ} \mathrm{F}$ to $72^{\circ} \mathrm{F}$

Relative humidity: $30 \%$ to $70 \%$

Room fluorescent light: 12 hours/day

Room air changes: at least 14/hour

Doses

$0,25,75,150$, or $300 \mathrm{mg} / \mathrm{kg}$ in $0.5 \%$ methylcellulose (dosing volume $5 \mathrm{~mL} / \mathrm{kg}$ )

\section{Type and Frequency of Observation of Does}

Observed for viability (cageside) at least twice daily from GD 3 through GD 29. Detailed observations (out of cage) were performed at least once during the prestudy period and at least once daily while on study (1 to 3 hours post-dose). Animals were weighed daily beginning on GD 3. Feed consumption was recorded at 3-day intervals from GD 3 through GD 29.

\section{Primary Method of Euthanasia}

Intravenous injection (adults) or intraperitoneal injection (fetuses) of a solution containing sodium pentobarbital

\section{Necropsy and Postmortem Evaluation of Does}

On GD 29, terminal body and gravid uterine weights were recorded, and the uterine contents were examined. The number of corpora lutea on each ovary was recorded. The number and location of all fetuses (live and dead) and resorptions (early or late) and the total number of implantation sites were recorded; if no macroscopic evidence of pregnancy, the uterus was stained to visualize potential evidence of implantation sites.

For animals removed early, gross necropsy including an examination of the thoracic and abdominal viscera was performed. The uterus of each female was examined to determine pregnancy status or, if no evidence of pregnancy, stained to visualize possible early implantation sites.

\section{Fetal Evaluation}

Live fetuses were counted, sexed, weighed, and examined for external morphologic abnormalities including examination of the oral cavity for cleft palate.

$\mathrm{GD}=$ gestation day.

\section{Statistical Methods}

In the dose range-finding studies and the prenatal developmental toxicity study, statistical analyses were performed on data from pregnant females that survived until the end of the study and were examined on GD 21 (rats) or GD 29 (rabbits) and from live fetuses. Statistical analyses were performed using SAS 9.3 (SAS Institute, Cary NC).

\section{Descriptive Statistics}

Maternal Parameters: Maternal body weights were measured daily starting at GD 3 and reported as means. Terminal maternal body weights at GD 21 (rats) or GD 29 (rabbits) were adjusted for gravid uterine weight by subtracting the gravid uterine weight from the female's body weight. Body weight gains were calculated over each 3-day interval and from GD 6 to GD 21 (rats) or GD 29 (rabbits). Daily feed consumption was averaged over each 3-day interval and from GD 6 to GD 21 (rats) or GD 29 (rabbits). These continuous variables, in addition to gravid uterine weights and other organ weights, hematology, and clinical chemistry were summarized with means and standard errors. 
Placental and Fetal Parameters: Data on uterine contents are reported as means and standard errors of counts per dam/litter (corpora lutea, implants, resorptions, dead fetuses) and as total numbers of occurrences (resorptions, dead fetuses). Data from females that were not pregnant or that did not survive to the end of the study were not included. Postimplantation loss is calculated as a percentage of the number of implants per dam. Fetal findings are reported as means and standard errors of counts per litter (numbers of live fetuses, male fetuses, female fetuses), means and standard errors of litter means (fetal weight, male fetal weight, female fetal weight), and total numbers of occurrences (total number of live fetuses). In addition, several calculated variables are reported, including the percentage of live male fetuses per litter.

Incidences of morphological findings from the gross, external, visceral, skeletal and head examinations of pathology of placentae and fetuses are presented as number and percentage of affected fetuses and as number and percentage of affected litters.

\section{Analysis of Maternal Parameters and Uterine Contents}

Maternal organ and body weight data, which historically have approximately normal distributions, were analyzed with the parametric multiple comparison procedures of Dunnett ${ }^{65}$ and Williams. ${ }^{66 ; 67}$ Non-normally distributed variables, such as food consumption, hematology, clinical chemistry, and uterine content endpoints, were analyzed using the nonparametric multiple comparison methods of Shirley ${ }^{68}$ (as modified by Williams ${ }^{69}$ ) and Dunn. ${ }^{70}$ For normally distributed and non-normally distributed variables, the Jonckheere test ${ }^{71}$ was used to assess the significance of dose-related trends at $\mathrm{p}<0.01$ to determine whether a monotonic trend-sensitive test (the Williams or Shirley test) was more appropriate than a test that does not assume a monotonic dose-related trend (the Dunnett or Dunn test). Prior to statistical analysis, extreme values identified by the outlier test of Dixon and Massey ${ }^{72}$ were examined by NTP personnel, and implausible values were eliminated from the analysis.

Fetal body weights were analyzed using mixed-effects linear models, with litter as a random effect to account for potential within-litter correlations. To test for a linear trend, dose was entered into the model as its numeric value and its significance was evaluated. For pairwise comparisons with the control group, a second mixed-effects model with dose entered into the model as a categorical variable was estimated, followed by the Dunnett ${ }^{65}$ and $\mathrm{Hsu}^{73}$ multiple comparisons tests.

\section{Analysis of Incidences of Gross Pathology and Morphology Findings}

Incidences of gross findings, malformations, and variations in the fetuses were summarized and analyzed as the number of litters affected and as the number of fetuses affected. Incidences of gross findings, malformations, and numbers of litters affected were analyzed using the CochranArmitage trend test ${ }^{74}$ and the Fisher exact test. ${ }^{75}$ The numbers of fetuses affected were analyzed using mixed-effects logistic regression in which the litter was a random effect to account for potential litter effects. ${ }^{76-78}$ For each fetal finding, an initial mixed-effects logistic regression model used the numeric value of dose to assess the significance of a dose-related trend; a subsequent logistic regression model incorporated dose as a categorical variable to compare each dose group to the control group. To conduct the mixed-effects logistic regression analyses, at least one finding was required per dose group, and the correlation matrix describing the relationship between litters was required to be "positive definite.” If the mixed-effects logistic 
regression failed to converge or did not meet the specified criteria, two separate analyses were used to bracket the true $\mathrm{P}$ value. The Cochran-Armitage trend test and the Fisher exact test were used with the litter as the experimental unit to calculate the upper limit for the true p value and with the fetus as the experimental unit to calculate the lower limit for the true $\mathrm{p}$ value.

\section{Historical Control Data}

The concurrent control group represents the most valid comparison to the treated groups and is the only control group analyzed statistically in NTP developmental and reproductive toxicity studies. However, historical control data are often helpful in interpreting potential exposurerelated effects, particularly for uncommon fetal findings that occur at a very low incidence. For meaningful comparisons, the conditions for studies in the historical control database must be generally similar. Factors that could affect the background incidences of fetal findings at a variety of anatomical sites are diet, sex, strain/stock, route of exposure, study type, and laboratory that conducted the study. The NTP historical control database for teratology studies contains all fetal evaluations (e.g., teratology studies or modified one-generation studies) for each laboratory. In general, the historical control database for a given study includes studies using the same route of administration and study design. Historical control data for rats in this Developmental and Reproductive Toxicity Technical Report represents data from gavage studies conducted at Southern Research Institute. The concurrent controls are included in the historical control data set. NTP historical control data are available online at https://ntp.niehs.nih.gov/go/historical_controls.

\section{Quality Assurance Methods}

The dose range-finding and prenatal developmental toxicity studies were conducted in compliance with Food and Drug Administration Good Laboratory Practice Regulations (21 CFR, Part 58). Records from these studies were submitted to the NTP Archives. The prenatal developmental toxicity study was audited retrospectively by an independent quality assessment contractor. Separate audits covered completeness and accuracy of the final study data tables for the dose range-finding and prenatal developmental toxicity studies and a draft of this NTP Developmental and Reproductive Toxicity Technical Report. Audit procedures and findings are presented in the reports and are on file at NIEHS. The audit findings were reviewed and assessed by NTP staff, and all comments were resolved or otherwise addressed during the preparation of this report. 


\section{Results}

\section{Data Availability}

NTP evaluated all study data. Data relevant for evaluating toxicological findings are presented here. All study data are available in the NTP Chemical Effects in Biological Systems (CEBS) database: https://doi.org/10.22427/NTP-DATA-002-03277-0000-0000-1. ${ }^{50}$

\section{Dose Range-finding Study in Rats}

\section{Maternal Findings}

\section{Viability and Clinical Observations}

All rats survived until the end of the study (Table 3). Clinical observations of red or brown vaginal discharge occurred in all groups $(4,5,7,10,10$, and 9 dams in the $0,20,40,80,160$, and $320 \mathrm{mg} / \mathrm{kg}$ groups, respectively; Appendix $\mathrm{E}^{50}$ ). Other observations included brown discoloration of the nares (1, 2, 8, and 10 dams in the 40, 80, 160 and $320 \mathrm{mg} / \mathrm{kg}$ groups, respectively) and piloerection in all dams administered 160 or $320 \mathrm{mg} / \mathrm{kg}$, which occurred beginning on gestation day (GD) 7 through the end of the dosing period.

Table 3. Maternal Disposition of Rats in the Dose Range-finding Gavage Study of Vinpocetine

\begin{tabular}{lcccccc}
\hline & $\mathbf{0 ~} \mathbf{~} \mathbf{g} / \mathbf{k g}$ & $\mathbf{2 0} \mathbf{~} \mathbf{~ g} / \mathbf{k g}$ & $\mathbf{4 0} \mathbf{~} \mathbf{~ g} / \mathbf{k g}$ & $\mathbf{8 0} \mathbf{~} \mathbf{g} / \mathbf{k g}$ & $\mathbf{1 6 0} \mathbf{~} \mathbf{~ g} \mathbf{k g}$ & $\mathbf{3 2 0} \mathbf{~} \mathbf{~ g} \mathbf{k g}$ \\
\hline Time-mated females & 10 & 10 & 10 & 10 & 10 & 10 \\
Pregnant (on GD 21) & 8 & 10 & 8 & 10 & 10 & 9 \\
Nonpregnant (on GD 21) & 2 & 0 & 2 & 0 & 0 & 1 \\
\hline
\end{tabular}

GD = gestation day.

\section{Body Weights and Feed Consumption}

Dose-related decreases in mean maternal body weights and mean body weight gains were observed in groups administered $40 \mathrm{mg} / \mathrm{kg}$ or greater, relative to those of the vehicle controls, from GD 6 to GD 21 (Figure 4, Table 4. Maternal body weights were 28\%, 31\%, and 35\% lower than those of vehicle controls in the 80,160 , and $320 \mathrm{mg} / \mathrm{kg}$ groups, respectively. When adjusted for gravid uterine weight (at necropsy), maternal body weights were $4.5 \%, 11 \%$, and $14 \%$ lower than those of vehicle controls in the 80,160 , and $320 \mathrm{mg} / \mathrm{kg}$ groups, respectively and were associated with the embryo-fetal loss also observed in these groups. Daily mean body weights for dams in each dose group are available in Appendix E. ${ }^{50}$

Concomitant treatment-related, dose-dependent decreases in maternal feed consumption were observed with doses of $40 \mathrm{mg} / \mathrm{kg}$ or greater from GD 6 to GD 21 (Table 5) and were 8\%, 19\%, $28 \%$, and $38 \%$ lower than that of the vehicle controls in the 40, 80, 160, and $320 \mathrm{mg} / \mathrm{kg}$ groups, respectively. 


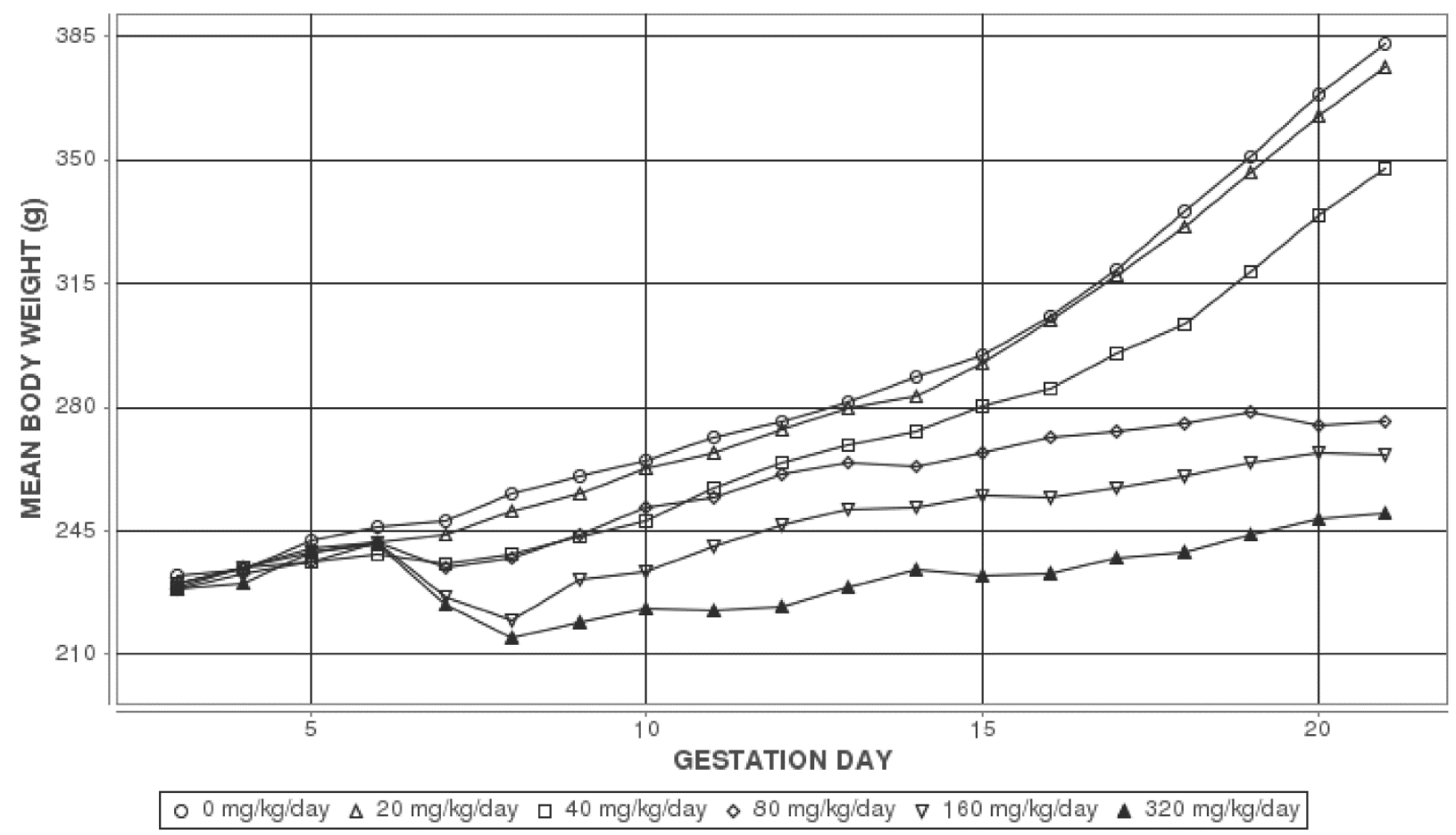

Figure 4. Maternal Growth Curves for Pregnant Rats Administered Vinpocetine by Gavage in the Dose Range-finding Study

Information for statistical significance in maternal weights is provided in Table 4 and Appendix E. ${ }^{50}$

Table 4. Summary of Maternal Body Weight Gains of Rats in the Dose Range-finding Gavage Study of Vinpocetine ${ }^{a}$

\begin{tabular}{|c|c|c|c|c|c|c|}
\hline $\begin{array}{c}\text { Gestation } \\
\text { Day Interval }\end{array}$ & $0 \mathrm{mg} / \mathrm{kg}$ & $20 \mathrm{mg} / \mathrm{kg}$ & $40 \mathrm{mg} / \mathrm{kg}$ & $80 \mathrm{mg} / \mathrm{kg}$ & $160 \mathrm{mg} / \mathrm{kg}$ & $320 \mathrm{mg} / \mathrm{kg}$ \\
\hline $6-21$ & $137.1 \pm 5.3^{* *}(8)$ & $134.5 \pm 8.5(10)$ & $109.1 \pm 14.3^{*}(8)$ & $34.3 \pm 3.1^{* *}(10)$ & $24.8 \pm 4.3^{* *}(10)$ & $9.3 \pm 2.4^{* *}(9)$ \\
\hline $3-6$ & $13.9 \pm 3.4(8)$ & $11.9 \pm 0.8(10)$ & $9.3 \pm 1.9(8)$ & $13.6 \pm 2.3(10)$ & $11.6 \pm 1.7(10)$ & $12.2 \pm 1.7(9)$ \\
\hline $6-9$ & $14.6 \pm 1.5^{* *}(8)$ & $13.8 \pm 1.6(10)$ & $5.2 \pm 4.8^{*}(8)$ & $2.1 \pm 2.2^{* *}(10)$ & $-10.2 \pm 2.2^{* *}(10)$ & $-21.6 \pm 3.0^{* *}(9)$ \\
\hline $9-12$ & $15.0 \pm 1.2^{*}(8)$ & $18.0 \pm 1.0(10)$ & $20.6 \pm 3.6(8)$ & $16.9 \pm 2.3(10)$ & $15.3 \pm 1.9(10)$ & $4.4 \pm 2.6^{* *}(9)$ \\
\hline $12-15$ & $19.0 \pm 1.9 * *(8)$ & $18.8 \pm 1.8(10)$ & $16.1 \pm 2.6(8)$ & $6.2 \pm 1.5^{* *}(10)$ & $8.0 \pm 2.7^{* *}(10)$ & $8.3 \pm 2.0^{* *}(9)$ \\
\hline $15-18$ & $41.1 \pm 1.4^{* *}(8)$ & $38.7 \pm 2.8(10)$ & $23.4 \pm 6.7^{* *}(8)$ & $8.5 \pm 1.3^{* *}(10)$ & $5.6 \pm 1.3^{* *}(10)$ & $7.2 \pm 2.2^{* *}(9)$ \\
\hline $18-21$ & $47.4 \pm 2.2 * *(8)$ & $45.2 \pm 3.4(10)$ & $43.8 \pm 6.7$ (8) & $0.6 \pm 2.3^{* *}(10)$ & $6.0 \pm 2.7 * *(10)$ & $11.0 \pm 2.8^{* *}(9)$ \\
\hline
\end{tabular}

*Statistically significant ( $\leq 0.05$ ) trend (by the Jonckheere test) or by pairwise comparison (Williams or Dunnett test). A significant trend test is indicated in the vehicle control column. A significant pairwise comparison with the vehicle control group is indicated in the dose group column.

$* * \mathrm{p} \leq 0.01$.

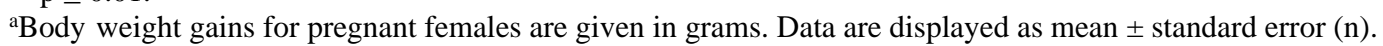


Table 5. Summary of Maternal Feed Consumption of Rats in the Dose Range-finding Gavage Study of Vinpocetine ${ }^{\mathrm{a}}$

\begin{tabular}{ccccccc}
\hline $\begin{array}{c}\text { Gestation } \\
\text { Day Interval }\end{array}$ & $\mathbf{0 ~} \mathbf{~ m g} / \mathbf{k g}$ & $\mathbf{2 0 ~} \mathbf{~ m g} / \mathbf{k g}$ & $\mathbf{4 0 ~} \mathbf{~ m g} / \mathbf{k g}$ & $\mathbf{8 0 ~} \mathbf{~ m g} / \mathbf{k g}$ & $\mathbf{1 6 0} \mathbf{~ m g} / \mathbf{k g}$ & $\mathbf{3 2 0} \mathbf{~ m g} / \mathbf{k g}$ \\
\hline $6-21$ & $21.2 \pm 0.4^{* *}(8)$ & $21.2 \pm 0.6(10)$ & $19.5 \pm 0.8(8)$ & $17.1 \pm 0.4^{* *}(10)$ & $15.2 \pm 0.5^{* *}(10)$ & $13.0 \pm 0.4^{* *}(9)$ \\
$3-6$ & $18.9 \pm 0.8(8)$ & $19.0 \pm 0.5(10)$ & $18.5 \pm 0.8(8)$ & $18.8 \pm 0.8(10)$ & $18.7 \pm 0.4(10)$ & $18.9 \pm 0.7(9)$ \\
$6-9$ & $18.4 \pm 0.7^{* *}(8)$ & $17.3 \pm 0.6(10)$ & $14.0 \pm 1.0^{* *}(8)$ & $11.5 \pm 0.3^{* *}(10)$ & $6.8 \pm 0.5^{* *}(10)$ & $5.3 \pm 0.7^{* *}(9)$ \\
$9-12$ & $20.8 \pm 0.5^{* *}(8)$ & $20.4 \pm 0.5(10)$ & $18.8 \pm 0.9(8)$ & $18.1 \pm 0.5^{* *}(10)$ & $15.7 \pm 0.5^{* *}(10)$ & $11.7 \pm 0.9^{* *}(9)$ \\
$12-15$ & $21.2 \pm 0.5^{* *}(8)$ & $21.6 \pm 0.6(10)$ & $21.5 \pm 1.0(8)$ & $19.8 \pm 0.4(10)$ & $18.7 \pm 0.8^{*}(10)$ & $16.3 \pm 0.6^{* *}(9)$ \\
$15-18$ & $22.5 \pm 0.4^{* *}(8)$ & $23.8 \pm 0.9(10)$ & $21.0 \pm 1.7(8)$ & $19.7 \pm 0.7(10)$ & $18.4 \pm 0.8^{* *}(10)$ & $16.1 \pm 0.7^{* *}(9)$ \\
$18-21$ & $22.8 \pm 0.5^{* *}(8)$ & $22.8 \pm 0.8(10)$ & $22.4 \pm 1.5(8)$ & $16.7 \pm 0.7^{* *}(10)$ & $16.3 \pm 0.6^{* *}(10)$ & $15.6 \pm 0.4^{* *}(9)$ \\
\hline
\end{tabular}

*Statistically significant ( $\leq 0.05)$ trend (by the Jonckheere test) or pairwise comparison (by the Shirley or Dunn test). A

significant trend test is indicated in the vehicle control column. A significant pairwise comparison with the vehicle control group is indicated in the dose group column.

$* * \mathrm{p} \leq 0.01$.

${ }^{a}$ Feed consumption for pregnant females is given in grams/day. Data are displayed as mean \pm standard error. Number of dams with feed consumption measured is given in parentheses.

\section{Maternal and Litter Observations}

At necropsy, no gross observations related to vinpocetine administration were observed.

There was an exposure-related effect on percent postimplantation loss as a result of increased early resorptions across all groups (Table 6). Although not statistically significant at 20 and $40 \mathrm{mg} / \mathrm{kg}$, these values were greater than those of the vehicle controls. At doses of $80 \mathrm{mg} / \mathrm{kg}$ and above, dams exhibited total resorption of their litters, except for one dam in the $160 \mathrm{mg} / \mathrm{kg}$ group. Because of the increased postimplantation loss, the number of live fetuses per litter decreased in the $40 \mathrm{mg} / \mathrm{kg}$ group in comparison to the vehicle controls, and there were no live fetuses at doses of $80 \mathrm{mg} / \mathrm{kg}$ and above with the exception of the one litter in the $160 \mathrm{mg} / \mathrm{kg}$ group that contained 12 live fetuses. These findings were associated with reductions in mean gravid uterine weights $(13.7 \%$, 26.0\%, 97.6\%, 88.8\%, and $96.8 \%$ less than the vehicle control group at 20,40, 80, 160, and $320 \mathrm{mg} / \mathrm{kg}$, respectively).

No exposure-related effects were observed on fetal weight or fetal sex ratio in the 20 or $40 \mathrm{mg} / \mathrm{kg}$ groups; fetal weight and sex ratio could not be evaluated at 80,160 , or $320 \mathrm{mg} / \mathrm{kg}$ due to the presence of only one litter among these groups (Table 6). 
Table 6. Summary of Uterine Content Data for Rats in the Dose Range-finding Gavage Study of Vinpocetine

\begin{tabular}{|c|c|c|c|c|c|c|}
\hline & $0 \mathrm{mg} / \mathrm{kg}$ & $20 \mathrm{mg} / \mathrm{kg}$ & $40 \mathrm{mg} / \mathrm{kg}$ & $80 \mathrm{mg} / \mathrm{kg}$ & $160 \mathrm{mg} / \mathrm{kg}$ & $320 \mathrm{mg} / \mathrm{kg}$ \\
\hline \multicolumn{7}{|l|}{ Pregnancy Summary } \\
\hline Mated females & 10 & 10 & 10 & 10 & 10 & 10 \\
\hline Pregnant females & 8 & 10 & 8 & 10 & 10 & 9 \\
\hline Pregnant females examined on GD $21^{\mathrm{a}}$ & 8 & 10 & 8 & 10 & 10 & 9 \\
\hline Corpora lutea per female ${ }^{b}$ & $15.63 \pm 0.50(8)$ & $16.20 \pm 0.49(10)$ & $17.25 \pm 1.08(8)$ & $16.50 \pm 0.70(10)$ & $17.00 \pm 0.54(10)$ & $15.44 \pm 0.50(9)$ \\
\hline Implantations $^{\mathrm{b}}$ per female & $14.38 \pm 0.42(8)$ & $14.10 \pm 0.74(10)$ & $14.00 \pm 0.65(8)$ & $13.40 \pm 1.1(10)$ & $14.50 \pm 0.76(10)$ & $14.56 \pm 0.73(9)$ \\
\hline Percent postimplantation loss ${ }^{\mathrm{b}}$ & $5.30 \pm 1.78^{* *}(8)$ & $18.41 \pm 11.70(10)$ & $27.55 \pm 12.35(8)$ & $100.00 \pm 0.00 * *(10)$ & $90.77 \pm 9.23 * *(10)$ & $100.00 \pm 0.00 * *(9)$ \\
\hline Total resorptions per litter ${ }^{\mathrm{b}}$ & $0.75 \pm 0.25^{* *}(8)$ & $2.60 \pm 1.65(10)$ & $3.88 \pm 1.79(8)$ & $13.40 \pm 1.19 * *(10)$ & $13.30 \pm 1.56^{* *}(10)$ & $14.56 \pm 0.73^{* *}(9)$ \\
\hline Early resorptions per litter ${ }^{\mathrm{b}}$ & $0.75 \pm 0.25^{* *}(8)$ & $2.60 \pm 1.65(10)$ & $3.88 \pm 1.79(8)$ & $13.40 \pm 1.19 * *(10)$ & $13.30 \pm 1.56^{* *}(10)$ & $14.56 \pm 0.73 * *(9)$ \\
\hline Late resorptions per litter ${ }^{\mathrm{b}}$ & $0.00 \pm 0.00(8)$ & $0.00 \pm 0.00(10)$ & $0.00 \pm 0.00(8)$ & $0.00 \pm 0.00(10)$ & $0.00 \pm 0.00(10)$ & $0.00 \pm 0.00(9)$ \\
\hline Dead fetuses per litter ${ }^{\mathrm{b}}$ & $0.00 \pm 0.00(8)$ & $0.00 \pm 0.00(10)$ & $0.00 \pm 0.00(8)$ & $0.00 \pm 0.00(10)$ & $0.00 \pm 0.00(10)$ & $0.00 \pm 0.00(9)$ \\
\hline Number of early resorptions ${ }^{c}$ & 6 & 26 & 31 & 134 & 133 & 131 \\
\hline Number of late resorptions & 0 & 0 & 0 & 0 & 0 & 0 \\
\hline Number of whole litter resorptions ${ }^{a}$ & $0 * *$ & 1 & 1 & $10 * *$ & $9 * *$ & $9 * *$ \\
\hline Number of dead fetuses & 0 & 0 & 0 & 0 & 0 & 0 \\
\hline \multicolumn{7}{|l|}{ Live Fetuses $^{\mathrm{b}}$} \\
\hline Number of live fetuses & 109 & 115 & 81 & 0 & 12 & 0 \\
\hline Live fetuses per litter & $13.63 \pm 0.53 * *(8)$ & $11.50 \pm 1.78(10)$ & $10.13 \pm 1.85(8)$ & $0.00 \pm 0.00 * *(10)$ & $1.20 \pm 1.20^{* *}(10)$ & $0.00 \pm 0.00 * *$ \\
\hline Live male fetuses per litter & $5.88 \pm 0.55^{* *}(8)$ & $5.70 \pm 0.96(10)$ & $6.13 \pm 1.08(8)$ & $0.00 \pm 0.00^{* *}(10)$ & $0.40 \pm 0.40^{* *}(10)$ & $0.00 \pm 0.00 * *$ \\
\hline Live female fetuses per litter & $7.75 \pm 0.73^{* *}(8)$ & $5.80 \pm 1.04(10)$ & $4.00 \pm 1.16^{*}(8)$ & $0.00 \pm 0.00 * *(10)$ & $0.80 \pm 0.80 * *(10)$ & $0.00 \pm 0.00^{* *}(9)$ \\
\hline Percent live male fetuses per litter & $43.35 \pm 4.01(8)$ & $48.83 \pm 4.82(9)$ & $64.60 \pm 7.92(7)$ & & $33.33(1)$ & \\
\hline \multicolumn{7}{|l|}{ Fetal Weight $(\mathrm{g})^{\mathrm{c}}$} \\
\hline Fetal body weight per litter & $5.18 \pm 0.07(8)$ & $5.26 \pm 0.16(9)$ & $5.06 \pm 0.16(7)$ & $--^{\mathrm{d}}$ & $4.98(1)$ & $-^{\mathrm{d}}$ \\
\hline Male fetal weight per litter & $5.33 \pm 0.07(8)$ & $5.41 \pm 0.16(9)$ & $5.16 \pm 0.16(7)$ & & $5.06(1)$ & \\
\hline Female fetal weight per litter & $5.06 \pm 0.07(8)$ & $5.11 \pm 0.14(9)$ & $4.92 \pm 0.19(6)$ & & $4.95(1)$ & \\
\hline
\end{tabular}




\section{Vinpocetine, NTP DART 03}

\begin{tabular}{|c|c|c|c|c|c|c|}
\hline & $0 \mathrm{mg} / \mathrm{kg}$ & $20 \mathrm{mg} / \mathrm{kg}$ & $40 \mathrm{mg} / \mathrm{kg}$ & $80 \mathrm{mg} / \mathrm{kg}$ & $160 \mathrm{mg} / \mathrm{kg}$ & $320 \mathrm{mg} / \mathrm{kg}$ \\
\hline \multicolumn{7}{|c|}{ Gravid Uterine Weight (g) ${ }^{\mathrm{e}}$} \\
\hline Gravid uterine weight & $96.41 \pm 3.22 * *(8)$ & $83.23 \pm 11.81(10)$ & $71.35 \pm 12.39 *(8)$ & $2.35 \pm 0.20^{* *}(10)$ & $10.78 \pm 8.21^{* *}(10)$ & $3.09 \pm 0.56^{* *}(9)$ \\
\hline Terminal body weight & $383.2 \pm 4.7 * *(8)$ & $376.2 \pm 10.7(10)$ & $347.5 \pm 13.9 * *(8)$ & $276.1 \pm 3.4^{* *}(10)$ & $266.3 \pm 5.4^{* *}(10)$ & $250.2 \pm 5.3 * *(9)$ \\
\hline Adjusted body weight & $286.83 \pm 3.30 * *(8)$ & $292.96 \pm 8.77(10)$ & $276.18 \pm 4.45(8)$ & $273.76 \pm 3.31(10)$ & $255.53 \pm 10.69 * *(10)$ & $247.10 \pm 5.39 * *(9)$ \\
\hline
\end{tabular}

Values are reported per litter as mean \pm standard error (n) and do not include nonpregnant animals or those that did not survive to the end of the study.

GD = gestation day.

*Statistically significant $(\mathrm{p} \leq 0.05)$ trend (denoted in vehicle control column) or pairwise comparison (denoted in dose group column).

${ }^{* *} \mathrm{p} \leq 0.01$.

a Statistical analysis performed by the Cochran-Armitage (trend) and Fisher exact (pairwise) tests.

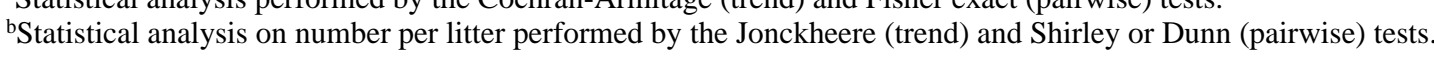

cStatistical analysis performed using a mixed-effects linear model with litter as a random effect.

${ }^{\mathrm{d}}$ No live fetuses in dose group.

eStatistical analysis performed by the Jonckheere (trend) and Williams or Dunnett (pairwise) tests; adjusted body weight = terminal body weight minus gravid uterine weight. 


\section{Fetal Findings}

\section{External}

No external malformations or variations were attributed to vinpocetine exposure at 20, 40, 80, 160 , or $320 \mathrm{mg} / \mathrm{kg}$ per day (Appendix $\mathrm{E}^{50}$ ). External findings in exposed fetuses were limited to a singular occurrence of subcutaneous hemorrhage in the $20 \mathrm{mg} / \mathrm{kg}$ group, which was therefore considered to be unrelated to vinpocetine exposure.

\section{Dose Selection Rationale for the Prenatal Development Toxicity Study in Rats}

In the dose range-finding study, embryo-fetal loss occurred at all doses (20, 40, 80, 160, and $320 \mathrm{mg} / \mathrm{kg}$ per day), with a significant increase in the number of fetal resorptions compared to the control group observed between 40 and $80 \mathrm{mg} / \mathrm{kg}$ per day (28\% and 100\% postimplantation loss, respectively). In accordance with these findings, $60 \mathrm{mg} / \mathrm{kg}$ per day was chosen as the highest dose for the prenatal developmental toxicity study. To provide adequate dose spacing for evaluation of potential dose-response relationships and ideally to capture the no-observed-effect level (NOEL), approximately half log-dose intervals were used. The doses selected for the prenatal developmental toxicity study were $0,5,20$, and $60 \mathrm{mg} / \mathrm{kg}$ per day.

\section{Prenatal Developmental Toxicity Study in Rats}

\section{Maternal Findings}

\section{Viability and Clinical Observations}

No animals were removed from the study prior to scheduled necropsy (Table 7). There were test article-related clinical observations at $\geq 20 \mathrm{mg} / \mathrm{kg}$, which were limited to a dose-related increase in the incidence of red or brown vaginal discharge $(6,4,13$, and 17 dams in the $0,5,20$, and $60 \mathrm{mg} / \mathrm{kg}$ groups, respectively; Appendix $\mathrm{E}^{50}$ ). Observations of abnormal vaginal discharge generally began on GD 13 and continued until GD 19. There were no treatment-related clinical observations in the $5 \mathrm{mg} / \mathrm{kg}$ animals.

Table 7. Maternal Disposition of Rats in the Prenatal Developmental Toxicity Gavage Study of Vinpocetine

\begin{tabular}{lcccc}
\hline & $\mathbf{0 ~} \mathbf{~ m g} / \mathbf{k g}$ & $\mathbf{5 ~} \mathbf{~ g} / \mathbf{k g}$ & $\mathbf{2 0} \mathbf{~ m g} / \mathbf{k g}$ & $\mathbf{6 0} \mathbf{~ m g} / \mathbf{k g}$ \\
\hline Time-mated Females & 25 & 25 & 25 & 25 \\
Pregnant (on GD 21) & 21 & 20 & 22 & 20 \\
Nonpregnant (on GD 21) & 4 & 5 & 3 & 5 \\
\hline
\end{tabular}

$\mathrm{GD}=$ gestation day.

\section{Body Weights and Feed Consumption}

Significant decreases in mean maternal body weights and mean body weight gains during gestation occurred in the $60 \mathrm{mg} / \mathrm{kg}$ group (Figure 5; Table 8). Relative to the vehicle controls, administration of $60 \mathrm{mg} / \mathrm{kg}$ vinpocetine resulted in a $23 \%$ reduction in maternal body weight on GD 21 and a 61\% reduction in maternal body weight gain from GD 6 to GD 21. The decrease in maternal weight was associated with lower gravid uterine weight. Mean adjusted body weight at 
necropsy (total minus gravid uterine weight) was not significantly affected with vinpocetine administration. The maternal body weight decreases in the $60 \mathrm{mg} / \mathrm{kg}$ group were associated with 83\% postimplantation loss (compared to 3\% in the vehicle control group), which included total litter resorptions in 12 dams and resulted in fewer live fetuses. There were no significant maternal body weight changes in the 5 or $20 \mathrm{mg} / \mathrm{kg}$ groups. Daily mean body weights for dams in each dose group are available in Appendix E. ${ }^{50}$

Treatment-related effects on feed consumption were limited to the $60 \mathrm{mg} / \mathrm{kg} /$ day group and consisted of a slight decrease in overall feed consumption from GD 6 to GD 21 in this dose group (9.5\% lower than the vehicle control group; Table 9). Feed consumption in the 5 and $20 \mathrm{mg} / \mathrm{kg} /$ day dose groups was similar to that of the vehicle control group.

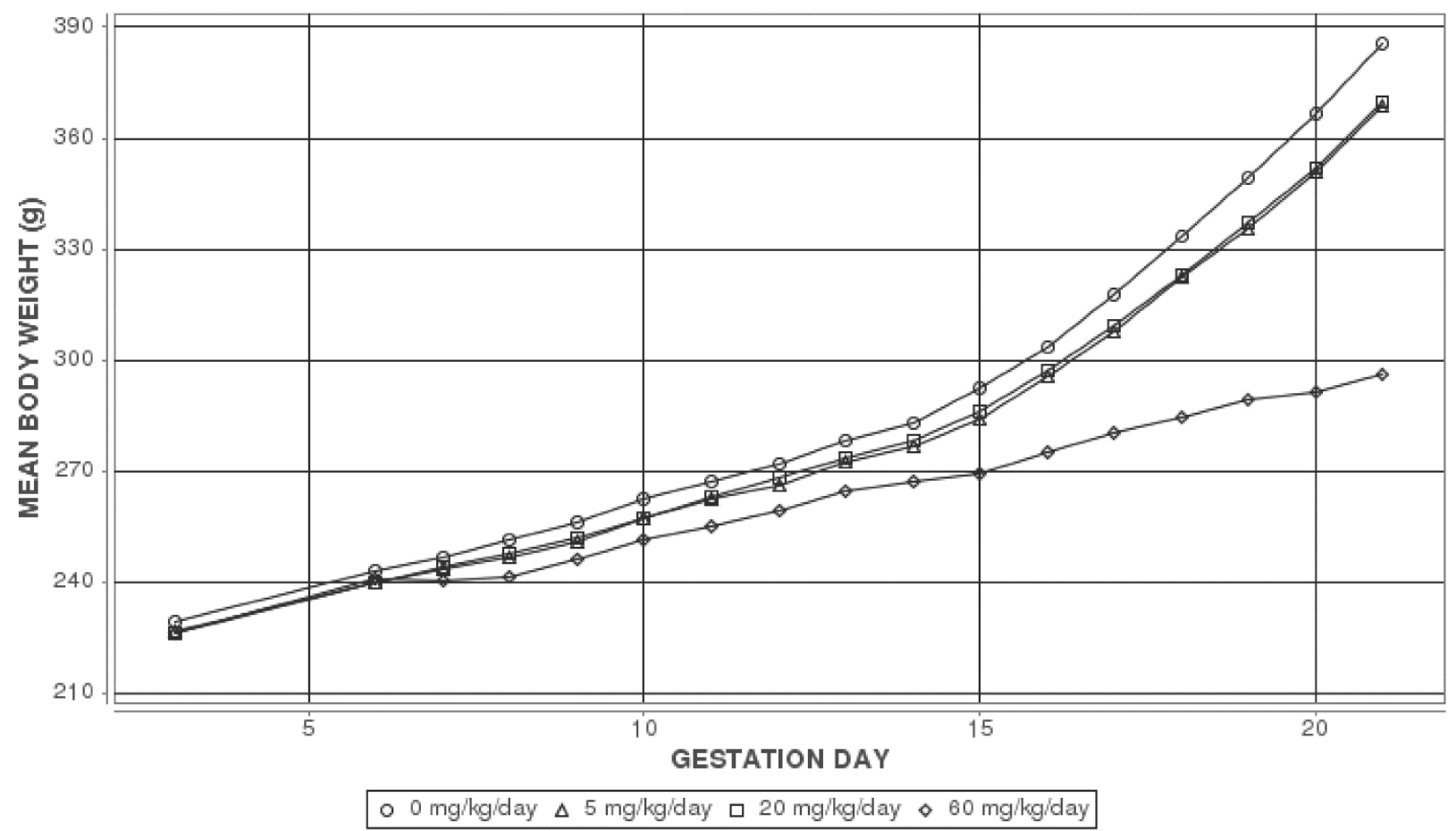

Figure 5. Maternal Growth Curves for Pregnant Rats Administered Vinpocetine by Gavage in the Prenatal Developmental Toxicity Study

Information for statistical significance in maternal weights is provided in Table 8 and Appendix E. ${ }^{50}$ 
Table 8. Summary of Maternal Body Weight Gains of Rats in the Prenatal Developmental Toxicity Gavage Study of Vinpocetine ${ }^{a}$

\begin{tabular}{|c|c|c|c|c|}
\hline $\begin{array}{l}\text { Gestation Day } \\
\text { Interval }\end{array}$ & $0 \mathrm{mg} / \mathrm{kg}$ & $5 \mathrm{mg} / \mathrm{kg}$ & $20 \mathrm{mg} / \mathrm{kg}$ & $60 \mathrm{mg} / \mathrm{kg}$ \\
\hline $6-21$ & $142.8 \pm 3.4^{* *}(21)^{\mathrm{b}}$ & $128.7 \pm 7.4(20)$ & $130.0 \pm 5.1(22)$ & $55.3 \pm 7.9 * *(20)$ \\
\hline $3-6$ & $13.7 \pm 1.0(21)$ & $13.1 \pm 1.0(20)$ & $13.5 \pm 1.2(22)$ & $14.5 \pm 2.0(20)$ \\
\hline $6-9$ & $13.2 \pm 0.7^{* *}(21)$ & $11.3 \pm 0.8(20)$ & $12.2 \pm 0.9(22)$ & $5.2 \pm 1.0^{* *}(20)$ \\
\hline $9-12$ & $16.0 \pm 0.6(21)$ & $15.4 \pm 0.9(20)$ & $16.0 \pm 0.8(22)$ & $13.4 \pm 1.2(20)$ \\
\hline $12-15$ & $20.7 \pm 0.8^{* *}(21)$ & $17.7 \pm 1.3(20)$ & $17.8 \pm 0.8(22)$ & $9.9 \pm 1.7^{* *}(20)$ \\
\hline $15-18$ & $40.8 \pm 1.4^{* *}(21)$ & $38.1 \pm 2.4(20)$ & $37.0 \pm 2.0(22)$ & $15.4 \pm 2.5^{* *}(20)$ \\
\hline $18-21$ & $52.2 \pm 1.7^{* *}(21)$ & $46.2 \pm 3.3(20)$ & $47.0 \pm 2.4(22)$ & $11.5 \pm 4.5^{* *}(20)$ \\
\hline
\end{tabular}

**Statistically significant ( $\leq 0.01$ ) trend (by the Jonckheere test) or pairwise comparison (by the Williams or Dunnett test). A significant trend test is indicated in the vehicle control column. A significant pairwise comparison with the vehicle control group is indicated in the dose group column.

aBody weight gains for pregnant females are given in grams. Data are displayed as mean \pm standard error.

${ }^{b}$ Number of dams weighed is given in parentheses.

Table 9. Summary of Maternal Feed Consumption of Rats in the Prenatal Developmental Toxicity Gavage Study of Vinpocetine ${ }^{a}$

\begin{tabular}{|c|c|c|c|c|}
\hline $\begin{array}{c}\text { Gestation Day } \\
\text { Interval }\end{array}$ & $0 \mathrm{mg} / \mathrm{kg}$ & $5 \mathrm{mg} / \mathrm{kg}$ & $20 \mathrm{mg} / \mathrm{kg}$ & $60 \mathrm{mg} / \mathrm{kg}$ \\
\hline $6-21$ & $22.0 \pm 0.3^{* *}(21)$ & $21.6 \pm 0.4(20)$ & $22.2 \pm 0.3(22)$ & $19.9 \pm 0.4^{* *}(20)$ \\
\hline $3-6$ & $19.6 \pm 0.6(16)$ & $19.5 \pm 0.4(17)$ & $19.8 \pm 0.4(18)$ & $20.4 \pm 0.6(16)$ \\
\hline $6-9$ & $20.0 \pm 0.4 * *(21)$ & $19.6 \pm 0.3(20)$ & $19.3 \pm 0.3(22)$ & $17.2 \pm 0.4^{* *}(20)$ \\
\hline $9-12$ & $20.7 \pm 0.3^{*}(21)$ & $20.1 \pm 0.4(20)$ & $20.9 \pm 0.3(22)$ & $18.8 \pm 0.5^{* *}(20)$ \\
\hline $12-15$ & $21.2 \pm 0.3(21)$ & $21.0 \pm 0.5(20)$ & $21.5 \pm 0.4(22)$ & $21.5 \pm 0.6(20)$ \\
\hline $15-18$ & $23.5 \pm 0.3(21)$ & $23.3 \pm 0.5(20)$ & $24.7 \pm 0.4(22)$ & $21.7 \pm 0.5^{*}(20)$ \\
\hline $18-21$ & $24.4 \pm 0.4^{* *}(21)$ & $24.1 \pm 0.6(20)$ & $24.7 \pm 0.4(22)$ & $20.2 \pm 0.7^{* *}(20)$ \\
\hline
\end{tabular}

*Statistically significant ( $\leq 0.05$ ) trend (by the Jonckheere test) or pairwise comparison (by the Shirley or Dunn test). A significant trend test is indicated in the vehicle control column. A significant pairwise comparison with the vehicle control group is indicated in the dose group column.

$* * \mathrm{p} \leq 0.01$.

${ }^{a}$ Feed consumption for pregnant females is given in grams/day. Data are displayed as mean \pm standard error. Number of dams with feed consumption measured is given in parentheses.

\section{Maternal and Litter Observations}

There were no notable maternal necropsy findings. The number of pregnant females and the mean numbers of corpora lutea and implantation sites were similar across groups.

There was a significant effect on percent postimplantation loss in the $60 \mathrm{mg} / \mathrm{kg}$ group (83.1\% compared to $3.3 \%$ in the vehicle control group) as a result of resorption of entire litters in 12 of the dams and increased incidences of resorptions in 7 of the dams (Table 10). Because of the increased postimplantation loss, there was a decrease in the number of live fetuses per litter in the $60 \mathrm{mg} / \mathrm{kg}$ group (2.6 compared to 14.0 in vehicle controls), which was associated with an $80 \%$ decrease in gravid uterine weight in this group. Mean percent postimplantation loss for the 5 and $20 \mathrm{mg} / \mathrm{kg}$ groups ( $10.7 \%$ and $11.1 \%$, respectively) was higher than in the concurrent vehicle control group (3.3\%) and higher than NTP historical control values (2.9\% to $8.0 \%)$. The higher percent loss in the 5 and $20 \mathrm{mg} / \mathrm{kg}$ groups resulted from one dam in each exposure group with whole litter resorptions. 
There was a smaller number of litters at $60 \mathrm{mg} / \mathrm{kg}$. Although no exposure-related effects on male fetal body weights were noted, female fetal body weights averaged slightly less (8\%) than for the vehicle control group (Table 10). The fetal sex ratio was statistically higher in the $60 \mathrm{mg} / \mathrm{kg}$ group ( $82 \%$ male) than in the vehicle control group ( $46 \%$ male); however, with the small number of viable litters and fetuses available for assessment, the finding was considered spurious.

Table 10. Summary of Uterine Content Data for Rats in the Prenatal Developmental Toxicity Gavage Study of Vinpocetine

\begin{tabular}{|c|c|c|c|c|}
\hline & $0 \mathrm{mg} / \mathrm{kg}$ & $5 \mathrm{mg} / \mathrm{kg}$ & $20 \mathrm{mg} / \mathrm{kg}$ & $60 \mathrm{mg} / \mathrm{kg}$ \\
\hline \multicolumn{5}{|l|}{ Pregnancy Summary } \\
\hline Mated females & 25 & 25 & 25 & 25 \\
\hline Pregnant females & 21 & 20 & 22 & 20 \\
\hline Pregnant females examined on GD $21^{\mathrm{a}}$ & 21 & 20 & 22 & 20 \\
\hline Corpora lutea per female ${ }^{\mathrm{b}}$ & $15.86 \pm 0.58(21)$ & $16.00 \pm 0.70(20)$ & $15.41 \pm 0.42(22)$ & $16.70 \pm 0.44(20)$ \\
\hline Implantations per female & $14.38 \pm 0.49(21)$ & $12.55 \pm 0.92(20)$ & $12.82 \pm 0.85(22)$ & $12.95 \pm 1.04(20)$ \\
\hline Percent postimplantation loss ${ }^{\mathrm{b}}$ & $3.29 \pm 1.33^{* *}(21)$ & $10.67 \pm 5.29(20)$ & $11.13 \pm 4.65(22)$ & $83.13 \pm 6.47 * *(20)$ \\
\hline Total resorptions per litter ${ }^{\mathrm{b}}$ & $0.38 \pm 0.15^{* *}(21)$ & $0.60 \pm 0.21(20)$ & $0.95 \pm 0.27(22)$ & $10.40 \pm 1.21^{* *}(20)$ \\
\hline Early resorptions per litter ${ }^{\mathrm{b}}$ & $0.33 \pm 0.14^{* *}(21)$ & $0.60 \pm 0.21(20)$ & $0.86 \pm 0.27(22)$ & $10.40 \pm 1.21^{* *}(20)$ \\
\hline Late resorptions per litter ${ }^{\mathrm{b}}$ & $0.05 \pm 0.05$ & $0.00 \pm 0.00(20)$ & $0.09 \pm 0.06(22)$ & $0.00 \pm 0.00(20)$ \\
\hline Dead fetuses per litter ${ }^{\mathrm{b}}$ & $0.05 \pm 0.05(21)$ & $0.00 \pm 0.00(20)$ & $0.00 \pm 0.00(22)$ & $0.00 \pm 0.00(20)$ \\
\hline Number of Early Resorptions ${ }^{c}$ & 7 & 12 & 19 & 208 \\
\hline Number of late resorptions ${ }^{\mathrm{c}}$ & 1 & 0 & 2 & 0 \\
\hline Number of whole litter resorptions ${ }^{\mathrm{a}}$ & $0 * *$ & 1 & 1 & $12 * *$ \\
\hline Number of dead fetuses ${ }^{c}$ & 1 & 0 & 0 & 0 \\
\hline \multicolumn{5}{|l|}{ Live Fetuses $^{\mathrm{b}}$} \\
\hline Number of live fetuses & 293 & 239 & 261 & 51 \\
\hline Live fetuses per litter & $13.95 \pm 0.55 * *(21)$ & $11.95 \pm 1.06(20)$ & $11.86 \pm 0.88(22)$ & $2.55 \pm 1.00 * *(20)$ \\
\hline Live male fetuses per litter & $6.38 \pm 0.42^{* *}(21)$ & $4.95 \pm 0.62(20)$ & $5.50 \pm 0.59(22)$ & $1.80 \pm 0.69 * *(20)$ \\
\hline Live female fetuses per litter & $7.57 \pm 0.57^{* *}(21)$ & $7.00 \pm 0.74(20)$ & $6.36 \pm 0.60(22)$ & $0.75 \pm 0.42 * *(20)$ \\
\hline Percent live male fetuses per litter & $46.47 \pm 2.99(21)$ & $41.63 \pm 3.55(19)$ & $45.74 \pm 3.44(21)$ & $82.19 \pm 8.29 *(8)$ \\
\hline \multicolumn{5}{|l|}{ Fetal Weight $(g)^{d}$} \\
\hline Fetal weight per litter & $5.15 \pm 0.07(21)$ & $5.29 \pm 0.16(19)$ & $5.21 \pm 0.12(21)$ & $5.11 \pm 0.10(8)$ \\
\hline Male fetal weight per litter & $5.28 \pm 0.06(21)$ & $5.49 \pm 0.21(19)$ & $5.35 \pm 0.12(21)$ & $5.18 \pm 0.08(8)$ \\
\hline Female fetal weight per litter & $5.03 \pm 0.07(21)$ & $5.10 \pm 0.10(19)$ & $5.09 \pm 0.12(21)$ & $4.63 \pm 0.06(4)$ \\
\hline \multicolumn{5}{|l|}{ Gravid Uterine Weight (g) ${ }^{\mathrm{e}}$} \\
\hline Gravid uterine weight & $97.79 \pm 3.11^{* *}(21)$ & $83.89 \pm 6.59(20)$ & $85.07 \pm 5.28(22)$ & $19.52 \pm 6.53^{* *}(20)$ \\
\hline Terminal body weight & $385.7 \pm 4.2^{* *}(21)$ & $368.5 \pm 8.2(20)$ & $370.0 \pm 5.5(22)$ & $296.1 \pm 8.2^{* *}(20)$ \\
\hline Adjusted body weight & $287.89 \pm 2.33^{*}(21)$ & $284.58 \pm 3.60(20)$ & $284.90 \pm 2.20(22)$ & $276.60 \pm 2.79 *(20)$ \\
\hline \multicolumn{5}{|c|}{$\begin{array}{l}\text { Values are reported per litter as mean } \pm \text { standard error }(\mathrm{n}) \text { and do not include nonpregnant animals or those that did not survive to } \\
\text { the end of the study. } \\
\text { *Statistically significant ( } \mathrm{p} \leq 0.05 \text { ) trend (denoted in vehicle control column) or pairwise comparison (denoted in dose group } \\
\text { column). } \\
\text { **p } \leq 0.01 \text {. } \\
\text { GD = gestation day. } \\
\text { aStatistical analysis performed by the Cochran-Armitage (trend) and Fisher exact (pairwise) tests. } \\
\text { bStatistical analysis performed by the Jonckheere (trend) and Shirley or Dunn (pairwise) tests. } \\
\text { cNo statistical analyses were performed on number of early resorptions, number of late resorptions, or number of dead fetuses. } \\
\text { dStatistical analysis performed using a mixed-effects linear model with litter as a random effect (trend and pairwise). } \\
\text { eStatistical analysis performed by the Jonckheere (trend) and the Williams or Dunnett (pairwise) tests; adjusted body } \\
\text { weight = terminal body weight minus gravid uterine weight. }\end{array}$} \\
\hline
\end{tabular}




\section{Fetal Findings}

\section{External}

Fetal external abnormalities were unrelated to vinpocetine exposure and limited to singular occurrences of generalized subcutaneous edema in the 5 and $20 \mathrm{mg} / \mathrm{kg}$ groups, a singular occurrence of omphalocele in the $20 \mathrm{mg} / \mathrm{kg}$ group, and singular occurrence of a bent or short tail in two separate fetuses in the $20 \mathrm{mg} / \mathrm{kg}$ group (Appendix $\mathrm{E}^{50}$ ).

\section{Visceral}

An exposure-related effect was observed in the heart: increased incidences of ventricular septum defects (VSDs), a malformation, occurred in $0 \%, 1.3 \%, 3.1 \%$, and $3.9 \%$ of the fetuses (and $0 \%$, $15.8 \%$, 33.3\%, and $25.0 \%$ of litters) in the $0,5,20$, and $60 \mathrm{mg} / \mathrm{kg}$ groups, respectively (Table 11; Appendix $\mathrm{E}^{50}$ ). The NTP historical control range for VSDs is $0 \%$ to $0.5 \%$ for affected fetuses and litters, respectively. Several other visceral and skeletal abnormalities were noted in two and four fetuses with VSDs in the 5 and $20 \mathrm{mg} / \mathrm{kg}$ groups and in one fetus in the $60 \mathrm{mg} / \mathrm{kg}$ group; however, no other fetal malformations were observed in the remainder of the fetuses with VSDs.

Other malformations in the heart included misshapen aortic valves, large right atrium, and thick left ventricle wall (Table 11); however, those findings were not considered to be exposure related because of the high background incidence (misshapen aortic valves) or occurrence in a single fetus (large right atrium and thick left ventricle wall).

In the major vessels and thoracic viscera, there were singular occurrences of a supernumerary right carotid artery, patent ductus arteriosus, absent lung lobe accessory, fused right cranial lung lobe, thin diaphragm, and a diaphragm hernia and multiple occurrences of absent innominate arteries and short innominate arteries (Appendix $\mathrm{E}^{50}$ ). These findings were considered incidental, and not exposure related, because they are a common background finding (absent or short innominate arteries) ${ }^{79}$ or exhibited no trend with dose. 
Table 11. Summary of Selected Fetal Visceral Findings in Rats in the Prenatal Developmental Toxicity Gavage Study of Vinpocetine

\begin{tabular}{|c|c|c|c|c|}
\hline & 0 mg/kg & $5 \mathrm{mg} / \mathrm{kg}$ & $20 \mathrm{mg} / \mathrm{kg}$ & $60 \mathrm{mg} / \mathrm{kg}$ \\
\hline Number of Fetuses Examined & 293 & 239 & 261 & 51 \\
\hline Number of Litters Examined & 21 & 19 & 21 & 8 \\
\hline \multicolumn{5}{|l|}{ Heart } \\
\hline \multicolumn{5}{|l|}{ Aortic valve, misshapen - [M] } \\
\hline Fetuses & $19(6.48)$ & $14(5.86)$ & $17(6.51)$ & $0(0.0)^{*}$ \\
\hline Litters & $12(57.14)^{* *}$ & $11(57.89)$ & $10(47.62)$ & $0(0.00)^{* *}$ \\
\hline \multicolumn{5}{|l|}{ Atrium, right, large $-[\mathrm{M}]$} \\
\hline Fetuses & $0(0.0)$ & $0(0.0)$ & $1(0.38)$ & $0(0.0)$ \\
\hline Litters & $0(0.00)$ & $0(0.00)$ & $1(4.76)$ & $0(0.00)$ \\
\hline \multicolumn{5}{|c|}{ Ventricle, ventricular septum defect $-[\mathrm{M}]^{\mathrm{a}}$} \\
\hline Fetuses & $0(0.0)^{* *}$ & $3(1.26)$ & $8(3.07)^{* *}$ & $2(3.92)^{*}$ \\
\hline Litters & $0(0.00)$ & $3(15.79)$ & $7(33.33)^{* *}$ & $2(25.00)$ \\
\hline \multicolumn{5}{|l|}{ Ventricle, left, thick wall - [M] } \\
\hline Fetuses & $0(0.0)$ & $0(0.0)$ & $1(0.38)$ & $0(0.0)$ \\
\hline Litters & $0(0.00)$ & $0(0.00)$ & $1(4.76)$ & $0(0.00)$ \\
\hline \multicolumn{5}{|l|}{ Major Vessels } \\
\hline \multicolumn{5}{|c|}{ Carotid artery, right, supernumerary - [M] } \\
\hline Fetuses & $0(0.0)$ & $0(0.0)$ & $0(0.0)$ & $1(1.96)$ \\
\hline Litters & $0(0.00)$ & $0(0.00)$ & $0(0.00)$ & $1(12.50)$ \\
\hline \multicolumn{5}{|l|}{ Ductus arteriosus, patent - [V] } \\
\hline Fetuses & $0(0.0)$ & $0(0.0)$ & $1(0.38)$ & $0(0.0)$ \\
\hline Litters & $0(0.00)$ & $0(0.00)$ & $1(4.76)$ & $0(0.00)$ \\
\hline \multicolumn{5}{|l|}{ Innominate artery, absent - [V] } \\
\hline Fetuses & $4(1.37)$ & $7(2.93)$ & $8(3.07)$ & $1(1.96)$ \\
\hline Litters & $4(19.05)$ & $6(31.58)$ & $5(23.81)$ & $1(12.50)$ \\
\hline \multicolumn{5}{|l|}{ Innominate artery, short - [V] } \\
\hline Fetuses & $3(1.02)$ & 4 (1.67) & $2(0.77)$ & 1 (1.96) \\
\hline Litters & $3(14.29)$ & $4(21.05)$ & $2(9.52)$ & $1(12.50)$ \\
\hline
\end{tabular}

Upper row denotes number of affected fetuses and (\%) and lower row the number of affected litters and (\%).

Statistical analysis for litter data and for fetal data (without the litter effects) performed by the Cochran-Armitage (trend) and Fisher exact (pairwise) tests.

*Statistically significant $(\mathrm{p} \leq 0.05)$ trend (denoted in the vehicle control column) or pairwise comparison (denoted in the dose group column);**(p $\leq 0.01)$. Statistical analysis of fetuses with litter-based adjustments performed by mixed-effects logistic regression models found no statistically significant trend or pairwise comparison.

$[\mathrm{M}]=$ malformation; $[\mathrm{V}]$ = variation .

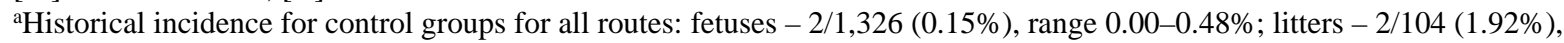
range $0.00-5.26 \%$.

\section{Head}

Malformations observed in vinpocetine-treated groups included a single incidence of hydrocephaly in one fetus in the $5 \mathrm{mg} / \mathrm{kg}$ group (Appendix $\mathrm{E}^{50}$ ). Additionally, a single fetus in 
the $20 \mathrm{mg} / \mathrm{kg}$ group had the variation of dilated ventricles. These findings were incidental and were not considered to be exposure related.

\section{Skeletal}

In the fetal vertebrae, there was a significant trend for increased incidences of incomplete ossification throughout the thoracic centra that was considered exposure related due to dosedependent increases by pairwise comparison in the 20 and $60 \mathrm{mg} / \mathrm{kg}$ groups (Table 12; Appendix $\mathrm{E}^{50}$ ). The incidence of this variation at $60 \mathrm{mg} / \mathrm{kg}(17 \%)$ exceeded the historical control range $(0 \%$ to $0.82 \%)$. Additional exposure-related findings included supernumerary ribs that occurred in a dose-dependent manner and that were present in multiple litters per group. Significant trends of increasing incidence with increasing dose were noted for full (malformation) and short (less than one third the length of the rib above it; variation) thoracolumbar ribs (Table 12). An increased number of fetuses was found with full supernumerary thoracolumbar ribs on the left, right, and bilaterally, which culminated in total incidences of full supernumerary thoracolumbar ribs in $4.6 \%$ and $25.5 \%$ of the fetuses in the 20 and $60 \mathrm{mg} / \mathrm{kg}$ groups, respectively. This increased incidence was statistically significant by pairwise comparison at $60 \mathrm{mg} / \mathrm{kg}(\mathrm{p} \leq 0.01)$. Although increased incidences of short supernumerary thoracolumbar ribs are a common background lesion in this strain of rat, the findings were statistically significant for both the trend test and pairwise comparison at 20 and $60 \mathrm{mg} / \mathrm{kg}$ ( $\mathrm{p} \leq 0.05$ ), which supports the idea that increases of full supernumerary thoracolumbar ribs were exposure related.

In the $60 \mathrm{mg} / \mathrm{kg}$ group, there was an increased incidence of greater than 26 presacral vertebrae (Table 12). Whether this increased incidence is related to exposure is unclear; however, the incidences were outside of the historical control range $(0 \%)$, and all the fetuses with this variation also had either bilateral full supernumerary ribs or left full supernumerary ribs.

Table 12. Summary of Selected Fetal Skeletal Findings in Rats in the Prenatal Developmental Toxicity Gavage Study of Vinpocetine

\begin{tabular}{|c|c|c|c|c|}
\hline & $0 \mathrm{mg} / \mathrm{kg}$ & $5 \mathrm{mg} / \mathrm{kg}$ & $20 \mathrm{mg} / \mathrm{kg}$ & $60 \mathrm{mg} / \mathrm{kg}$ \\
\hline Number of Fetuses Examined & 293 & 239 & 260 & 47 \\
\hline Number of Litters Examined & 21 & 19 & 21 & 7 \\
\hline \multicolumn{5}{|l|}{ Vertebrae } \\
\hline \multicolumn{5}{|c|}{ Cervical arch, multiple sites, misshapen - [M] } \\
\hline Fetuses & $0(0.0)$ & $1(0.42)$ & $0(0.0)$ & $0(0.0)$ \\
\hline Litters & $0(0.00)$ & $1(5.26)$ & $0(0.00)$ & $0(0.00)$ \\
\hline \multicolumn{5}{|c|}{ Thoracic arch, 6th right, misshapen - [M] } \\
\hline Fetuses & $0(0.0)$ & $0(0.0)$ & $0(0.0)$ & $1(2.13)$ \\
\hline Litters & $0(0.00)$ & $0(0.00)$ & $0(0.00)$ & $1(14.29)$ \\
\hline \multicolumn{5}{|c|}{ Thoracic arch, multiple sites, misshapen - [M] } \\
\hline Fetuses & $0(0.0)$ & $1(0.42)$ & $0(0.0)$ & $0(0.0)$ \\
\hline Litters & $0(0.00)$ & $1(5.26)$ & $0(0.00)$ & $0(0.00)$ \\
\hline \multicolumn{5}{|c|}{ Thoracic centrum, 1st, hemicentric - [V] } \\
\hline Fetuses & $0(0.0)$ & $1(0.42)$ & $0(0.0)$ & $0(0.0)$ \\
\hline Litters & $0(0.00)$ & $1(5.26)$ & $0(0.00)$ & $0(0.00)$ \\
\hline Thoracic centrum, 12th, hem & & & & \\
\hline
\end{tabular}




\begin{tabular}{|c|c|c|c|c|}
\hline & $0 \mathrm{mg} / \mathrm{kg}$ & $5 \mathrm{mg} / \mathrm{kg}$ & $20 \mathrm{mg} / \mathrm{kg}$ & $60 \mathrm{mg} / \mathrm{kg}$ \\
\hline Fetuses & $0(0.0)$ & $1(0.42)$ & $0(0.0)$ & $0(0.0)$ \\
\hline Litters & $0(0.00)$ & $1(5.26)$ & $0(0.00)$ & $0(0.00)$ \\
\hline \multicolumn{5}{|c|}{ Thoracic centrum, 1st, incomplete ossification - [V] } \\
\hline Fetuses & $0(0.0)$ & $0(0.0)$ & $1(0.38)$ & $0(0.0)$ \\
\hline Litters & $0(0.00)$ & $0(0.00)$ & $1(4.76)$ & $0(0.00)$ \\
\hline \multicolumn{5}{|c|}{ Thoracic centrum, 5th, incomplete ossification - [V] } \\
\hline Fetuses & $0(0.0)$ & $0(0.0)$ & $1(0.38)$ & $0(0.0)$ \\
\hline Litters & $0(0.00)$ & $0(0.00)$ & $1(4.76)$ & $0(0.00)$ \\
\hline \multicolumn{5}{|c|}{ Thoracic centrum, 6th, incomplete ossification - [V] } \\
\hline Fetuses & $0(0.0)$ & $0(0.0)$ & $0(0.0)$ & $1(2.13)$ \\
\hline Litters & $0(0.00)$ & $0(0.00)$ & $0(0.00)$ & $1(14.29)$ \\
\hline \multicolumn{5}{|c|}{ Thoracic centrum, 9th, incomplete ossification - [V] } \\
\hline Fetuses & $0(0.0)$ & $0(0.0)$ & $0(0.0)$ & $1(2.13)$ \\
\hline Litters & $0(0.00)$ & $0(0.00)$ & $0(0.00)$ & $1(14.29)$ \\
\hline \multicolumn{5}{|c|}{ Thoracic centrum, 10th, incomplete ossification - [V] } \\
\hline Fetuses & $1(0.34)$ & $0(0.0)$ & $0(0.0)$ & $1(2.13)$ \\
\hline Litters & $1(4.76)$ & $0(0.00)$ & $0(0.00)$ & $1(14.29)$ \\
\hline \multicolumn{5}{|c|}{ Thoracic centrum, 11th, incomplete ossification - [V] } \\
\hline Fetuses & $0(0.0)^{* *}$ & $0(0.0)$ & $3(1.15)$ & $2(4.26)^{*}$ \\
\hline Litters & $0(0.00)^{* *}$ & $0(0.00)$ & $3(14.29)$ & $2(28.57)$ \\
\hline \multicolumn{5}{|c|}{ Thoracic centrum, 12th, incomplete ossification - [V] } \\
\hline Fetuses & $0(0.0)^{* *}$ & $0(0.0)$ & $1(0.38)$ & $3(6.38)^{* *}$ \\
\hline Litters & $0(0.00)^{* *}$ & $0(0.00)$ & $1(4.76)$ & $2(28.57)$ \\
\hline \multicolumn{5}{|c|}{ Thoracic centrum, 13th, incomplete ossification - [V] } \\
\hline Fetuses & $0(0.0)^{* *}$ & $0(0.0)$ & $0(0.0)$ & $2(4.26)^{*}$ \\
\hline Litters & $0(0.00)^{* *}$ & $0(0.00)$ & $0(0.00)$ & $2(28.57)$ \\
\hline \multicolumn{5}{|c|}{ Thoracic centrum, multiple sites, incomplete ossification - [V] } \\
\hline Fetuses & $0(0.0)$ & $1(0.42)$ & $0(0.0)$ & $0(0.0)$ \\
\hline Litters & $0(0.00)$ & $1(5.26)$ & $0(0.00)$ & $0(0.00)$ \\
\hline \multicolumn{5}{|c|}{ Thoracic centrum, incomplete ossification, total - [V] ${ }^{\mathrm{a}}$} \\
\hline Fetuses & $1(0.34)^{* * \# \#}$ & $1(0.42)$ & $6(2.31)^{* \#}$ & $8(17.02)^{* * \# \#}$ \\
\hline Litters & $1(4.76)^{* *}$ & $1(5.26)$ & $5(23.81)$ & $3(42.86)^{*}$ \\
\hline \multicolumn{5}{|c|}{ Lumbar arch, 5th left, fused - [M] } \\
\hline Fetuses & $0(0.0)$ & $0(0.0)$ & $0(0.0)$ & $1(2.13)$ \\
\hline Litters & $0(0.00)$ & $0(0.00)$ & $0(0.00)$ & $1(14.29)$ \\
\hline \multicolumn{5}{|c|}{ Lumbar centrum, 5th, fused $-[\mathrm{M}]$} \\
\hline Fetuses & $0(0.0)$ & $0(0.0)$ & $0(0.0)$ & $1(2.13)$ \\
\hline Litters & $0(0.00)$ & $0(0.00)$ & $0(0.00)$ & $1(14.29)$ \\
\hline \multicolumn{5}{|c|}{ Lumbar centrum, 1st, incomplete ossification - [V] } \\
\hline Fetuses & $0(0.0)$ & $1(0.42)$ & $0(0.0)$ & $0(0.0)$ \\
\hline Litters & $0(0.00)$ & $1(5.26)$ & $0(0.00)$ & $0(0.00)$ \\
\hline \multicolumn{5}{|c|}{ Lumbar centrum, 3rd, incomplete ossification - [V] } \\
\hline Fetuses & $0(0.0)$ & $0(0.0)$ & $1(0.38)$ & $0(0.0)$ \\
\hline
\end{tabular}




\begin{tabular}{|c|c|c|c|c|}
\hline & $0 \mathrm{mg} / \mathrm{kg}$ & $5 \mathrm{mg} / \mathrm{kg}$ & $20 \mathrm{mg} / \mathrm{kg}$ & $60 \mathrm{mg} / \mathrm{kg}$ \\
\hline Litters & $0(0.00)$ & $0(0.00)$ & $1(4.76)$ & $0(0.00)$ \\
\hline \multicolumn{5}{|c|}{ Presacral vertebrae, greater than 26 - [V] } \\
\hline Fetuses & $0(0.0)^{* *}$ & $0(0.0)$ & $0(0.0)$ & $4(8.51)^{* *}$ \\
\hline Litters & $0(0.00)^{* *}$ & $0(0.00)$ & $0(0.00)$ & $2(28.57)$ \\
\hline \multicolumn{5}{|c|}{ Sacral centrum, multiple sites, misshapen - $[\mathrm{M}]$} \\
\hline Fetuses & $0(0.0)$ & $1(0.42)$ & $0(0.0)$ & $0(0.0)$ \\
\hline Litters & $0(0.00)$ & $1(5.26)$ & $0(0.00)$ & $0(0.00)$ \\
\hline \multicolumn{5}{|c|}{ Supernumerary Rib } \\
\hline \multicolumn{5}{|c|}{ Thoracolumbar, left, full - [M] } \\
\hline Fetuses & $0(0.0)^{* *}$ & $1(0.42)$ & $2(0.77)$ & $3(6.38) * *$ \\
\hline Litters & $0(0.00)$ & $1(5.26)$ & $2(9.52)$ & $1(14.29)$ \\
\hline \multicolumn{5}{|c|}{ Thoracolumbar, right, full - [M] } \\
\hline Fetuses & $1(0.34)$ & $2(0.84)$ & $1(0.38)$ & $1(2.13)$ \\
\hline Litters & $1(4.76)$ & $2(10.53)$ & $1(4.76)$ & $1(14.29)$ \\
\hline \multicolumn{5}{|c|}{ Thoracolumbar, bilateral, full - [M] } \\
\hline Fetuses & $0(0.0)^{* *}$ & $2(0.84)$ & $9(3.46)^{* *}$ & $8(17.02)^{* *}$ \\
\hline Litters & $0(0.00)$ & $2(10.53)$ & $1(4.76)$ & $2(28.57)$ \\
\hline \multicolumn{5}{|c|}{ Thoracolumbar, full, total $-[\mathrm{M}]^{\mathrm{b}}$} \\
\hline Fetuses & $1(0.34)^{* * \# \#}$ & $5(2.09)$ & $12(4.62)^{* *}$ & $12(25.53) * * \#$ \\
\hline Litters & $1(4.76)^{*}$ & $3(15.79)$ & $4(19.05)$ & $3(42.86)^{*}$ \\
\hline \multicolumn{5}{|c|}{ Thoracolumbar, left, short - [V] } \\
\hline Fetuses & $21(7.17)^{* \#}$ & $10(4.18)$ & $22(8.46)$ & $7(14.89)$ \\
\hline Litters & $13(61.90)$ & $6(31.58)$ & $13(61.90)$ & $5(71.43)$ \\
\hline \multicolumn{5}{|c|}{ Thoracolumbar, right, short - [V] } \\
\hline Fetuses & $2(0.68)^{*}$ & $11(4.6)^{* * \#}$ & $16(6.15)^{* * \# \#}$ & $2(4.26)^{\#}$ \\
\hline Litters & $2(9.52)$ & $6(31.58)$ & $12(57.14)^{* *}$ & $2(28.57)$ \\
\hline \multicolumn{5}{|c|}{ Thoracolumbar, bilateral, short - [V] } \\
\hline Fetuses & $6(2.05)$ & $9(3.77)$ & $17(6.54)^{* * \#}$ & $1(2.13)$ \\
\hline Litters & $4(19.05)$ & $5(26.32)$ & $11(52.38)^{*}$ & $1(14.29)$ \\
\hline \multicolumn{5}{|c|}{ Thoracolumbar, short, total - [V] } \\
\hline Fetuses & $29(9.9)^{* * \#}$ & $30(12.55)$ & $55(21.15)^{* * \#}$ & $10(21.28)^{* \#}$ \\
\hline Litters & 14 (66.67) & 10 (52.63) & 17 (80.95) & $5(71.43)$ \\
\hline
\end{tabular}

Upper row denotes number of affected fetuses and (\%); lower row the number of affected litters and (\%).

*Statistically significant $(\mathrm{p} \leq 0.05)$ analysis for litter data and for fetal data (without the litter effects) performed by the CochranArmitage (trend) and Fisher exact (pairwise) tests. Statistically significant trend is denoted in the vehicle control column; a significant pairwise comparison is denoted in the dose group column.

${ }^{* *} \mathrm{p} \leq 0.01$.

\#Statistically significant ( $\leq$ 0.05) trend (denoted in the vehicle control column) or pairwise comparison (denoted in the dose group column); statistical analysis of fetuses with litter-based adjustments performed by mixed-effects logistic regression.

${ }^{\#} \mathrm{p} \leq 0.01$.

$[\mathrm{M}]=$ malformation; $[\mathrm{V}]=$ variation .

${ }^{a}$ Historical incidence in control groups for gavage studies: fetuses - 3/1,325 (0.23\%), range 0.00-0.82\%; litters - 3/104 (2.88\%), range $0.00 \%-11.11 \%$.

bHistorical incidence in control groups for gavage studies: fetuses - 14/1,324 (1.06\%), range 0.34-3.35\%; litters - 13/104 (12.50\%), range $4.76-31.58 \%$. 
Additionally, singular occurrences of incomplete ossification were noted in the lumbar centrum in the 5 and $20 \mathrm{mg} / \mathrm{kg}$ groups; the occurrences were considered incidental and not exposure related. All malformations present in the vertebrae (misshapen cervical arch, misshapen sacral centrum, misshapen thoracic arch, fused lumbar arch, and fused lumbar centrum) were limited to three fetuses and therefore were not considered related to vinpocetine exposure.

\section{Dose Selection Rationale for the Dose Range-finding Study in Rabbits}

Dose selection for the range-finding study in rabbits was informed by both the results from the dose range-finding study in the rat and by toxicokinetic data on vinpocetine in rabbits from the literature. Toxicokinetic data on vinpocetine in rats and rabbits demonstrate similar plasma AUC and $\mathrm{C}_{\max }$ levels. ${ }^{27 ;}$ 28; 30; 33-35 Therefore, the doses chosen for the rabbits were similar to those chosen for the dose range-finding study in rats $(0,25,75,150$, and $300 \mathrm{mg} / \mathrm{kg} / \mathrm{day})$.

\section{Dose Range-finding Study in Rabbits}

\section{Maternal Findings}

\section{Viability and Clinical Observations}

All vehicle control and dosed rabbits survived until the end of the study (Table 13), with the exception of one female in the $150 \mathrm{mg} / \mathrm{kg}$ group that was removed on GD 25 due to abortion. This doe also had clinical observations beginning on GD 21 of red abnormal vaginal discharge and red substance present in the cage pan that were consistent with the abortion (Appendix $\mathrm{E}^{50}$ ). Clinical observations of red vaginal discharge and red discoloring of the vagina also occurred in one animal each from the vehicle control and $300 \mathrm{mg} / \mathrm{kg}$ groups beginning on GD 22 and GD 20, respectively. These clinical observations were not accompanied by abortions; however, postimplantation loss was noted in the doe from the $300 \mathrm{mg} / \mathrm{kg}$ group. An additional incidence of red substance in the cage pan was observed on GD 20 in a doe from the $300 \mathrm{mg} / \mathrm{kg}$ group that also had $66.7 \%$ postimplantation loss.

Table 13. Maternal Disposition of Rabbits in the Dose Range-finding Gavage Study of Vinpocetine

\begin{tabular}{lccccc}
\hline & $\mathbf{0 ~} \mathbf{~ m g} / \mathbf{k g}$ & $\mathbf{2 5} \mathbf{~} \mathbf{g} / \mathbf{k g}$ & $\mathbf{7 5} \mathbf{~ \mathbf { g }} / \mathbf{k g}$ & $\mathbf{1 5 0} \mathbf{~} \mathbf{g} / \mathbf{k g}$ & $\mathbf{3 0 0} \mathbf{~} \mathbf{g} / \mathbf{k g}$ \\
\hline Time-mated females & 8 & 8 & 8 & 8 & 8 \\
Pregnant (on GD 29) & 8 & 7 & 8 & 7 & 8 \\
Euthanasia aborted-pregnant & 0 & 0 & 0 & $1^{\mathrm{a}}$ & 0 \\
Nonpregnant (on GD 29) & 0 & 1 & 0 & 0 & 0 \\
\hline
\end{tabular}

GD = gestation day.

aDoe removed on GD 25.

\section{Body Weights and Feed Consumption}

Treatment-related decreases in maternal body weights were noted from GD 12 to GD 29 in the $300 \mathrm{mg} / \mathrm{kg}$ group, relative to the vehicle control group (Figure 6; Table 14). Decreases in mean maternal body weight gains, compared to vehicle controls, were $44 \%$ and $34 \%$ for the 150 and $300 \mathrm{mg} / \mathrm{kg}$ groups, respectively (Table 14). Feed consumption decreased at 150 and $300 \mathrm{mg} / \mathrm{kg}$ (Table 15) and embryo-fetal loss increased at $300 \mathrm{mg} / \mathrm{kg}$ (20.4\% compared to $1.4 \%$ in the 
vehicle control group; Table 16). Daily mean body weight changes for does in each dose group are available in Appendix E. ${ }^{50}$

Treatment-related maternal feed consumption decreased in the 150 and $300 \mathrm{mg} / \mathrm{kg}$ groups during gestation (Table 15). Decreases in feed consumption across several dosing intervals (11\% to $30 \%$ in both high-dose groups compared to the vehicle control group) culminated in overall decreases of $17 \%$ and $26 \%$ for 150 and $300 \mathrm{mg} / \mathrm{kg}$ groups, respectively, during the GD 7 to GD 29 interval.

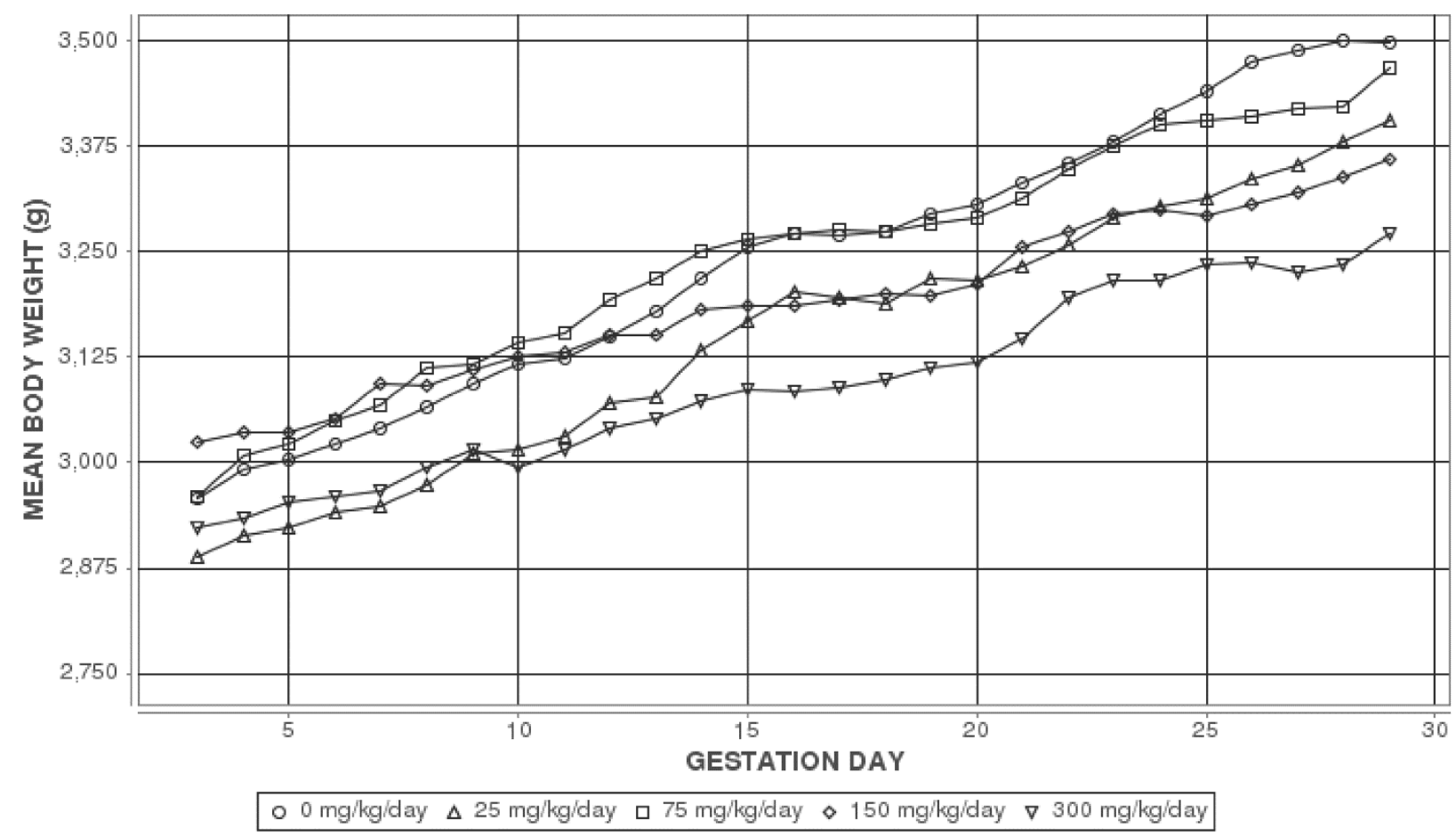

Figure 6. Maternal Growth Curves for Pregnant Rabbits Administered Vinpocetine by Gavage in the Dose Range-finding Study

Information for statistical significance in maternal weights is provided in Table 14 and Appendix E. ${ }^{50}$ 
Table 14. Summary of Maternal Body Weight Gains of Rabbits in the Dose Range-finding Gavage Study of Vinpocetine ${ }^{a}$

\begin{tabular}{|c|c|c|c|c|c|}
\hline $\begin{array}{c}\text { Gestation Day } \\
\text { Interval }\end{array}$ & $0 \mathrm{mg} / \mathrm{kg}$ & $25 \mathrm{mg} / \mathrm{kg}$ & $75 \mathrm{mg} / \mathrm{kg}$ & $150 \mathrm{mg} / \mathrm{kg}$ & $300 \mathrm{mg} / \mathrm{kg}$ \\
\hline $7-29$ & $460.2 \pm 33.8^{* *}(8)$ & $458.2 \pm 46.2(7)$ & $399.3 \pm 58.4(8)$ & $256.7 \pm 40.9 * *(7)$ & $304.1 \pm 33.2^{* *}(8)$ \\
\hline $3-7$ & $81.5 \pm 17.7(8)$ & $61.6 \pm 20.1(7)$ & $108.0 \pm 10.7(8)$ & $69.2 \pm 19.3(8)$ & $45.3 \pm 13.1(8)$ \\
\hline 7-9 & $53.2 \pm 8.2(8)$ & $61.6 \pm 11.1(7)$ & $49.1 \pm 10.8(8)$ & $14.9 \pm 19.9(8)$ & $47.3 \pm 29.3(8)$ \\
\hline $9-12$ & $56.8 \pm 15.1(8)$ & $60.8 \pm 13.4(7)$ & $74.9 \pm 22.4(8)$ & $40.9 \pm 16.0$ & $26.8 \pm 19.6(8)$ \\
\hline $12-15$ & $105.3 \pm 11.1^{* *}(8)$ & $97.7 \pm 10.2(7)$ & $71.5 \pm 17.8(8)$ & $36.1 \pm 36.7$ (8) & $46.0 \pm 20.7(8)$ \\
\hline $15-18$ & $20.0 \pm 9.5(8)$ & $19.4 \pm 9.3(7)$ & $11.0 \pm 10.2(8)$ & $12.5 \pm 9.9(8)$ & $11.0 \pm 11.8(8)$ \\
\hline $18-21$ & $56.3 \pm 12.6(8)$ & $43.8 \pm 10.0(7)$ & $39.3 \pm 11.3(8)$ & $55.5 \pm 23.8$ (8) & $47.4 \pm 23.6(8)$ \\
\hline $21-24$ & $82.2 \pm 6.7(8)$ & $71.5 \pm 18.1(7)$ & $88.0 \pm 12.7(8)$ & $44.0 \pm 10.8(8)$ & $71.4 \pm 15.3(8)$ \\
\hline $24-27$ & $76.0 \pm 11.5^{* *}(8)$ & $48.4 \pm 14.6(7)$ & $18.4 \pm 18.6^{* *}(8)$ & $24.9 \pm 11.7^{*}(7)$ & $7.3 \pm 12.4^{* *}(8)$ \\
\hline $27-29$ & $10.3 \pm 16.2(8)$ & $55.5 \pm 8.0(7)$ & $47.1 \pm 9.6(8)$ & $38.7 \pm 15.4(7)$ & $46.9 \pm 17.6(8)$ \\
\hline
\end{tabular}

*Statistically significant ( $\leq 0.05$ ) trend (by the Jonckheere test) or pairwise comparison (by the Williams or Dunnett test). A significant trend test is indicated in the vehicle control column. A significant pairwise comparison with the vehicle control group is indicated in the dose group column.

$* * \mathrm{p} \leq 0.01$.

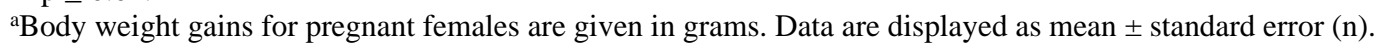

Table 15. Summary of Maternal Feed Consumption of Rabbits in the Dose Range-finding Gavage Study of Vinpocetine ${ }^{a}$

\begin{tabular}{|c|c|c|c|c|c|}
\hline $\begin{array}{l}\text { Gestation Day } \\
\text { Interval }\end{array}$ & 0 mg/kg & $25 \mathrm{mg} / \mathrm{kg}$ & 75 mg/kg & $150 \mathrm{mg} / \mathrm{kg}$ & $300 \mathrm{mg} / \mathrm{kg}$ \\
\hline $7-29$ & $137.6 \pm 4.3^{* *}(8)$ & $131.8 \pm 5.7(7)$ & $125.2 \pm 4.0(8)$ & $101.3 \pm 11.4^{* *}(7)$ & $113.8 \pm 8.9 *(8)$ \\
\hline $3-7$ & $149.1 \pm 0.8(8)$ & $143.2 \pm 7.1(7)$ & $149.8 \pm 0.5(8)$ & $139.6 \pm 7.6(8)$ & $147.4 \pm 2.6(8)$ \\
\hline $7-9$ & $148.9 \pm 2.0^{*}(8)$ & $143.0 \pm 5.3(7)$ & $148.7 \pm 2.1(8)$ & $131.1 \pm 9.0(8)$ & $118.7 \pm 15.4(8)$ \\
\hline $9-12$ & $145.1 \pm 4.3^{*}(8)$ & $141.1 \pm 5.5(7)$ & $137.4 \pm 6.7(8)$ & $107.3 \pm 13.4(8)$ & $106.1 \pm 18.6(8)$ \\
\hline $12-15$ & $128.6 \pm 9.4(8)$ & $131.8 \pm 8.1(7)$ & $117.6 \pm 9.9(8)$ & $92.5 \pm 20.9(8)$ & $102.9 \pm 18.3(8)$ \\
\hline $15-18$ & $142.9 \pm 4.1^{*}(8)$ & $138.7 \pm 6.7(7)$ & $118.5 \pm 10.9$ (8) & $98.7 \pm 20.0(8)$ & $109.6 \pm 15.9(8)$ \\
\hline $18-21$ & $148.0 \pm 2.4^{* *}(8)$ & $137.9 \pm 6.3(7)$ & $132.5 \pm 6.7(8)$ & $109.3 \pm 8.7^{* *}(8)$ & $131.2 \pm 6.0^{*}(8)$ \\
\hline $21-24$ & $142.6 \pm 5.2(8)$ & $127.8 \pm 10.8(7)$ & $137.1 \pm 6.1(8)$ & $117.2 \pm 8.6(8)$ & $127.3 \pm 5.9(8)$ \\
\hline $24-27$ & $134.7 \pm 5.6^{*}(8)$ & $126.9 \pm 9.1(7)$ & $106.6 \pm 8.8(8)$ & $89.8 \pm 10.6^{* *}(7)$ & $110.3 \pm 3.2(8)$ \\
\hline $27-29$ & $96.1 \pm 14.4(8)$ & $100.7 \pm 18.4(7)$ & $95.0 \pm 24.2(8)$ & $97.1 \pm 14.3(7)$ & $102.0 \pm 16.2(8)$ \\
\hline
\end{tabular}

*Statistically significant ( $\leq 0.05)$ trend (by the Jonckheere test) or pairwise comparison (by the Shirley or Dunn test). A significant trend test is indicated in the vehicle control column. A significant pairwise comparison with the vehicle control group is indicated in the dose group column.

$* * \mathrm{p} \leq 0.01$.

${ }^{\text {a}}$ Feed consumption for pregnant females is given in grams/day. Data are displayed as mean \pm standard error (n). 


\section{Maternal and Litter Observations}

At necropsy, there were no notable maternal gross pathology findings (Appendix $\mathrm{E}^{50}$ ). There was an exposure-related effect on embryo-fetal survival in the $300 \mathrm{mg} / \mathrm{kg}$ group (Table 16). Uterine examination revealed fewer live fetuses per litter in the $300 \mathrm{mg} / \mathrm{kg}$ group (mean of 6.5 compared to 9.1 in the vehicle control group), which was associated with an increase in early resorptions per litter (mean of 1.6 compared to 0.1 per litter in the vehicle control group). Overall, these findings in the $300 \mathrm{mg} / \mathrm{kg}$ group led to an increase in percent postimplantation loss $(20.4 \%$ compared to $1.4 \%$ in the vehicle control group) which was associated with a $34 \%$ reduction in mean gravid uterine weight. No exposure-related effects were found on embryo-fetal survival in any group administered $150 \mathrm{mg} / \mathrm{kg}$ or less.

Mean fetal weights were reduced for both males and females in the $300 \mathrm{mg} / \mathrm{kg}$ group $(10.7 \%$ and $10.6 \%$ less than the vehicle control group, respectively). No effects were noted at the lower doses.

\section{Fetal Findings}

\section{External}

There were no external malformations or variations attributed to vinpocetine exposure at 25, 75 , 150 , or $300 \mathrm{mg} / \mathrm{kg}$ per day (Appendix $\mathrm{E}^{50}$ ). External findings were limited to a singular occurrence of localized subcutaneous edema in the $75 \mathrm{mg} / \mathrm{kg}$ group and one incidence of subcutaneous hemorrhage in each of the vehicle control, 25, and $150 \mathrm{mg} / \mathrm{kg}$ groups; those were considered incidental and unrelated to vinpocetine exposure. 
Table 16. Summary of Uterine Content Data for Rabbits in the Dose Range-finding Gavage Study of Vinpocetine

\begin{tabular}{|c|c|c|c|c|c|}
\hline & $0 \mathrm{mg} / \mathrm{kg}$ & $25 \mathrm{mg} / \mathrm{kg}$ & $75 \mathrm{mg} / \mathrm{kg}$ & $150 \mathrm{mg} / \mathrm{kg}$ & $300 \mathrm{mg} / \mathrm{kg}$ \\
\hline \multicolumn{6}{|l|}{ Pregnancy Summary } \\
\hline Mated females & 8 & 8 & 8 & 8 & 8 \\
\hline Pregnant females & 8 & 7 & 8 & 8 & 8 \\
\hline Pregnant females examined on GD $29^{a}$ & 8 & 7 & 8 & 7 & 8 \\
\hline Corpora lutea per female ${ }^{b}$ & $9.50 \pm 0.38(8)$ & $8.71 \pm 0.47(7)$ & $9.63 \pm 0.53(8)$ & $8.86 \pm 0.40(7)$ & $9.13 \pm 0.61(8)$ \\
\hline Implantations per female ${ }^{\mathrm{b}}$ & $9.25 \pm 0.41(8)$ & $8.00 \pm 0.44(7)$ & $9.25 \pm 0.56(8)$ & $7.71 \pm 0.68(7)$ & $8.38 \pm 0.56(8)$ \\
\hline Percent postimplantation loss ${ }^{\mathrm{b}}$ & $1.39 \pm 1.39(8)$ & $3.37 \pm 2.18(7)$ & $2.53 \pm 1.66(8)$ & $3.57 \pm 3.57(7)$ & $20.42 \pm 9.05(8)$ \\
\hline Total resorptions per litter ${ }^{\mathrm{b}}$ & $0.13 \pm 0.13(8)$ & $0.14 \pm 0.14(7)$ & $0.25 \pm 0.16(8)$ & $0.14 \pm 0.14(7)$ & $1.88 \pm 0.85(8)$ \\
\hline Early resorptions per litter ${ }^{\mathrm{b}}$ & $0.13 \pm 0.13 *(8)$ & $0.00 \pm 0.00(7)$ & $0.00 \pm 0.00(8)$ & $0.14 \pm 0.14(7)$ & $1.63 \pm 0.71(8)$ \\
\hline Late resorptions per litter ${ }^{\mathrm{b}}$ & $0.00 \pm 0.00(8)$ & $0.14 \pm 0.14(7)$ & $0.25 \pm 0.16(8)$ & $0.00 \pm 0.00(7)$ & $0.25 \pm 0.25(8)$ \\
\hline Dead fetuses per litter ${ }^{\mathrm{b}}$ & $0.00 \pm 0.00(8)$ & $0.14 \pm 0.14(7)$ & $0.00 \pm 0.00(8)$ & $0.00 \pm 0.00(7)$ & $0.00 \pm 0.00(8)$ \\
\hline Number of early resorptions ${ }^{\mathrm{C}}$ & 1 & 0 & 0 & 1 & 13 \\
\hline Number of late resorptions ${ }^{c}$ & 0 & 1 & 2 & 0 & 2 \\
\hline Number of whole litter resorptions & 0 & 0 & 0 & 0 & 0 \\
\hline Number of dead fetuses ${ }^{c}$ & 0 & 1 & 0 & 0 & 0 \\
\hline \multicolumn{6}{|l|}{ Live Fetuses $^{\mathrm{b}}$} \\
\hline Number of live fetuses & 73 & 54 & 72 & 53 & 52 \\
\hline Live fetuses per litter & $9.13 \pm 0.44 *(8)$ & $7.71 \pm 0.42(7)$ & $9.00 \pm 0.53(8)$ & $7.57 \pm 0.81(7)$ & $6.50 \pm 0.73 *(8)$ \\
\hline Live male fetuses per litter & $3.50 \pm 0.94(8)$ & $3.86 \pm 0.63(7)$ & $4.63 \pm 0.38(8)$ & $3.86 \pm 0.91(7)$ & $3.38 \pm 0.73^{*}(8)$ \\
\hline Live female fetuses per litter & $5.63 \pm 0.68 *(8)$ & $3.86 \pm 0.70(7)$ & $4.38 \pm 0.63(8)$ & $3.71 \pm 0.42(7)$ & $3.13 \pm 0.67(8)$ \\
\hline Percent live male fetuses per litter & $36.30 \pm 8.71(8)$ & $50.68 \pm 8.87(7)$ & $52.67 \pm 5.63(8)$ & $45.15 \pm 9.80(7)$ & $50.80 \pm 9.02(8)$ \\
\hline \multicolumn{6}{|l|}{ Fetal Weight (g) ${ }^{\mathrm{d}}$} \\
\hline Fetal weight per litter & $39.72 \pm 1.33^{* *}(8)$ & $41.47 \pm 0.95(7)$ & $37.53 \pm 0.90(8)$ & $39.36 \pm 1.74(7)$ & $35.78 \pm 1.15(8)$ \\
\hline Male fetal weight per litter & $40.87 \pm 1.59 * *(8)$ & $42.70 \pm 0.97(7)$ & $38.50 \pm 1.15(8)$ & $38.06 \pm 1.62(6)$ & $36.49 \pm 2.00(8)$ \\
\hline
\end{tabular}




\section{Vinpocetine, NTP DART 03}

\begin{tabular}{|c|c|c|c|c|c|}
\hline & $0 \mathrm{mg} / \mathrm{kg}$ & $25 \mathrm{mg} / \mathrm{kg}$ & $75 \mathrm{mg} / \mathrm{kg}$ & $150 \mathrm{mg} / \mathrm{kg}$ & $300 \mathrm{mg} / \mathrm{kg}$ \\
\hline Female fetal weight per litter & $38.76 \pm 1.57 *(8)$ & $40.37 \pm 1.12(7)$ & $36.35 \pm 1.01(8)$ & $39.29 \pm 1.75(7)$ & $34.65 \pm 0.95(8)$ \\
\hline \multicolumn{6}{|l|}{ Gravid Uterine Weight (g) ${ }^{\mathrm{e}}$} \\
\hline Gravid uterine weight & $515.25 \pm 14.70^{* *}(8)$ & $470.05 \pm 20.66(7)$ & $483.91 \pm 32.24(8)$ & $421.86 \pm 39.25^{*}(7)$ & $340.94 \pm 27.73^{* *}(8)$ \\
\hline Terminal body weight & $3,449.4 \pm 64.6^{*}(8)$ & $3,406.5 \pm 58.0(7)$ & $3,467.7 \pm 95.0(8)$ & $3,358.4 \pm 105.6(7)$ & $3,271.4 \pm 34.2(8)$ \\
\hline Adjusted body weight & $2,984.19 \pm 64.86(8)$ & $2,936.41 \pm 42.60(7)$ & $2,983.75 \pm 75.64(8)$ & $2,936.53 \pm 110.63(7)$ & $2,930.44 \pm 46.81(8)$ \\
\hline
\end{tabular}

Values are reported per litter as mean \pm standard error (n) and do not include nonpregnant animals or those that did not survive to the end of the study.

$\mathrm{GD}=$ gestation day.

*Statistically significant $(\mathrm{p} \leq 0.05)$ trend (denoted in vehicle control column) or pairwise comparison (denoted in dose group column).

$* * \mathrm{p} \leq 0.01$.

a Statistical analysis performed by the Cochran-Armitage (trend) and Fisher exact (pairwise) tests.

bStatistical analysis performed by the Jonckheere (trend) and Shirley or Dunn (pairwise) tests.

cNo statistical analyses were performed on number of early resorptions, number of late resorptions, or number of dead fetuses.

${ }^{\mathrm{d} S}$ Statistical analysis performed using a mixed-effects linear model with litter as a random effect (trend and pairwise).

eStatistical analysis performed by the Jonckheere (trend) and Williams or Dunnett (pairwise) tests. Adjusted body weight = terminal body weight minus gravid uterine weight. 


\section{Discussion}

Vinpocetine is a semisynthetic derivative of vincamine, an alkaloid extract derived from the periwinkle plant Vinca minor. Vinpocetine has been widely available as a pharmaceutical in Europe, Russia, China, and Japan for treatment of cerebrovascular and cognitive disorders. ${ }^{6}$ However, in the United States it is available as a dietary supplement with claims of cognitive enhancement. ${ }^{7-11}$ Interest in memory enhancement has shifted its use from a primarily older population to use by all ages, including women of childbearing potential (WOCBP). The one publication available for review ${ }^{47}$ provides insufficient information to effectively evaluate the safety of vinpocetine in a younger population that includes WOCBP.

The National Toxicology Program (NTP) conducted developmental studies with vinpocetine in the rat because of the possibility of widespread exposure to pregnant women and WOCBP and limited literature indicating that vinpocetine might not be safe for use during pregnancy. Additionally, a dose range-finding study in rabbits was included to see if effects occurred in a second species. The current Developmental and Reproductive Toxicity Technical Report presents the findings of the dose range-finding and prenatal developmental toxicity studies of vinpocetine in Sprague Dawley (Hsd:Sprague Dawley ${ }^{\circledR} \mathrm{SD}^{\circledR}$ ) rats and the dose range-finding study of vinpocetine in New Zealand White (Hra:NZW SPF) rabbits.

The prenatal toxicity study in rats provided clear evidence of developmental toxicity, with supportive evidence from the dose range-findings studies in rats and rabbits. In the dose rangefinding study in rats, daily oral gavage exposure of $0,20,40,80,160$, or $320 \mathrm{mg} / \mathrm{kg}$ resulted in lowered maternal body weight and body weight gains, decreased maternal feed consumption, clinical observations of abnormal vaginal discharge at $\geq 80 \mathrm{mg} / \mathrm{kg}$, and significant embryo-fetal loss in all exposed groups.

Because of the increased incidences of fetal resorptions between the 40 and $80 \mathrm{mg} / \mathrm{kg}$ groups in the dose range-finding study, $60 \mathrm{mg} / \mathrm{kg}$ of vinpocetine was chosen as the high dose in the prenatal developmental toxicity study in rats. Maternal effects at $60 \mathrm{mg} / \mathrm{kg}$ were similar to those in the dose range-finding study: lowered maternal body weights and body weight gains (although, there was no significant effect when corrected for uterine weight); decreased feed consumption; and an increase in red vaginal discharge. These findings are consistent with a review of the industry studies published by Cholnoky and Dömök ${ }^{47}$ in which oral gavage administration of vinpocetine to rats over the major period of organogenesis resulted in lowered maternal body weight gain at $50 \mathrm{mg} / \mathrm{kg}$ and uterine bleeding at 50 and $150 \mathrm{mg} / \mathrm{kg}$.

In addition, in both the dose range-finding and prenatal developmental toxicity studies in rats, a dose-related increase in postimplantation loss occurred at doses $\geq 40 \mathrm{mg} / \mathrm{kg}$. In the prenatal developmental toxicity study in rats, postimplantation loss of $83 \%$ occurred in dams administered $60 \mathrm{mg} / \mathrm{kg}$. This increased postimplantation loss was a result of 12 dams with whole litter resorptions. Of the limited data in the literature (one paper reviewing 14 studies), high fetal mortality was noted following administration of $150 \mathrm{mg} / \mathrm{kg}$ vinpocetine to the dams in one study and complete litter resorptions were observed in 55\% of the dams administered $135 \mathrm{mg} / \mathrm{kg}$ vinpocetine in another study. ${ }^{47}$

Evidence of teratogenicity in the rat prenatal developmental toxicity study consisted of exposurerelated increased incidences in ventricular septum defects (VSDs). The incidences of VSDs were 
significantly increased between the 5 and $20 \mathrm{mg} / \mathrm{kg}$ dose groups, but not in the $60 \mathrm{mg} / \mathrm{kg}$ group. The lack of a dose-responsive increase in the number of VSDs at $60 \mathrm{mg} / \mathrm{kg}$ was likely a result of the significant postimplantation loss observed in this dose group (there were only 51 fetuses available for evaluation); however, the percent of affected fetuses was increased at both 20 and $60 \mathrm{mg} / \mathrm{kg}$ (3.1\% and 3.9\%) and was outside the NTP historical control range (0.0\% to $0.5 \%)$ for Sprague Dawley rats.

VSDs are a malformation that arise from a disruption in the developmental processes that lead to partitioning of the ventricles and manifests as an opening in the interventricular septum (IVS). Development of the IVS is typically complete by GD 15 in rats, and consists of both muscular and membranous segments. ${ }^{80}$ VSDs can occur spontaneously, have been identified as the most common type of congenital heart disease in humans, and have been shown to close during postnatal development in both rats and humans. ${ }^{81-85}$ Membranous VSDs can also be induced in rats as a result of toxicant exposure. ${ }^{82 ; 86}$ Administration of trimethadione on GD 9 and GD 10 resulted in a high incidence of membranous VSDs that were morphologically similar to spontaneously occurring VSDs, albeit larger in size. ${ }^{82 ; 86}$ These toxicant-induced small membranous VSDs in rats have also been shown to close postnatally, indicative of a potential delay in cardiac development. ${ }^{82 ; 86}$ The increased incidences of VSDs seen in the current studies with vinpocetine exposure could be indicative of a developmental delay; however, signs of delay (decreases in fetal weight and delays in ossification) were only observed in the $60 \mathrm{mg} / \mathrm{kg}$ group, and the incidences of VSDs were noted in the 5 and $20 \mathrm{mg} / \mathrm{kg}$ dose groups. Additionally, Fleeman et al.$^{86}$ found no association between the occurrence of VSDs and decreased fetal weight, suggesting that VSDs are independent of overall fetal growth as measured by fetal weight. Therefore, the presence of VSDs at all doses in the current study were likely related to the administration of vinpocetine and not a secondary effect of delayed development.

Additional evidence of teratogenicity associated with vinpocetine exposure in the rats included significantly increased incidences in the formation of full supernumerary thoracolumbar ribs (SNRs). This malformation was present in $25.5 \%$ of the fetuses in the $60 \mathrm{mg} / \mathrm{kg}$ dose group where significant fetal mortality occurred (compared to $0.3 \%$ in the vehicle control group and $0.3 \%$ to $3.4 \%$ in the available historical control reports for fetuses from Sprague Dawley rats). The formation of supernumerary ribs in the thoracolumbar region is indicative of an alteration in early embryonic development of the axial skeleton ${ }^{87}$ and has been observed from exposure to a wide range of dissimilar chemicals in a dose-dependent manner, including sodium salicylate, ${ }^{88}$ bromoxynil phenol or bromoxynil octanoate, ${ }^{89}$ and valproic acid. ${ }^{90}$ Additionally, increased incidences of SNRs have previously been associated with maternal stress, although this effect appears to be species specific given that it has been demonstrated mainly in mice. ${ }^{91 ; 92}$ Aside from the maternal effects associated with significant embryo-fetal loss, the doses of vinpocetine administered in the current studies did not produce signs of maternal stress or toxicity, indicating that the increased incidences of full SNRs in the current studies were likely related to vinpocetine exposure.

As incidences of full SNRs are indicators of developmental changes in axial skeleton development, they are generally not isolated events. Their formation has been significantly correlated with other findings in mice, such as the presence of an additional presacral vertebra. ${ }^{31}$ An increase in the incidences of greater than 26 presacral vertebrae was seen in the current rat studies in fetuses from dams exposed to $60 \mathrm{mg} / \mathrm{kg}$ vinpocetine. All of the fetuses with this variation also had incidences of full SNRs (bilateral or on the left only). 
Incidences of short SNRs, or rudimentary ribs, were significantly increased in the fetuses of dams exposed to 20 and $60 \mathrm{mg} / \mathrm{kg}$ vinpocetine. However, increased incidences of short SNRs are a common background variation in this strain of rat, and their presence is transient and has been shown to diminish during the postnatal period in rats. ${ }^{93-95}$ In contrast, full SNRs have been shown to persist from birth into adulthood, as demonstrated by Foulon et al. ${ }^{95}$ who examined salicylate-induced full SNRs over time through radiography. Incidences of full SNRs in the lumbar region have also been reported in humans, where they have been associated with adverse outcomes such as pain in the lumbar region and increased incidences of lumbar vertebrae L4 and L5 degeneration. ${ }^{31}$

Exposure to vinpocetine during gestation resulted in fetal growth retardation in the rats demonstrated by significant increases in the percentage of fetuses with incomplete ossification of the thoracic centrum and decreased fetal weights. The thoracic centrum is the body, or centrum, of the thoracic vertebrae and is routinely ossified before birth. Aside from fetal weight, the degree of ossification of the main components of the axial skeleton and the extremities in the fetus are typical indicators of developmental status. ${ }^{96}$ Cyclophosphamide is an example of another toxicant for which prenatal exposure in mice and rats resulted in fetal resorptions, as well as growth retardation, delayed ossification, and skeletal malformations. ${ }^{97-99}$ Maternal stress and malnutrition, especially during the period of rapid fetal growth late in gestation, can also result in reduced fetal weight and incomplete skeletal ossification. That mode of action, however, is not likely for vinpocetine exposure in these studies, because the reduced maternal body weights and feed consumption seen in this study were a result of fetal loss and not loss of non-uterine body mass of the dams.

A dose range-finding study was also performed in rabbits to determine if the effects observed in rats would be observed in species other than rodents. In the dose range-finding study in rabbits, daily oral gavage exposure of $0,25,75,150$, or $300 \mathrm{mg} / \mathrm{kg}$ did not result in overt maternal toxicity. As was seen in the rats, the vinpocetine-exposed does displayed several effects related to embryo-fetal loss, including decreased body weights and feed consumption and clinical observations of abnormal vaginal discharge. Those effects, however, were mainly limited to the does in the $300 \mathrm{mg} / \mathrm{kg}$ group. Information available in the literature on fetal effects of vinpocetine administration during gestation in rabbits was limited to a paragraph in the Cholnoky and Dömök ${ }^{47}$ summary of safety tests. Although few details were reported, the authors noted that a small significant reduction in body weight gain in the high-dose group was observed (orally administered, $18 \mathrm{mg} / \mathrm{kg}$ ) with no other evidence of maternal toxicity.

Similar to the rats, in the current rabbit study there was an increase in percent postimplantation loss; however, it was limited to the $300 \mathrm{mg} / \mathrm{kg}$ group and the magnitude of the response was less than in the rat, although significantly increased compared to the vehicle control group. Additionally, a decrease in fetal weight at $300 \mathrm{mg} / \mathrm{kg}$ was observed in both male and female rabbits.

The developmental toxicity of vinpocetine was notable in that related findings, including embryo-fetal lethality and decreased fetal weights, occurred in two species in the absence of overt maternal toxicity. The doses where these effects were significant were $60 \mathrm{mg} / \mathrm{kg}$ in the rat and $300 \mathrm{mg} / \mathrm{kg}$ in the rabbit. In a toxicokinetics study in pregnant rats, significant fetal transfer of vinpocetine occurred following repeat administration of vinpocetine ( 5 and $20 \mathrm{mg} / \mathrm{kg}$ ) daily from GD 6 to GD $18 .^{32}$ In this study, pooled fetal $\mathrm{C}_{\max }$ and AUC values were $\geq 55 \%$ of dam values. 
Additionally, this study identified the rapid metabolism of vinpocetine to its main metabolite, apovincaminic acid, in the dam, with apovincaminic acid levels 2.7-fold higher (based on Cmax and AUC) than vinpocetine in dam plasma. However, apovincaminic acid levels in the fetus were much lower than vinpocetine. Examination of the plasma levels of vinpocetine and apovincaminic acid in dosed rabbits on GD 19 revealed that both compounds were increased in a less than dose-proportional manner. In the limited comparison between the two species, dosenormalized vinpocetine levels in plasma at 1 and 2 hours after administration of the last dose were found to be 7 - to 15 -fold higher in the rats ( 5 and $20 \mathrm{mg} / \mathrm{kg}$ ) compared to the rabbits $(25 \mathrm{mg} / \mathrm{kg})$. In contrast, the dose-normalized apovincaminic acid levels in rabbits were 19- to 75fold higher than rats. These findings indicate a species difference in metabolism, with higher vinpocetine levels in the rat and higher apovincaminic acid levels in the rabbit, and offer a plausible explanation for the species difference observed in fetal mortality. ${ }^{36}$

For humans, the doses of vinpocetine recommended by the Physicians' Desk Reference for Nutritional Supplements and the doses that are suggested on available product labels range from 5 to $60 \mathrm{mg} /$ day ${ }^{23} \mathrm{~A}$ comparison of exposure in rats at $5 \mathrm{mg} / \mathrm{kg}$ to suggested doses in humans (single $10 \mathrm{mg}$ dose) suggested exposure multiples of $\leq 13.6$ and $\leq 8.5$ for $\mathrm{C}_{\max }$ and AUC, respectively, based on blood levels between the two species. ${ }^{32}$ These dose comparisons suggest that exposure to vinpocetine in rats following a repeated $5 \mathrm{mg} / \mathrm{kg}$ dose (as conducted in the current studies) is similar to that following a single $10 \mathrm{mg}$ dose in humans.

Exposure to vinpocetine during gestation in rats and rabbits resulted in evidence of developmental toxicity as exhibited by embryo-fetal death. Additional findings included reductions in fetal weight (rat and rabbit) and malformations and variations of the heart and skeleton in the rat. 


\section{Conclusions}

Under the conditions of this rat prenatal study, there was clear evidence of developmental toxicity of vinpocetine in Sprague Dawley (Hsd:Sprague Dawley ${ }^{\circledR} \mathrm{SD}^{\circledR}$ ) rats attributable to increased postimplantation loss and increased incidences of ventricular septum defects, thoracolumbar ribs (full), and incomplete ossification of the thoracic centrum in the absence of overt maternal toxicity. 


\section{References}

1. World of Chemicals. Vinpocetine. India: Kimberlite Softwares Pvt. Ltd.; 2017. http://www.worldofchemicals.com/chemicals/chemical-properties/vinpocetine.html

2. Szabó L, Kalaus G, Szántay C. Synthesis of vinca alkaloids and related compounds, $X V^{1)}$ a new synthetic route to (+)-vincaminic and (+)-apovincaminic esters. Arch Pharm. 1983; 316:629-638. http://dx.doi.org/10.1002/ardp.19833160709

3. Kuge Y, Nakazawa H, Kometani T, Sugaya T, Mochida K, Tomioka S. A facile one-pot synthesis of vinpocetine. Synth Commun. 1994; 24(6):759-766.

http://dx.doi.org/10.1080/00397919408011297

4. Linnea SA. Vinpocetine. Riazzino (TI), Switzerland: Linnea SA; 2017.

https://www.linnea.ch/products.php?vinpocetine [Accessed: July 10, 2017]

5. Mondelo FC, inventor. Process for the obtention of the ethyl ester of the apovincaminic acid. United States patent 4,870,178; 1989

6. Bereczki D, Fekete I. Vinpocetine for acute ischemic stroke. Stroke. 2008; 39(8):2404-2405. http://dx.doi.org/10.1161/STROKEAHA.108.514174

7. Manconi EBFPF, Binaghi F, Pitzus F. A double-blind clinical trial of vinpocetine in the treatment of cerebral insufficiency of vascular and degenerative origin. Curr Ther Res. 1986; 40(4):702-709.

8. Peruzza M, DeJacobis M. A double-blind placebo controlled evaluation of the efficacy and safety of vinpocetine in the treatment of patients with chronic vascular or degenerative senile cerebral dysfunction. Adv Ther. 1986; 3:201-209.

9. Thal LJ, Salmon DP, Lasker B, Bower D, Klauber MR. The safety and lack of efficacy of vinpocetine in Alzheimer's disease. J Am Geriatr Soc. 1989; 37(6):515-520.

http://dx.doi.org/10.1111/j.1532-5415.1989.tb05682.x

10. Feigin VL, Doronin BM, Popova TF, Gribatcheva EV, Tchervov DV. Vinpocetine treatment in acute ischaemic stroke: A pilot single-blind randomized clinical trial. Eur J Neurol. 2001; 8(1):81-85. http://dx.doi.org/10.1046/j.1468-1331.2001.00181.x

11. Szatmári S, Whitehouse P. Vinpocetine for cognitive impairment and dementia. Cochrane Database Syst Rev. 2003; (3).

12. Ley BM. Vinpocetine: Boost your brain power with periwinkle extract. Detriot Lakes, MN:

B.L. Publications; 2000. p. 48.

13. South C. Clayton's health facts: Vinpocetine. Boise, ID: Bodybuilding.com, LLC; 2007. https://web.archive.org/web/20130512171026/http:/www.bodybuilding.com/fun/southfacts_vin. $\underline{\mathrm{htm}}$

14. Gedeon Richter Ltd. Cavinton In: Chemical Works of Gedeon Richter Ltd. Budapest, Hungary: Gedeon Richter Ltd; 1984. p. 360-363. 
15. Taiji H, Kanzaki J. Clinical study of vinpocetine in the treatment of vertigo. Jpn Pharmacol Ther. 1986; 14(577):89.

16. Truss MC, Stief CG, Ückert S, Becker AJ, Schultheiss D, Machtens S, Jonas U. Initial clinical experience with the selective phosphodiesterase-I isoenzyme inhibitor vinpocetine in the treatment of urge incontinence and low compliance bladder. World J Urol. 2000; 18(6):439-443. http://dx.doi.org/10.1007/PL00007088

17. Thorne Research Inc. Vinpocetine. Altern Med Rev. 2002; 7(3):240-243.

18. Sitges M, Aldana BI, Reed RC. Effect of the anti-depressant sertraline, the novel anti-seizure drug vinpocetine and several conventional antiepileptic drugs on the epileptiform EEG activity induced by 4-aminopyridine. Neurochem Res. 2016; 41(6):1365-1374.

http://dx.doi.org/10.1007/s11064-016-1840-1

19. Crosby MG, Bennett RM, inventors. Compositions and methods for enhancing or treating female sexual response. United States patent 6,737,084 B2; 2004

20. Crosby MG, Bennett RM, inventors. Compositions and methods for enhancing and treating female sexual response. United States patent 8,128,972 B2; 2012

21. Luciano J, inventor. Dietary supplement and a method to enhance sleep and lucid dreaming. United States patent 8,092,840 B2; 2012

22. Misra AR, Gandhi NI, Bajaj MR, Shah BB, Samant RS, Rana H, inventors. Intranasal delivery to improve the performance of children suffering from dyslexia. World Intellectual Property Organization, International Bureau. International Publication Number WO 2011/055383 A2; 2011

23. Hendler SS, Rorvik D. Vinpocetine In: PDR for Nutritional Supplements. Montvale, NJ: Thomson Healthcare; 2001. p. 460.

24. Avula B, Chittiboyina AG, Sagi S, Wang YH, Wang M, Khan IA, Cohen PA. Identification and quantification of vinpocetine and picamilon in dietary supplements sold in the United States. Drug Test Anal. 2016; 8(3-4):334-343. http://dx.doi.org/10.1002/dta.1853

25. Federal Register. Request for comment on the status of vinpocetine. Washington, DC: U.S. Department of Health and Human Services, U.S. Food and Drug Administration; 2016. Docket No. FDA-2016-N-2523. Federal Register Vol. 81, No. 173.

26. Vereczkey L. Pharmacokinetics and metabolism of vincamine and related compounds. Eur J Drug Metab Pharmacokinet. 1985; 10(2):89-103. http://dx.doi.org/10.1007/BF03189702

27. Xia H-M, Su L-N, Guo J-W, Liu G-M, Pang Z-Q, Jiang X-G, Chen J. Determination of vinpocetine and its primary metabolite, apovincaminic acid, in rat plasma by liquid chromatography-tandem mass spectrometry. J Chromatogr B. 2010; 878(22):1959-1966. http://dx.doi.org/10.1016/j.jchromb.2010.05.029

28. Sozański T, Magdalan J, Trocha M, Szumny A, Merwid-Ląd A, Słupski W, KaraźniewiczŁada M, Kiełbowicz G, Ksiądzyna D, Szeląg A. Omeprazole does not change the oral 
bioavailability or pharmacokinetics of vinpocetine in rats. Pharmacol Rep. 2011; 63(5):12581263. http://dx.doi.org/10.1016/S1734-1140(11)70648-X

29. Vereczkey L, Szporny L. Metabolism of ethyl apovincaminate in the rat. Arzneimittelforschung. 1976; 26(10a):1933-1938.

30. Vereczkey L, Szentirmay Z, Szporny L. Kinetic metabolism of vinpocetine in the rat. Arzneimittelforschung. 1979; 29(6):953-956.

31. Chernoff N, Rogers JM. Hypoxia and the edema syndrome: Elucidation of a mechanism of teratogenesis. Birth Defects Res B: Dev Reprod Toxicol. 2010; 89(4):300-303. http://dx.doi.org/10.1002/bdrb.20258

32. Waidyanatha S, Toy H, South N, Gibbs S, Mutlu E, Burback B, McIntyre BS, Catlin N. Systemic exposure of vinpocetine in pregnant Sprague Dawley rats following repeated oral exposure: An investigation of fetal transfer. Toxicol Appl Pharmacol. 2018; 338:83-92. http://dx.doi.org/10.1016/j.taap.2017.11.011

33. Nie S, Fan X, Peng Y, Yang X, Wang C, Pan W. In vitro and in vivo studies on the complexes of vinpocetine with hydroxypropyl- $\beta$-cyclodextrin. Arch Pharm Res. 2007; 30(8):991-1001. http://dx.doi.org/10.1007/BF02993968

34. Ribeiro LSS, Falcão AC, Patrício JAB, Ferreira DC, Veiga FJB. Cyclodextrin multicomponent complexation and controlled release delivery strategies to optimize the oral bioavailability of vinpocetine. J Pharm Sci. 2007; 96(8):2018-2028. http://dx.doi.org/10.1002/jps.20294

35. Xu H, He L, Nie S, Guan J, Zhang X, Yang X, Pan W. Optimized preparation of vinpocetine proliposomes by a novel method and in vivo evaluation of its pharmacokinetics in New Zealand rabbits. J Control Release. 2009; 140(1):61-68. http://dx.doi.org/10.1016/j.jconrel.2009.07.014

36. Catlin N, Waidyanatha S, Mylchreest E, Miller-Pinsler L, Cunny H, Foster P, Sutherland V, McIntyre B. Embryo-fetal development studies with the dietary supplement vinpocetine in the rat and rabbit. Birth Defects Res. 2018; 110(10):883-896. http://dx.doi.org/10.1002/bdr2.1207

37. Szakács T, Veres Z, Vereczkey L. In vitro-in vivo correlation of the pharmacokinetics of vinpocetine. Pol J Pharmacol. 2001; 53(6):623-628.

38. Vereczkey L, Czira G, Tamás J, Szentirmay Z, Botár Z, Szporny L. Pharmacokinetics of vinpocetine in humans. Arzneimittelforschung. 1979; 29(6):957-960.

39. Grandt R, Beitinger H, Schaltenbrand R, Braun W. Vinpocetine pharmacokinetics in elderly subjects. Arzneimittelforschung. 1989; 39(12):1599-1602.

40. Miskolczi P, Kozma K, Polgar M, Vereczkey L. Pharmacokinetics of vinpocetine and its main metabolite apovincaminic acid before and after the chronic oral administration of vinpocetine to humans. Eur J Drug Metab Pharmacokinet. 1990; 15(1):1-5.

http://dx.doi.org/10.1007/BF03190120 
41. Lohmann A, Dingler E, Sommer W, Schaffler K, Wober W, Schmidt W. Bioavailability of vinpocetine and interference of the time of application with food intake. Arzneimittelforschung. 1992; 42(7):914-917.

42. Abd Elbary A, Foda N, El-Gazayerly O, El Khatib M. Reversed phase liquid chromatographic determination of vinpocetine in human plasma and its pharmacokinetic application. Anal Lett. 2002; 35(6):1041-1054. http://dx.doi.org/10.1081/AL-120004554

43. Gulyás B, Halldin C, Sandell J, Karlsson P, Sóvágó J, Kárpáti E, Kiss B, Vas A, Cselényi Z, Farde L. PET studies on the brain uptake and regional distribution of [11C] vinpocetine in human subjects. Acta Neurol Scand. 2002; 106(6):325-332. http://dx.doi.org/10.1034/j.16000404.2002.01302.x

44. Gulyás B, Halldin C, Sóvágó J, Sandell J, Cselényi Z, Vas Á, Kiss B, Kárpáti E, Farde L. Drug distribution in man: A positron emission tomography study after oral administration of the labelled neuroprotective drug vinpocetine. Eur J Nucl Med Mol Imag. 2002; 29(8):1031-1038. http://dx.doi.org/10.1007/s00259-002-0823-4

45. Miskolczi P, Vereczkey L, Szalay L, Göndöcs C. Effect of age on the pharmacokinetics of vinpocetine (Cavinton) and apovincaminic acid. Eur J Clin Pharmacol. 1987; 33(2):185-189. http://dx.doi.org/10.1007/BF00544565

46. Vlase L, Bodiu B, Leucuta SE. Pharmacokinetics and comparative bioavailability of two vinpocetine tablet formulations in healthy volunteers by using the metabolite apovincaminic acid as pharmacokinetic parameter. Arzneimittelforschung. 2005; 55(11):664-668.

47. Cholnoky E, Dömök LI. Summary of safety tests of ethyl apovincaminate. Arzneimittelforschung. 1976; 26(10a):1938-1944.

48. Pálosi E, Szporny L. Effects of ethyl apovincaminate on the central nervous system. Arzneimittelforschung. 1976; 26(10a):1926-1929.

49. Ebi O. Open-labeled phase III clinical trials with vinpocetine in Japan. Ther Hung. 1985; 33(1):41-49.

50. National Toxicology Program (NTP). DART-03: Growth and clinical finding tables (I), pathology tables (PA), developmental and reproductive tables (R) from NTP developmental and reproductive toxicity studies. Research Triangle Park, NC. 2019.

http://dx.doi.org/10.22427/NTP-DATA-002-03277-0000-0000-1

51. Chernoff N, Setzer RW, Miller DB, Rosen MB, Rogers JM. Effects of chemically induced maternal toxicity on prenatal development in the rat. Teratology. 1990; 42(6):651-658. http://dx.doi.org/10.1002/tera.1420420610

52. U.S. Environmental Protection Agency (USEPA). Guidelines for developmental toxicity risk assessment. Washington, DC: U.S. Environmental Protection Agency, Risk Assessment Forum; 1991. EPA Document No. EPA/600/FR-91/001.

53. Tyl RW. Commentary on the role of maternal toxicity on developmental toxicity. Birth Defects Res B: Dev Reprod Toxicol. 2012; 95(3):262-266. http://dx.doi.org/10.1002/bdrb.21015 
54. Organisation for Economic Co-operation and Development (OECD). OECD guideline for the testing of chemicals: Proposal for updating guideline 414: Prenatal developmental toxicity study. Paris, France: Organisation for Economic Co-operation and Development; 2001. https://ntp.niehs.nih.gov/iccvam/suppdocs/feddocs/oecd/oecd_gl414.pdf

55. Makris SL, Solomon HM, Clark R, Shiota K, Barbellion S, Buschmann J, Ema M, Fujiwara M, Grote K, Hazelden KP. Terminology of developmental abnormalities in common laboratory mammals (version 2). Congenit Anom. 2009; 49(3):123-246. http://dx.doi.org/10.1111/j.17414520.2009.00239.x

56. Suckow M, Stevens K, Wilson R. The laboratory rabbit, guinea pig, hamster, and other rodents. Amsterdam, Netherlands: Elsevier, Academic Press; 2012.

57. Suckow MA, Weisbroth SH, Franklin CL. The laboratory rat, 2nd ed. Amsterdam, Netherlands: Elsevier; 2006.

58. Hayes AW, Kruger CL. Hayes’ principles and methods of toxicology. 6th ed. Boca Raton, FL: CRC Press; 2014. p. 1670-1672.

59. Salewski E. Färbemethode zum makroskopischen nachweis von implantationsstellen am uterus der ratte. Naunyn-Schmiedeberg's Arch Pharmacol. 1964; 247(4):367.

http://dx.doi.org/10.1007/BF02308461

60. Tyl RW, Marr MC. Developmental toxicity texting - methodology. Developmental and Reproductive Toxicology. 2nd ed. New York, NY: Taylor and Francis Group; 2006. p. 201-261.

61. Staples RE. Detection of visceral alterations in mammalian fetuses. Teratology. 1974; 9:A37A38.

62. Stuckhardt JL, Poppe SM. Fresh visceral examination of rat and rabbit fetuses used in teratogenicity testing. Teratog Carcinog Mutagen. 1984; 4(2):181-188.

http://dx.doi.org/10.1002/tcm.1770040203

63. Thompson RF. Chapter 4: Basic neuroanatomy. Foundations of Physiological Psychology. New York, NY: Harper and Row Publishers; 1967. p. 79-82.

64. Marr MC, Price CJ, Myers CB, Morrissey RE. Developmental stages of the CD®(SpragueDawley) rat skeleton after maternal exposure to ethylene glycol. Teratology. 1992; 46(2):169181. http://dx.doi.org/10.1002/tera.1420460210

65. Dunnett CW. A multiple comparison procedure for comparing several treatments with a control. J Am Stat Assoc. 1955; 50(272):1096-1121.

http://dx.doi.org/10.1080/01621459.1955.10501294

66. Williams DA. A test for differences between treatment means when several dose levels are compared with a zero dose control. Biometrics. 1971; 27:103-117.

http://dx.doi.org/10.2307/2528930

67. Williams DA. The comparison of several dose levels with a zero dose control. Biometrics. 1972; 28:519-531. http://dx.doi.org/10.2307/2556164 
68. Shirley E. A non-parametric equivalent of Williams' test for contrasting increasing dose levels of a treatment. Biometrics. 1977; 33:386-389. http://dx.doi.org/10.2307/2529789

69. Williams DA. A note on Shirley's nonparametric test for comparing several dose levels with a zero-dose control. Biometrics. 1986; 42:183-186. http://dx.doi.org/10.2307/2531254

70. Dunn OJ. Multiple comparisons using rank sums. Technometrics. 1964; 6(3):241-252. http://dx.doi.org/10.1080/00401706.1964.10490181

71. Jonckheere AR. A distribution-free k-sample test against ordered alternatives. Biometrika. 1954; 41(1/2):133-145. http://dx.doi.org/10.2307/2333011

72. Dixon WJ, Massey FJ, Jr. Introduction to statistical analysis, 2nd ed. McGraw-Hill Book Company, Inc: New York, NY; 1957. p. 276-278, 412.

73. Hsu JC. The factor analytic approach to simultaneous inference in the general linear model. J Comput Graph Stat. 1992; 1(2):151-168.

74. Armitage P. Tests for linear trends in proportions and frequencies. Biometrics. 1955; 11(3):375-386. http://dx.doi.org/10.2307/3001775

75. Gart JJ, Chu KC, Tarone RE. Statistical issues in interpretation of chronic bioassay tests for carcinogenicity. J Natl Cancer Inst. 1979; 62(4):957-974.

76. Zorrilla EP. Multiparous species present problems (and possibilities) to developmentalists. Dev Psychobiol. 1997; 30(2):141-150. https://doi.org/10.1002/(SICI)10982302(199703)30:2\%3C141::AID-DEV5\%3E3.0.CO;2-Q

77. Pendergast JF, Gange SJ, Lindstrom MJ. Correlated binary data In: Armitage P, Colton T, editors. Encyclopedia of Biostatistics. Hoboken, NJ: John Wiley; 2005. http://dx.doi.org/10.1002/0470011815.b2a10018

78. Li B, Lingsma HF, Steyerberg EW, Lesaffre E. Logistic random effects regression models: A comparison of statistical packages for binary and ordinal outcomes. BMC Med Res Methodol. 2011; 11(1):77. http://dx.doi.org/10.1186/1471-2288-11-77

79. Scott Jr WJ, Resnick E, Hummler H, Clozel JP, Bürgin H. Cardiovascular alterations in rat fetuses exposed to calcium channel blockers. Reprod Toxicol. 1997; 11(2-3):207-214. http://dx.doi.org/10.1016/S0890-6238(97)00008-7

80. DeSesso JM. Comparative features of vertebrate embryology. Developmental and Reproductive Toxicology: A Practical Approach. Boca Raton, FL: CRC Press; 2006. p. 147-197.

81. Roguin N, Du Z-D, Barak M, Nasser N, Hershkowitz S, Milgram E. High prevalence of muscular ventricular septal defect in neonates. J Am Coll Cardiol. 1995; 26(6):1545-1548. http://dx.doi.org/10.1016/0735-1097(95)00358-4

82. Solomon HM, Wier PJ, Fish CJ, Hart TK, Johnson CM, Posobiec LM, Gowan CC, Maleeff $\mathrm{BE}$, Kerns WD. Spontaneous and induced alterations in the cardiac membranous ventricular septum of fetal, weanling, and adult rats. Teratology. 1997; 55(3):185-194. https://doi.org/10.1002/(SICI)1096-9926(199703)55:3\%3C185::AID-TERA3\%3E3.0.CO;2-1 
83. Du Z-D, Roguin N, Wu X-J. Spontaneous closure of muscular ventricular septal defect identified by echocardiography in neonates. Cardiol Young. 1998; 8(4):500-505. http://dx.doi.org/10.1017/S1047951100007174

84. Paladini D, Palmieri S, Lamberti A, Teodoro A, Martinelli P, Nappi C. Characterization and natural history of ventricular septal defects in the fetus. Ultrasound Obstet Gynecol. 2000; 16(2):118-122. http://dx.doi.org/10.1046/j.1469-0705.2000.00202.x

85. Hoffman JIE, Kaplan S. The incidence of congenital heart disease. J Am Coll Cardiol. 2002; 39(12):1890-1900. http://dx.doi.org/10.1016/S0735-1097(02)01886-7

86. Fleeman TL, Cappon GD, Hurtt ME. Postnatal closure of membranous ventricular septal defects in Sprague-Dawley rat pups after maternal exposure with trimethadione. Birth Defects Res B: Dev Reprod Toxicol. 2004; 71(3):185-190. http://dx.doi.org/10.1002/bdrb.20011

87. Branch S, Rogers JM, Brownie CF, Chernoff N. Supernumerary lumbar rib: Manifestation of basic alteration in embryonic development of ribs. J Appl Toxicol. 1996; 16(2):115-119. https://doi.org/10.1002/(SICI)1099-1263(199603)16:2\%3C115::AID-JAT309\%3E3.0.CO;2-H

88. Foulon O, Girard H, Pallen C, Urtizberea M, Repetto-Larsay M, Blacker AM. Induction of supernumerary ribs with sodium salicylate. Reprod Toxicol. 1999; 13(5):369-374. http://dx.doi.org/10.1016/S0890-6238(99)00029-5

89. Rogers JM, Francis BM, Barbee BD, Chernoff N. Developmental toxicity of bromoxynil in mice and rats. Fundam Appl Toxicol. 1991; 17(3):442-447. http://dx.doi.org/10.1016/0272-

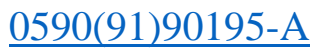

90. Narotsky MG, Francis EZ, Kavlock RJ. Developmental toxicity and structure-activity relationships of aliphatic acids, including dose-response assessment of valproic acid in mice and rats. Fundam Appl Toxicol. 1994; 22(2):251-265. http://dx.doi.org/10.1006/faat.1994.1029

91. Beyer PE, Chernoff N. The induction of supernumerary ribs in rodents: Role of the maternal stress. Teratog Carcinog Mutagen. 1986; 6(5):419-429.

http://dx.doi.org/10.1002/tcm.1770060508

92. Chernoff N, Kavlock RJ, Beyer PE, Miller D. The potential relationship of maternal toxicity, general stress, and fetal outcome. Teratog Carcinog Mutagen. 1987; 7(3):241-253.

http://dx.doi.org/10.1002/tcm.1770070306

93. Wickramaratne GA. The post-natal fate of supernumerary ribs in rat teratogenicity studies. J Appl Toxicol. 1988; 8(2):91-94. http://dx.doi.org/10.1002/jat.2550080205

94. Chernoff N, Rogers JM, Turner CI, Francis BM. Significance of supernumerary ribs in rodent developmental toxicity studies: Postnatal persistence in rats and mice. Fundam Appl Toxicol. 1991; 17(3):448-453. http://dx.doi.org/10.1016/0272-0590(91)90196-B

95. Foulon O, Jaussely C, Repetto M, Urtizberea M, Blacker AM. Postnatal evolution of supernumerary ribs in rats after a single administration of sodium salicylate. J Appl Toxicol. 2000; 20(3):205-209. https://doi.org/10.1002/(SICI)1099-1263(200005/06)20:3\%3C205::AIDJAT635\%3E3.0.CO;2-G 
96. Khera KS. Common fetal aberrations and their teratologic significance: A review. Fundam Appl Toxicol. 1981; 1(1):13-18. http://dx.doi.org/10.1093/toxsci/1.1.13

97. Ujházy E, Preinerová M, Jozefík M. Effects of cyclophosphamide on the prenatal development of the Swiss strain mice. Neoplasma. 1979; 26(5):529-537.

98. Jeyaseelan N, Singh S. Forelimb malformation in rats caused by cyclophosphamide. Acta Orthop Scand. 1984; 55(6):643-646. http://dx.doi.org/10.3109/17453678408992414

99. Matalon ST, Ornoy A, Lishner M. Review of the potential effects of three commonly used antineoplastic and immunosuppressive drugs (cyclophosphamide, azathioprine, doxorubicin on the embryo and placenta). Reprod Toxicol. 2004; 18(2):219-230.

http://dx.doi.org/10.1016/j.reprotox.2003.10.014

100. Sadtler's know-it-all IR spectral library. Retrieved from Bio-Rad Informatics "KnowItAll" System V.9.5 (No. 61,553). Hercules, CA: Bio-Rad; 2014.

101. The Merck Index. 14th ed. Whitehouse Station, NJ: Merck \& Co., Inc.; 2006. p. 1719.

102. Hummel Surfactants Library. IR - Surfactants, Hummel - Wiley. Product Code - 465700, Spectra - 1,030. Bio-Rad Spectral Databases; 2018.

http://www.knowitall.com/literature/english/databases/465700-Bio-

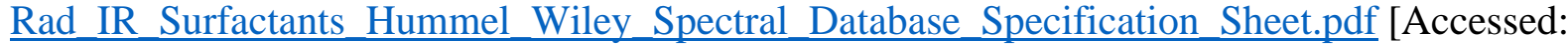

August 28, 2018]

103. Socrates G. Infrared Characteristic Group Frequencies (ICGF). 2nd ed. New York, NY:

John Wiley \& Sons. 1994. 


\section{Appendix A. Chemical Characterization and Dose Formulation Studies}

\section{Table of Contents}

A.1. Procurement and Characterization

A-2

A.2. Preparation and Analysis of Dose Formulations.................................................... A -3

\section{Tables}

Table A-1. Gas Chromatography Systems Used in the Gavage Studies of Vinpocetine A-4

Table A-2. Preparation and Storage of Dose Formulations in the Gavage Studies of Vinpocetine in Rats and Rabbits A-5

Table A-3. Results of Analyses of Dose Formulations Administered to Female Rats in the Dose Range-finding Gavage Study of Vinpocetine

Table A-4. Results of Analyses of Dose Formulations Administered to Female Rats in the Prenatal Developmental Toxicity Gavage Study of Vinpocetine...

Table A-5. Results of Analyses of Dose Formulations Administered to Female Rabbits in the Dose Range-finding Gavage Study of Vinpocetine A-6

\section{Figures}

Figure A-1. Fourier Transform Infrared Absorption Spectrum of Vinpocetine A-7

Figure A-2. Proton Nuclear Magnetic Resonance Spectrum of Vinpocetine 


\section{A.1. Procurement and Characterization}

\section{A.1.1. Vinpocetine}

Vinpocetine was obtained from Maypro Industries, LLC (Purchase, NY) in one lot (VA201211001) that was used in the dose range-finding studies in rats and rabbits and the prenatal developmental toxicity gavage study in rats. Identity, purity, and stability analyses were conducted by the analytical chemistry laboratory at Battelle (Columbus, $\mathrm{OH}$ ) for the study laboratory at Southern Research (Birmingham, AL). Reports on analyses performed in support of the vinpocetine studies are on file at the National Institute of Environmental Health Sciences (NIEHS).

Lot VA201211001 of the chemical, a white crystalline powder, was identified as vinpocetine using Fourier transform infrared (FTIR) spectroscopy, proton and carbon-13 nuclear magnetic resonance (NMR) spectroscopy, and gas chromatography (GC) with mass spectrometry detection. The optical activity analysis indicated an average rotation of $+131.6^{\circ}$, which is consistent with the optical rotation of vinpocetine. FTIR spectra were consistent with a literature spectrum $^{100}$ and the structure of vinpocetine. The proton and carbon-13 NMR spectra were consistent with those expected for the proposed structure of vinpocetine and with the ACD-predicted (Advanced Chemistry Development) spectra. Representative FTIR and proton NMR spectra are presented in Figure A-1 and Figure A-2, respectively. The mass spectrum of the major peak from the gas chromatographic analysis was consistent with the identity of vinpocetine; a single impurity observed in this analysis was tentatively identified as apovincamine, a structurally similar compound. Optical activity analysis of the bulk chemical conducted by Exova (Santa Fe Springs, CA) indicated an average rotation of $+131.6^{\circ}$, consistent with the rotation range specified by the manufacturer.

Karl Fischer titration and elemental analyses of lot VA201211001 were conducted by Galbraith Laboratories, Inc. (Knoxville, TN). Additional elemental analyses (72 elements; sodium through uranium) were conducted by Elemental Analysis, Inc. (Lexington, KY) using proton-induced Xray emission (PIXE) spectroscopy. The purity of the test chemical was determined using melting point analysis conducted on a Perkin-Elmer (Shelton, CT) Diamond differential scanning calorimetry (DSC) instrument scanning from $140^{\circ} \mathrm{C}$ to $152^{\circ} \mathrm{C}$ at a rate of $1^{\circ} \mathrm{C}$ per minute. Purity profiles were obtained using high-performance liquid chromatography (HPLC) with ultraviolet (UV) detection and GC with flame ionization detection (FID) by system A (Table A-1). The HPLC system included an Agilent 1100 instrument (Agilent, Santa Clara, CA), a C18, 250 $\mathrm{mm} \times 4.6 \mathrm{~mm}, 4 \mu \mathrm{m}$ particle size column (Phenomenex, Torrance, CA), mobile phases (A) 10:90 (v:v) methanol:0.05 M ammonium acetate (pH 8.0) and (B) 90:10 (v:v) methanol:0.05 M ammonium acetate ( $\mathrm{pH} 8.0)$, an isocratic gradient of $10 \% \mathrm{~A}$ and $90 \% \mathrm{~B}$, UV detection at $230 \mathrm{~nm}$, and a flow rate of $0.75 \mathrm{~mL} /$ minute. Screening for selected volatiles in the test chemical was performed using standard addition with authentic standards of non-halogenated (hexane, benzene, diethyl ether, acetone, 1,4-dioxane, and toluene), and halogenated (chloroform, carbon tetrachloride, trichloroethylene, and methylene chloride) volatile compounds using headspace GC/FID by system B.

Karl Fischer titration indicated less than $0.07 \%$ water. For lot VA201211001, elemental analyses for carbon, hydrogen, nitrogen, and oxygen agreed with the theoretical values for vinpocetine; PIXE analyses indicated no inorganic impurities greater than $0.1 \%$. Melting point analysis by 
DSC averaged $149.88^{\circ} \mathrm{C}$, which is consistent with a literature reference range $\left(147^{\circ} \mathrm{C}\right.$ to $153^{\circ} \mathrm{C}^{101}$ ) and differential scanning calorimetry indicated a purity of $99.9 \%$. HPLC/UV indicated one major peak (99.5\% of the total peak area) and two impurities greater than $0.1 \%$ of the total peak area $(0.17 \%$ and $0.28 \%)$. By comparison to retention times of authentic standards of structurally similar compounds, the larger impurity peak was tentatively identified as apovincamine. GC/FID indicated one major peak (99.3\% of the total peak area) and one reportable impurity ( $0.67 \%$ of the total peak area); retention time comparison indicated tentative identification of this impurity as apovincamine. Screening for volatiles indicated the presence of 0.018\% methylene chloride. The overall purity of lot VA201211001 was determined to be greater than $99.3 \%$.

Stability studies of the bulk chemical were performed using GC/FID by system A. These studies indicated that vinpocetine was stable as a bulk chemical for at least 14 days when stored in sealed amber glass vials at temperatures up to $60^{\circ} \mathrm{C}$. To ensure stability, the bulk chemical was stored by the analytical chemistry laboratory at room temperature in sealed double plastic bags in a plastic bucket. Reanalysis of the bulk chemical was performed twice by the analytical chemistry laboratory during the studies with GC/FID by system C and no degradation of the bulk chemical was detected.

\section{A.1.2. Methylcellulose}

Methylcellulose was obtained from Spectrum Chemical Manufacturing Corporation (Gardena, CA) in two lots (2CB0045 and 2DH0326); lot 2CB0045 was used in the dose range-finding study in rats, and lot 2DH0326 was used in the prenatal developmental toxicity study in rats and the dose range-finding study in rabbits. Lots 2DH0326 and 2CB0045 were identified by the analytical chemistry laboratory as methylcellulose using FTIR spectroscopy; sample spectra were in good agreement with the structure of methylcellulose and a literature reference ${ }^{102}$ and cited absorptions were consistent with the structure of methylcellulose. ${ }^{103}$ The methoxy content of lots 2DH0326 and 2CB0045 were determined by Galbraith Laboratories, Inc.; the results of duplicate determinations for methoxy group content were within the acceptance limits of $26.0 \%$ to $33.0 \%$.

\section{A.2. Preparation and Analysis of Dose Formulations}

The dose formulations were prepared once for each study by mixing vinpocetine with $0.5 \%$ aqueous methylcellulose solution to give the required concentrations (Table A-2). The dose formulations were stored at room temperature in clear glass bottles with Teflon ${ }^{\circledR}$-lined lids in sealed amber plastic bags for up to 38 days.

The analytical chemistry laboratory performed homogeneity studies of 0.1 and $200 \mathrm{mg} / \mathrm{mL}$ formulations, syringeability studies for 18- and 22-gauge gavage needles using the $200 \mathrm{mg} / \mathrm{mL}$ formulation, resuspendability studies of the $200 \mathrm{mg} / \mathrm{mL}$ formulation, and stability studies of the $0.1 \mathrm{mg} / \mathrm{mL}$ formulation; all of these analyses were conducted using GC/FID by system D (Table A-1). Homogeneity, syringeability, and resuspendability were confirmed, and stability was confirmed for at least 42 days for dose formulations stored in clear glass bottles with Teflon ${ }^{\circledR}$-lined lids packaged in sealed amber plastic bags at room temperature and for 3 hours under simulated animal room conditions (Table A-2). 
Periodic analyses of the dose formulations of vinpocetine were conducted by the analytical chemistry laboratory using GC/FID by system D. During the dose range-finding study in rats, the dose formulations were analyzed once; all five dose formulations analyzed and used were within $10 \%$ of the target concentrations (Table A-3). Animal room samples of these dose formulations were also analyzed; four of five were within $10 \%$ of the target concentrations. During the prenatal developmental toxicity study in rats, the dose formulations were analyzed once; animal room samples of these dose formulations were also analyzed (Table A-4). All three dose formulations and all three animal room samples were within $10 \%$ of the target concentrations. During the dose range-finding study in rabbits, the dose formulations were analyzed once (Table A-5). Of the dose formulations analyzed during the study, all eight were within $10 \%$ of the target concentrations; two of four animal room samples were within $10 \%$ of the target concentrations.

Table A-1. Gas Chromatography Systems Used in the Gavage Studies of Vinpocetine ${ }^{\text {a }}$

\begin{tabular}{|c|c|c|c|}
\hline Detection System & Column & Carrier Gas & $\begin{array}{c}\text { Oven Temperature } \\
\text { Program }\end{array}$ \\
\hline \multicolumn{4}{|l|}{ System A } \\
\hline Flame Ionization & $\begin{array}{l}\text { Rtx }^{\circledR}-5,30 \mathrm{~m} \times 0.32 \mathrm{~mm}, \\
0.5 \mu \mathrm{m} \text { film (Restek, } \\
\text { Bellefonte, PA) }\end{array}$ & Helium at $\sim 2 \mathrm{~mL} /$ minute & $\begin{array}{l}100^{\circ} \mathrm{C} \text { to } 150^{\circ} \mathrm{C} \text { at } \\
10^{\circ} \mathrm{C} / \text { minute, then } \\
15^{\circ} \mathrm{C} / \text { minute to } 300^{\circ} \mathrm{C} \text {, } \\
\text { held for } 15 \text { minutes }\end{array}$ \\
\hline \multicolumn{4}{|l|}{ System B } \\
\hline Flame Ionization & $\begin{array}{l}\text { Rtx }^{\circledR}-624,30 \mathrm{~m} \times 0.53 \mathrm{~mm} \text {, } \\
3.0 \mu \mathrm{m} \text { film (Restek) }\end{array}$ & Helium at $\sim 5 \mathrm{~mL} /$ minute & $\begin{array}{l}35^{\circ} \mathrm{C} \text { for } 14 \text { minutes, then } \\
15^{\circ} \mathrm{C} / \text { minute to } 40^{\circ} \mathrm{C} \text {, held } \\
\text { for } 3 \text { minutes, then } \\
15^{\circ} \mathrm{C} / \text { minute to } 240^{\circ} \mathrm{C} \text {, } \\
\text { held for } 2 \text { minutes }\end{array}$ \\
\hline \multicolumn{4}{|l|}{ System C } \\
\hline Flame Ionization & $\begin{array}{l}\mathrm{ZB}-5,30 \mathrm{~m} \times 0.32 \mathrm{~mm} \text {, } \\
0.25 \mu \mathrm{m} \text { film } \\
\text { (Phenomenex, Torrance, } \\
\text { CA) }\end{array}$ & Helium at $\sim 2 \mathrm{~mL} /$ minute & $\begin{array}{l}100^{\circ} \mathrm{C} \text { to } 150^{\circ} \mathrm{C} \text { at } \\
10^{\circ} \mathrm{C} / \text { minute, then } \\
15^{\circ} \mathrm{C} / \text { minute to } 300^{\circ} \mathrm{C} \text {, } \\
\text { held for } 15 \text { minutes }\end{array}$ \\
\hline \multicolumn{4}{|l|}{ System D } \\
\hline Flame Ionization & $\begin{array}{l}\text { Rtx }^{\circledR}-5,30 \mathrm{~m} \times 0.32 \mathrm{~mm}, \\
0.5 \mu \mathrm{m} \text { film (Restek) }\end{array}$ & Helium at $\sim 2 \mathrm{~mL} /$ minute & $\begin{array}{l}120^{\circ} \mathrm{C} \text { to } 150^{\circ} \mathrm{C} \text { at } \\
10^{\circ} \mathrm{C} / \text { minute, then } \\
15^{\circ} \mathrm{C} / \text { minute to } 300^{\circ} \mathrm{C} \text {, } \\
\text { held for } 15 \text { minutes }\end{array}$ \\
\hline
\end{tabular}

aThe gas chromatographs were manufactured by Agilent Technologies, Inc. (Santa Clara, CA). 
Table A-2. Preparation and Storage of Dose Formulations in the Gavage Studies of Vinpocetine in Rats and Rabbits

Dose Range-Finding and Prenatal Developmental Toxicity Studies

\section{Preparation}

The dosing vehicle was prepared by mixing methylcellulose with heated, deionized water while stirring and then diluting with water to form a $0.5 \%$ solution, which was allowed to cool. The formulations were prepared by adding the appropriate amount of vinpocetine to a small amount of the vehicle in a mixing container and stirring manually to form a paste. The formulations were diluted to $90 \%$ of the final volume with vehicle and stirred with a Silverson mixer (Silverson Machines, Inc., East Longmeadow, MA) at approximately 4,500 rpm for approximately 10 minutes. Formulations were then diluted to final volume with vehicle and stirred with a stir bar on a stir plate with a vigorous vortex for approximately 2 minutes. The dose formulations were prepared once for each study.

\section{Chemical Lot Number}

VA201211001

\section{Maximum Storage Time}

Up to 42 days (dose range-finding study in rats)

Up to 42 days (prenatal developmental toxicity study in rats)

Up to 42 days (dose range-finding study in rabbits)

\section{Storage Conditions}

Stored in clear glass bottles with Teflon ${ }^{\circledR}$-lined lids in sealed amber plastic bags at room temperature

\section{Study Laboratory}

Southern Research (Birmingham, AL)

Table A-3. Results of Analyses of Dose Formulations Administered to Female Rats in the Dose Range-finding Gavage Study of Vinpocetine

\begin{tabular}{lcccc}
\hline Date Prepared & Date Analyzed & $\begin{array}{c}\text { Target } \\
\text { Concentration } \\
(\mathbf{m g} / \mathbf{m L})\end{array}$ & $\begin{array}{c}\text { Determined } \\
\text { Concentration } \\
(\mathbf{m g} / \mathbf{m L})\end{array}$ & $\begin{array}{c}\text { Difference from } \\
\text { Target (\%) }^{\text {(\%) }}\end{array}$ \\
\hline February 10-14, 2014 & February 12, 2014 & 4 & $4.22^{\mathrm{b}}$ & +6 \\
& & 8 & 8.44 & +6 \\
& & 16 & 16.3 & +2 \\
& & 32 & $31.5^{\mathrm{c}}$ & -2 \\
& March 19, 2014 & 64 & $67.1^{\mathrm{b}}$ & +5 \\
& 4 & 4.29 & +7 \\
& 8 & 7.59 & -5 \\
& 16 & 15.2 & -5 \\
& 32 & 32.8 & +3 \\
& 64 & 55.2 & -14 \\
\hline
\end{tabular}

${ }^{\mathrm{a}}$ Results of triplicate analyses except as noted. Dosing volume $=5 \mathrm{~mL} / \mathrm{kg} ; 4 \mathrm{mg} / \mathrm{mL}=20 \mathrm{mg} / \mathrm{kg}, 8 \mathrm{mg} / \mathrm{mL}=40 \mathrm{mg} / \mathrm{kg}$, $16 \mathrm{mg} / \mathrm{mL}=80 \mathrm{mg} / \mathrm{kg}, 32 \mathrm{mg} / \mathrm{mL}=160 \mathrm{mg} / \mathrm{kg}$, and $64 \mathrm{mg} / \mathrm{mL}=320 \mathrm{mg} / \mathrm{kg}$.

bine replicates were analyzed.

'Five replicates were analyzed.

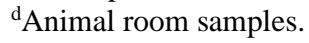


Table A-4. Results of Analyses of Dose Formulations Administered to Female Rats in the Prenatal Developmental Toxicity Gavage Study of Vinpocetine

\begin{tabular}{lcccc}
\hline Date Prepared & Date Analyzed & $\begin{array}{c}\text { Target } \\
\text { Concentration } \\
(\mathbf{m g} / \mathbf{m L})\end{array}$ & $\begin{array}{c}\text { Determined } \\
\text { Concentration } \\
(\mathbf{m g} / \mathbf{m L})\end{array}$ & $\begin{array}{c}\text { Difference from } \\
\text { Target (\%) }\end{array}$ \\
\hline January 5, 2015 & January 8-9, 2015 & 1 & $0.962^{\mathrm{b}}$ & -4 \\
& & 4 & 4.03 & +1 \\
& February 5-6, 2015c & 12 & $11.6^{\mathrm{b}}$ & -3 \\
& & 4 & 0.970 & -3 \\
& & 12 & 3.98 & -1 \\
\hline
\end{tabular}

${ }^{\mathrm{a}}$ Results of triplicate analyses except as noted. Dosing volume $=5 \mathrm{~mL} / \mathrm{kg} ; 1 \mathrm{mg} / \mathrm{mL}=5 \mathrm{mg} / \mathrm{kg}, 4 \mathrm{mg} / \mathrm{mL}=20 \mathrm{mg} / \mathrm{kg}$, and $12 \mathrm{mg} / \mathrm{mL}=60 \mathrm{mg} / \mathrm{kg}$.

${ }^{b}$ Nine replicates were analyzed.

${ }^{\mathrm{c} A n i m a l ~ r o o m ~ s a m p l e s . ~}$

Table A-5. Results of Analyses of Dose Formulations Administered to Female Rabbits in the Dose Range-finding Gavage Study of Vinpocetine

\begin{tabular}{ccccc}
\hline Date Prepared & Date Analyzed & $\begin{array}{c}\text { Target Concentration } \\
\text { (mg/mL) }\end{array}$ & $\begin{array}{c}\text { Determined } \\
\text { Concentration } \\
\text { (mg/mL) }\end{array}$ & $\begin{array}{c}\text { Difference from } \\
\text { Target (\%) }\end{array}$ \\
\hline April 13, 2015 & April 14-16, 2015 & 5 & $5.02^{\mathrm{b}}$ & 0 \\
& 5 & 5.07 & +1 \\
& 15 & 14.9 & -1 \\
& 15 & 15.0 & 0 \\
& 30 & 30.2 & +1 \\
& 30 & 30.3 & +1 \\
& 60 & 57.4 & -4 \\
& & 60 & $61.2^{\mathrm{b}}$ & +2 \\
& 5 & 5.84 & $+17^{\mathrm{d}}$ \\
& 15 & 28.0 & $+87^{\mathrm{d}}$ \\
& 30 & 29.9 & 0 \\
\hline
\end{tabular}

${ }^{a}$ Results of triplicate analyses except as noted. Dosing volume $=5 \mathrm{~mL} / \mathrm{kg} ; 5 \mathrm{mg} / \mathrm{mL}=25 \mathrm{mg} / \mathrm{kg}, 15 \mathrm{mg} / \mathrm{mL}=75 \mathrm{mg} / \mathrm{kg}$, $30 \mathrm{mg} / \mathrm{mL}=150 \mathrm{mg} / \mathrm{kg}$, and $60 \mathrm{mg} / \mathrm{mL}=300 \mathrm{mg} / \mathrm{kg}$.

${ }^{b}$ Nine replicates were analyzed.

${ }^{\mathrm{c}}$ Animal room samples.

${ }^{\mathrm{d}}$ High results believed to be caused by an inability to aliquot a representative sample for analysis due to small volumes remaining. 


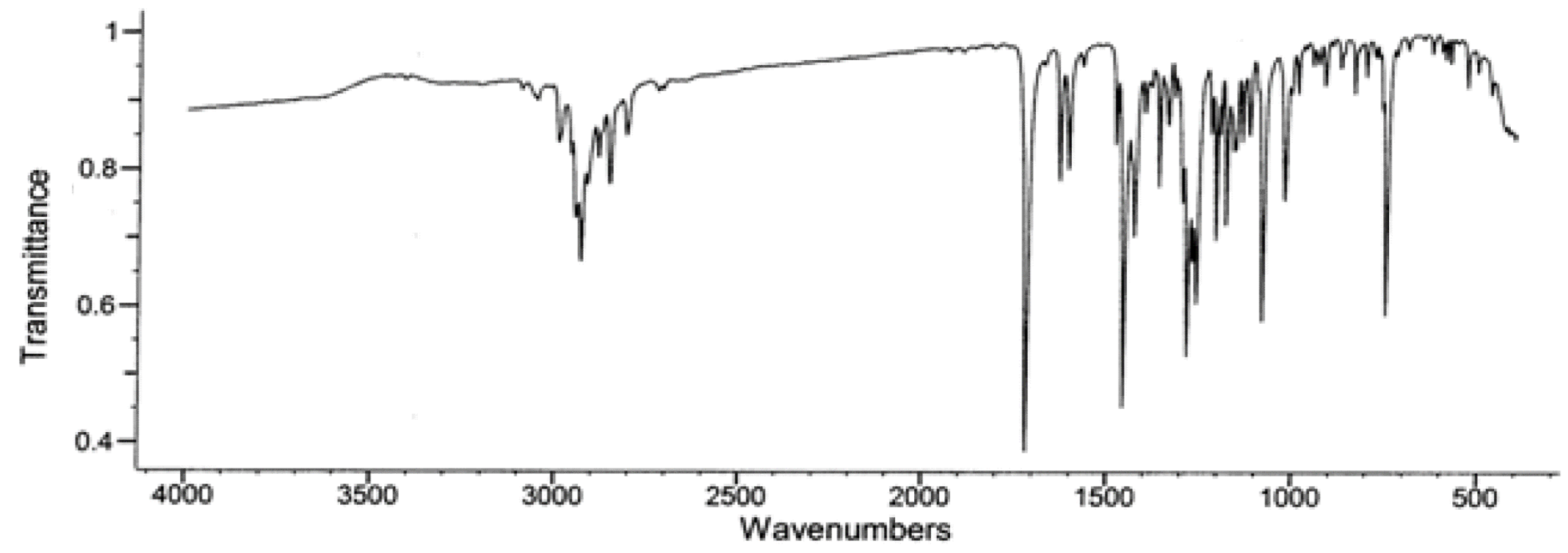

Figure A-1. Fourier Transform Infrared Absorption Spectrum of Vinpocetine 


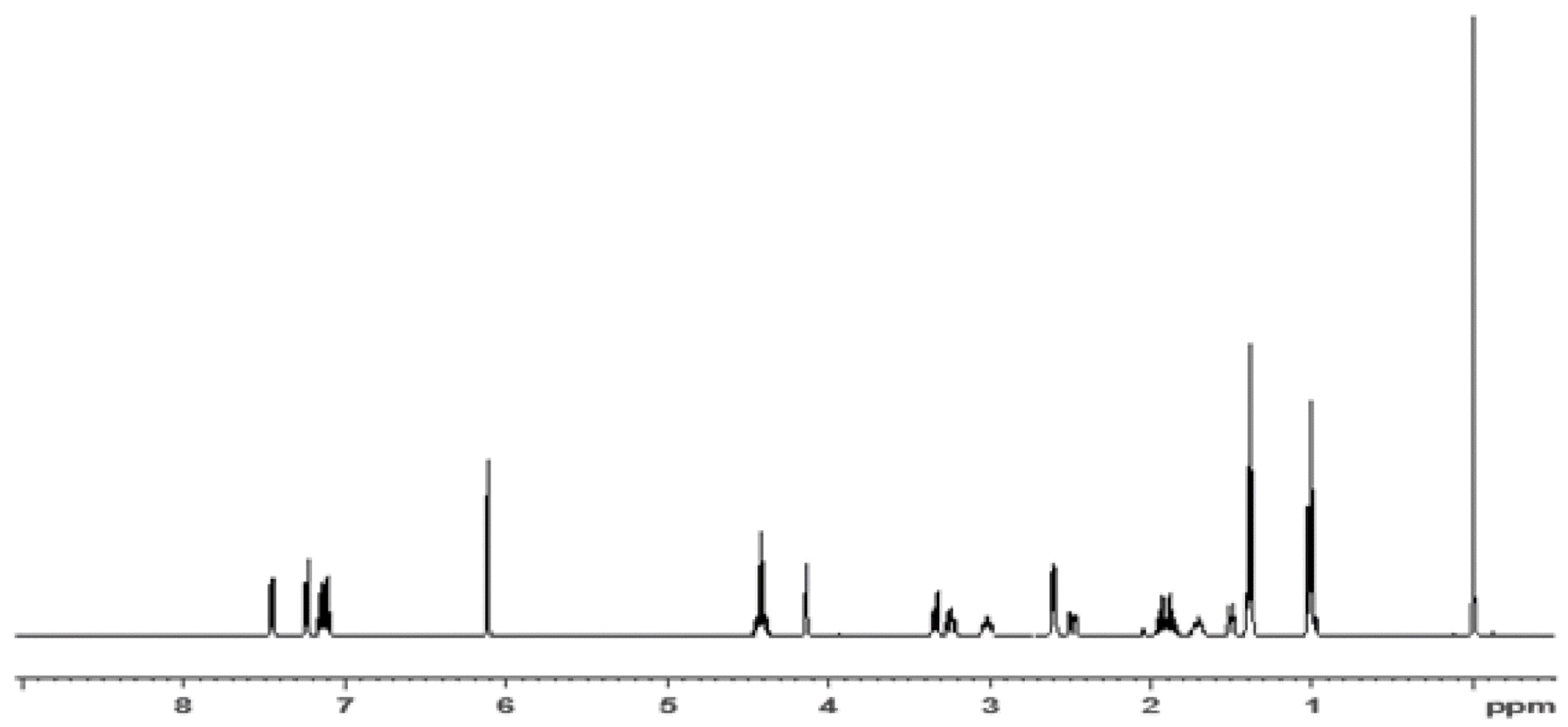

Figure A-2. Proton Nuclear Magnetic Resonance Spectrum of Vinpocetine 


\section{Appendix B. Ingredients, Nutrient Composition, and Contaminant Levels in NIH-07 Rat and Mouse Ration}

\section{Tables}

Table B-1. Ingredients of NIH-07 Rat and Mouse Ration

B-2

Table B-2. Vitamins and Minerals in NIH-07 Rat and Mouse Ration .......................................3

Table B-3. Nutrient Composition of NIH-07 Rat and Mouse Ration ..........................................

Table B-4. Contaminant Levels in NIH-07 Rat and Mouse Ration............................................6 
Table B-1. Ingredients of NIH-07 Rat and Mouse Ration

\begin{tabular}{lc}
\hline \multicolumn{1}{c}{ Ingredients } & Percent by Weight \\
\hline Ground \#2 Yellow Shelled Corn & 24.25 \\
Ground Hard Winter Wheat & 23.00 \\
Soybean Meal (47\% Protein) & 12.00 \\
Fish Meal (62\% Protein) & 10.00 \\
Wheat Middlings & 10.00 \\
Dried Skim Milk & 5.00 \\
Alfalfa Meal (Dehydrated, 17\% Protein) & 4.00 \\
Corn Gluten Meal (60\% Protein) & 3.00 \\
Soy Oil (without Preservatives) & 2.50 \\
Dried Brewer's Yeast & 2.00 \\
Dry Molasses & 1.50 \\
Calcium Phosphate, Dibasic (USP) & 1.25 \\
Calcium Carbonate (USP) & 0.50 \\
Sodium Chloride & 0.50 \\
Premixes (Vitamin) & 0.25 \\
Premixes (Mineral) & 0.15 \\
Choline Chloride (70\% Choline) & 0.10 \\
\hline USP = Unis &
\end{tabular}

USP = United States Pharmacopeia. 
Vinpocetine, NTP DART 03

Table B-2. Vitamins and Minerals in NIH-07 Rat and Mouse Ration

\begin{tabular}{lll}
\hline & \multicolumn{1}{c}{ Amount } & \multicolumn{1}{c}{ Source } \\
\hline Vitamins & $6,062 \mathrm{IU}$ & Stabilized vitamin A palmitate or acetate \\
$\mathrm{A}$ & $5,070 \mathrm{IU}$ & D-activated animal sterol \\
$\mathrm{D}$ & $3.09 \mathrm{mg}$ & Menadione sodium bisulfite complex \\
$\mathrm{K}$ & $22.0 \mathrm{IU}$ & $\alpha$-Tocopheryl acetate \\
$\mathrm{E}$ & $33.0 \mathrm{mg}$ & - \\
Niacin & $2.4 \mathrm{mg}$ & - \\
Folic Acid & $19.8 \mathrm{mg}$ & d-Calcium pantothenate \\
$d$-Pantothenic Acid & $3.8 \mathrm{mg}$ & - \\
Riboflavin & $11.0 \mathrm{mg}$ & Thiamine mononitrate \\
Thiamin & $50 \mathrm{\mu g}$ & - \\
$\mathrm{B}_{12}$ & $6.5 \mathrm{mg}$ & Pyridozine hydrochloride \\
Pyridoxine & $0.15 \mathrm{mg}$ & d-Biotin \\
Biotin & & \\
\hline Minerals & $132 \mathrm{mg}$ & Iron sulfate \\
Iron & $18 \mathrm{mg}$ & Zinc oxide \\
Zinc & $66 \mathrm{mg}$ & Manganese oxide \\
Manganese & $4.4 \mathrm{mg}$ & Copper sulfate \\
Copper & $1.5 \mathrm{mg}$ & Calcium iodate \\
Iodine & $0.44 \mathrm{mg}$ & Cobalt carbonate \\
Cobalt & & \\
\hline IU $=$ internationa units & &
\end{tabular}


Table B-3. Nutrient Composition of NIH-07 Rat and Mouse Ration

\begin{tabular}{|c|c|c|c|}
\hline Nutrient & Mean \pm Standard Deviation & Range & Number of Samples \\
\hline Protein (\% by Weight) & 23.6 & NA & 1 \\
\hline Crude fat (\% by Weight) & 5.3 & NA & 1 \\
\hline Crude fiber (\% by Weight) & 3.43 & NA & 1 \\
\hline Ash (\% by Weight) & 6.33 & NA & 1 \\
\hline \multicolumn{4}{|l|}{ Amino Acids (\% of Total Diet) } \\
\hline Arginine & $1.375 \pm 0.065$ & $1.30-1.43$ & 8 \\
\hline Cysteine & $0.321 \pm 0.035$ & $0.274-3.72$ & 8 \\
\hline Glycine & $1.145 \pm 0.077$ & $1.06-1.131$ & 8 \\
\hline Histidine & $0.516 \pm 0.023$ & $0.497-0.553$ & 8 \\
\hline Isoleucine & $0.982 \pm 0.025$ & $0.952-1.03$ & 8 \\
\hline Leucine & $1.996 \pm 0.054$ & $1.93-2.08$ & 8 \\
\hline Lysine & $1.261 \pm 0.032$ & $1.22-1.32$ & 8 \\
\hline Methionine & $0.487 \pm 0.015$ & $0.468-0.515$ & 8 \\
\hline Phenylalanine & $1.091 \pm 0.020$ & $1.07-1.12$ & 8 \\
\hline Threonine & $0.919 \pm 0.032$ & $0.883-0.961$ & 8 \\
\hline Tryptophan & $0.280 \pm 0.022$ & $0.266-0.326$ & 8 \\
\hline Tyrosine & $0.855 \pm 0.039$ & $0.785-0.894$ & 8 \\
\hline Valine & $1.134 \pm 0.0245$ & $1.11-1.17$ & 8 \\
\hline \multicolumn{4}{|c|}{ Essential Fatty Acids (\% of Total Diet) } \\
\hline Linoleic & $2.23 \pm 0.211$ & $2.04-2.59$ & 8 \\
\hline Linolenic & $0.25 \pm 0.028$ & $0.217-0.296$ & 8 \\
\hline \multicolumn{4}{|l|}{ Vitamins } \\
\hline Vitamin A (IU/kg) & 3,910 & NA & 1 \\
\hline$\alpha$-Tocopherol (ppm) & $48.07 \pm 4.38$ & $40.3-52.73$ & 8 \\
\hline Thiamine $(\mathrm{ppm})^{\mathrm{a}}$ & 13.4 & NA & 1 \\
\hline Riboflavin (ppm) & $14.3 \pm 3.58$ & $10.0-19.8$ & 8 \\
\hline Niacin (ppm) & $99.4 \pm 9.10$ & $87-112$ & 8 \\
\hline Pantothenic Acid (ppm) & $45.6 \pm 3.13$ & $40.4-51.1$ & 8 \\
\hline Pyridoxine (ppm) $)^{b}$ & $12.33 \pm 2.25$ & $9.63-15.6$ & 8 \\
\hline Folic Acid (ppm) & $2.47 \pm 0.550$ & $1.68-3.09$ & 8 \\
\hline Biotin (ppm) & $0.342 \pm 0.125$ & $0.25-0.64$ & 8 \\
\hline Vitamin B12 (ppb) & $50.21 \pm 7.47$ & $41.8-61.6$ & 8 \\
\hline Choline (as Chloride) (ppm) & $1,776 \pm 197$ & $1,570-2,200$ & 8 \\
\hline
\end{tabular}

\section{Minerals}

Calcium (\%) 
Vinpocetine, NTP DART 03

\begin{tabular}{lccc}
\hline \multicolumn{1}{c}{ Nutrient } & Mean \pm Standard Deviation & Range & Number of Samples \\
\hline Phosphorus (\%) & 0.919 & NA & 1 \\
Potassium (\%) & $0.829 \pm 0.036$ & $0.77-0.88$ & 8 \\
Chloride (\%) & $0.625 \pm 0.102$ & $0.441-0.800$ & 8 \\
Sodium (\%) & $0.368 \pm 0.047$ & $0.318-0.469$ & 8 \\
Magnesium (\%) & $0.183 \pm 0.009$ & $0.170-0.194$ & 8 \\
Iron (ppm) & $376.3 \pm 52.5$ & $276-455$ & 8 \\
Manganese (ppm) & $91.03 \pm 7.93$ & $80.7-104.0$ & 8 \\
Zinc (ppm) & $64.07 \pm 11.32$ & $52.4-89.2$ & 8 \\
Copper (ppm) & $14.11 \pm 2.91$ & $11.9-21.1$ & 8 \\
Iodine (ppm) & $1.71 \pm 0.886$ & $0.54-3.45$ & 8 \\
Chromium (ppm) & $3.96 \pm 0.033$ & $3.91-4.00$ & 8 \\
Cobalt (ppm) & $0.53 \pm 0.293$ & $0.01-0.963$ & 8 \\
\hline NA & & & 8 \\
\hline
\end{tabular}

$\mathrm{NA}=$ not applicable.

${ }^{\mathrm{a} A s}$ hydrochloride (thiamine and pyridoxine). 
Table B-4. Contaminant Levels in NIH-07 Rat and Mouse Ration ${ }^{\mathrm{a}}$

\begin{tabular}{|c|c|c|}
\hline & $\begin{array}{c}\text { Mean } \pm \text { Standard } \\
\text { Deviation }^{\mathrm{b}}\end{array}$ & Number of Samples \\
\hline \multicolumn{3}{|l|}{ Contaminants } \\
\hline Arsenic (ppm) & 0.436 & 1 \\
\hline Cadmium (ppm) & 0.085 & 1 \\
\hline Lead (ppm) & 0.117 & 1 \\
\hline Mercury (ppm) & $<0.012$ & 1 \\
\hline Selenium (ppm) & 0.34 & 1 \\
\hline Aflatoxins (ppb) & $<5.00$ & 1 \\
\hline Nitrate Nitrogen $(\mathrm{ppm})^{\mathrm{c}}$ & 9.65 & 1 \\
\hline Nitrite Nitrogen $(\mathrm{ppm})^{\mathrm{c}}$ & $<0.61$ & 1 \\
\hline BHA $(\mathrm{ppm})^{\mathrm{d}}$ & $<1.0$ & 1 \\
\hline BHT (ppm) $)^{\mathrm{d}}$ & $<1.0$ & 1 \\
\hline Aerobic Plate Count (CFU/gm) & $<10$ & 1 \\
\hline Coliform (MPN/gm) & $<3$ & 1 \\
\hline Escherichia coli (MPN/gm) & $<3$ & 1 \\
\hline Salmonella (MPN/gm) & Negative & 1 \\
\hline Total Nitrosamines (ppb) ${ }^{\mathrm{e}}$ & 0 & 1 \\
\hline$N$-Nitrosodimethylamine (ppb) & 0 & 1 \\
\hline$N$-Nitrosopyrrolidine (ppb) ${ }^{\mathrm{e}}$ & 0 & 1 \\
\hline \multicolumn{3}{|l|}{ Pesticides (ppm) } \\
\hline$\alpha$-BHC & $<0.01$ & 1 \\
\hline$\beta-\mathrm{BHC}$ & $<0.02$ & 1 \\
\hline$\gamma$-BHC & $<0.01$ & 1 \\
\hline$\delta$-BHC & $<0.01$ & 1 \\
\hline Heptachlor & $<0.01$ & 1 \\
\hline Aldrin & $<0.01$ & 1 \\
\hline Heptachlor epoxide & $<0.01$ & 1 \\
\hline DDE & $<0.01$ & 1 \\
\hline DDD & $<0.01$ & 1 \\
\hline DDT & $<0.01$ & 1 \\
\hline НCB & $<0.01$ & 1 \\
\hline Mirex & $<0.01$ & 1 \\
\hline Methoxychlor & $<0.05$ & 1 \\
\hline Dieldrin & $<0.01$ & 1 \\
\hline Endrin & $<0.01$ & 1 \\
\hline
\end{tabular}


Vinpocetine, NTP DART 03

\begin{tabular}{|c|c|c|}
\hline & $\begin{array}{c}\text { Mean } \pm \text { Standard } \\
\text { Deviation }^{b}\end{array}$ & Number of Samples \\
\hline Telodrin & $<0.01$ & 1 \\
\hline Chlordane & $<0.05$ & 1 \\
\hline Toxaphene & $<0.10$ & 1 \\
\hline Estimated PCBs & $<0.20$ & 1 \\
\hline Ronnel & $<0.01$ & 1 \\
\hline Ethion & $<0.02$ & 1 \\
\hline Trithion & $<0.05$ & 1 \\
\hline Diazinon & $<0.10$ & 1 \\
\hline Methyl chlorpyrifos & 0.045 & 1 \\
\hline Methyl parathion & $<0.02$ & 1 \\
\hline Ethyl parathion & $<0.02$ & 1 \\
\hline Malathion & 0.033 & 1 \\
\hline Endosulfan I & $<0.01$ & 1 \\
\hline Endosulfan II & $<0.01$ & 1 \\
\hline Endosulfane sulfate & $<0.03$ & 1 \\
\hline \multicolumn{3}{|c|}{$\begin{array}{l}\text { BHA = butylated hydroxyanisole; } \mathrm{BHT} \text { = butylated hydroxytoluene; } \mathrm{CFU}=\text { colony-forming units; MPN = most probable } \\
\text { number; BHC = hexachlorocyclohexane or benzene hexachloride; DDE = dichlorodiphenyldichloroethylene; } \\
\text { DDD = dichlorodiphenyldichloroethane; DDT = dichlorodiphenyltrichloroethane; HCB = hexachlorobenzene; } \\
\text { PCB = polychlorinated biphenyl. } \\
\text { aAll samples were irradiated. } \\
\text { 'For values less than the limit of detection, the detection limit is given as the mean. } \\
\text { 'Sources of contamination: alfalfa, grains, and fish meal. } \\
\text { dSources of contamination: soy oil and fish meal. } \\
\text { eAll values were corrected for percent recovery. }\end{array}$} \\
\hline
\end{tabular}


Vinpocetine, NTP DART 03

\section{Appendix C. Sentinel Animal Program \\ Tables of Contents}

C.1. Methods

.C-2

C.2. Results ....

C-2

\section{Tables}

Table C-1. Laboratory Methods and Agents Tested for in the Sentinel Animal Program ..........C-2 


\section{C.1. Methods}

Animals used in the National Toxicology Program are produced in optimally clean facilities to eliminate potential pathogens that may affect study results. The Sentinel Animal Program is part of the periodic monitoring of animal health that occurs during the toxicologic evaluation of test compounds. Under this program, the disease state of animals is monitored via sera or feces from extra (sentinel) or dosed animals in the study rooms. The sentinel animals and the study animals are subject to identical environmental conditions. Furthermore, the sentinel animals come from the same production source and weanling groups as the animals used for the studies of test compounds.

Ten New Zealand White rabbits were maintained for the dose range-finding rabbit study. Blood samples were collected and allowed to clot, and the serum was separated. All samples were processed appropriately and testing performed by IDEXX BioResearch [formerly Research Animal Diagnostic Laboratory (RADIL), University of Missouri (Columbia, MO)] for determination of the presence of pathogens. The laboratory methods and agents for which testing was performed are tabulated below; the times at which samples were collected during the study are also listed.

Table C-1. Laboratory Methods and Agents Tested for in the Sentinel Animal Program

\begin{tabular}{ll}
\hline \multicolumn{1}{c}{ Method and Test } & \multicolumn{1}{c}{ Time of Collection } \\
\hline Multiplex Fluorescent Immunoassay & \\
CAR bacillus & Study termination \\
Clostridium piliform & Study termination \\
Encephalitozoon cuniculi & Study termination \\
Rotavirus & Study termination \\
Immunofluorescence Assay & Study termination \\
Treponema & Study termination \\
\hline
\end{tabular}

\section{C.2. Results}

Antibodies to Rotavirus were detected in several samples. Rotavirus is a common virus in rabbits, and the laboratory determined that it did not affect the study. All other test results were negative. 


\section{Appendix D. Summary of Peer Review Panel Comments}

\section{Table of Contents}

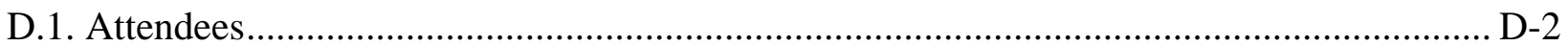

D.2. Introductions and Welcome .................................................................................. D-3

D.3. Public Comments ..................................................................................................... D-3

D.4. Background and Charge to the Panel ........................................................................ D-3

D.5. Prenatal Developmental Toxicity Studies of Tris(chloropropyl) Phosphate .................... D-4

D.6. Prenatal Developmental Toxicity Studies of 4-Methylcyclohexanemethanol................... D-6

D.7. Prenatal Developmental Toxicity Studies of Vinpocetine .......................................... D-10

D.8. Prenatal Developmental Toxicity Studies of Dimethylaminoethanol Bitartrate ............. D-13

D.9. Closing Remarks on the Draft Reports .................................................................... D-14

D.10. Approval of the Peer Review Report by the Chair of the Peer Review Panel ............... D-15 


\section{D.1. Attendees}

\section{Peer Review Panel}

Chair: George Daston, The Proctor and Gamble Company

Cheryl Broussard, Centers for Disease Control and Prevention

Alan Hoberman, Charles River Laboratories Preclinical Services

Linda Roberts, NapaTox Consulting LLC

Mary Alice Smith, University of Georgia

Kimberley Treinen, Sunovian Pharmaceuticals Inc.

National Toxicology Program Board of Scientific Counselors Liaison

Donald Stump, Charles River Laboratories International

\section{National Institute of Environmental Health Sciences Staff}

Brian Berridge

Chad Blystone

Bradley Collins

Michelle Cora

Helen Cunny

Shawn Harris

Michelle Hooth

Angela King-Herbert

Elizabeth Maull, Designated Federal Official

Barry McIntyre

Georgia Roberts

Kristen Ryan

Sheena Scruggs

Keith Shockley

Matthew Stout

Vicki Sutherland

Nigel Walker 
AtLee Watson

Mary Wolfe

\section{Other Federal Agency Staff}

Gonçalo Gamboa, FDA

\section{Contract Support Staff}

Susan Blaine, ICF

Dave Burch, ICF

Lindsey Green, ICF

Ernie Hood, Bridport Services

Steve McCaw, Image Associates

Blake Riley, ICF

Samantha Snow, ICF

\section{D.2. Introductions and Welcome}

The National Toxicology Program (NTP) convened a peer review panel for the draft NTP Developmental and Reproductive Toxicity Technical Reports for: Tris(chloropropyl) Phosphate, 4-Methylcyclohexanemethanol, Vinpocetine, and Dimethylaminoethanol Bitartrate on July 31, 2019, in Conference Room F193, Rall Building, National Institute for Environmental Health Sciences (NIEHS), Research Triangle Park, North Carolina (or via webcast).

- Dr. George Daston, panel chair, called the meeting to order at 8:30 a.m., welcomed everyone to the meeting, asked all attendees to introduce themselves, and reviewed the format for the peer review meeting for the panel and audience.

- Dr. Elizabeth Maull read the conflict of interest policy statement and briefed the attendees on meeting logistics.

- Dr. Donald Stump attended as the liaison to the NTP Board of Scientific Counselors.

\section{D.3. Public Comments}

Dr. Daston noted that no written public comments or requests for oral public comments on the draft technical reports had been received.

\section{D.4. Background and Charge to the Panel}

Dr. Chad Blystone gave a brief presentation on NTP draft technical reports, including information about the levels of evidence for developmental toxicity. He also described the Developmental and Reproductive Toxicity (DART) historical controls and the charge to the panel for the individual peer reviews: 
- Review and evaluate the scientific and technical elements of each study and its presentation.

- Determine whether each study's experimental design, conduct, and findings support NTP's conclusions regarding the developmental toxicity of the substances tested.

\section{D.5. Prenatal Developmental Toxicity Studies of Tris(chloropropyl) Phosphate}

\section{D.5.1. Presentation and Clarifying Questions}

Dr. Kristen Ryan summarized the studies and conclusions reported in the draft NTP Developmental and Reproductive Toxicity Technical Report on the Prenatal Development Studies of Tris(chloropropyl) Phosphate (CASRN 13674-84-5) in Sprague Dawley (Hsd:Sprague Dawley $\left.{ }^{\circledR} S D^{\circledR}\right)$ Rats (Gavage Studies).

Tris(chloropropyl) phosphate (TCPP) is a flame retardant found in a variety of commercial and consumer products. It is ubiquitous but not bioaccumulative in the environment. Exposure can occur via dermal, oral, or inhalation routes. TCPP is a mixture constituted primarily of four isomers; the research focus is often on the primary isomer due to its abundance. The test article used for the NTP studies contained all four isomers. The goal of this study was to characterize the effects of TCPP exposure on pregnant rats and developing fetuses.

The dose range-finding study was conducted in 11 time-mated female rats using doses of 0,300 , 650 , and 1,000 mg/kg/day, administered via gavage. Adverse signs at 1,000 mg/kg/day occurred throughout gestation. These results informed the use in the main study of doses of $0,162.5,325$, and $650 \mathrm{mg} / \mathrm{kg} /$ day in 25 time-mated female rats per group. An additional 25 control dams were added to this study to supplement historical control data for maternal and fetal findings. The main study findings revealed:

- No maternal treatment-related effects on mortality or body weights during gestation

o Clinical observations were of low incidence and limited to the $650 \mathrm{mg} / \mathrm{kg} /$ day group

o At $650 \mathrm{mg} / \mathrm{kg} /$ day, absolute and relative liver weights were increased approximately $26 \%$

- No treatment-related effects on uterine or litter parameters, such as implantations, litter size, live fetuses per litter, or fetal weight

- Fetal skeletal malformations of limited toxicological relevance (e.g., lumbar rudimentary ribs) or those that occurred as single or sporadic incidence

Under the conditions of this prenatal study, NTP's draft conclusion was:

- No evidence of developmental toxicity of TCPP in Hsd:Sprague Dawley rats administered 162.5, 325, or $650 \mathrm{mg} / \mathrm{kg} /$ day in the absence of overt maternal toxicity

There were no clarifying questions or comments about the presentation. 


\section{D.5.2. Peer Review Comments and Panel Discussion}

\section{D.5.2.1. First Reviewer - Dr. Cheryl Broussard}

Dr. Broussard indicated that the study was clearly described, well conducted, and the conclusions followed logically from the presented findings. She agreed with NTP's draft conclusions. Dr. Broussard then recommended adding language explaining the rationale for limiting soft tissue examination to only $50 \%$ of the heads. She also requested that NTP clarify more specifically where the audit procedures and findings were located to aid in transparency. The comments regarding soft tissue allocations and audit procedures applied to all reports. Finally, Dr. Broussard questioned why blood was not collected from the dams for clinical pathology.

- Dr. Ryan noted that the allocation for fetal exams was based on the study guidelines, with every other fetus allocated for head examination. She agreed that NTP could consider adding more information on fetal exam allocations and the use and location of the audit procedures and findings, which are archived electronically, to the reports.

- Dr. Ryan stated that blood chemistry was not typically required in this type of study. Furthermore, these endpoints were not identified in the literature as a primary concern for TCPP exposure.

\section{D.5.2.2. Second Reviewer - Dr. Alan Hoberman}

Dr. Hoberman stated that the study was well conducted, and he did not disagree with the conclusion. However, he noted that the only individual data presented in the reports were fetal data and that the public would benefit from having access to all individual animal data. This comment applied to all reports. The presence or absence of deviations should be included in the report. The historical control data lacked information on postimplantation loss percentages as well as other fetal information. The report failed to comment on an earlier study by Kawasaki (1982) that noted an increase in cervical ribs. Although Dr. Hoberman understood the use of two control groups, he noted that inclusion of group variations would have been informative. He also noted that this class of compound is known to produce enlarged livers, which may be considered an adaptive change rather than maternal toxicity. Because NTP referenced the changes in liver weights, the authors must have considered that the change in weight represented some sort of system perturbation. He recommended adding some discussion detailing why the enlarged liver was not considered as maternal toxicity.

In response to Dr. Hoberman's comments, Dr. Ryan indicated:

- NTP would consider adding language to the report specifying the location of the individual animal data.

- Deviations are listed in the good laboratory practices report. NTP would consider adding a line to the main report such as "no other deviations were noted."

- NTP is currently evaluating the historical control data and will be adding information (i.e., fetal and uterine parameters) to the database. Postimplantation loss observed in this study was limited to a single litter and was not considered an exposure-related finding.

- NTP evaluates cervical ribs as part of the fetal examinations. Although an increase in cervical ribs had been observed in the Kawasaki study, they were not seen in the NTP 
study, and, therefore, not populated in the historical control database. This information could be added.

- She reviewed the cross-reference data from dams to fetuses from the two control groups prior to the data being pooled and found that there were comparable findings in both control groups.

- NTP chose to report that no developmental toxicity was observed in the absence of overt maternal toxicity in this study and indicated that NTP would consider adding language to clarify the issues related to enlarged liver in the discussion.

\section{D.5.3. Vote on NTP Conclusion}

Dr. Daston called for a motion from the panel to approve the conclusion as written. Dr. Hoberman so moved and Dr. Kimberley Treinen seconded the motion. The panel voted unanimously (5 yes, 0 no, 0 abstentions) to approve the conclusion as written.

\section{D.6. Prenatal Developmental Toxicity Studies of 4-Methylcyclohexanemethanol}

\section{D.6.1. Presentation and Clarifying Questions}

Dr. AtLee Watson summarized the studies and conclusions reported in the draft NTP Developmental and Reproductive Toxicity Technical Report on the Prenatal Developmental Toxicity Studies of 4-Methylcyclohexanemethanol (CASRN 34885-03-5) in Sprague Dawley (Hsd:Sprague Dawley ${ }^{\circledR} S D^{\circledR}$ ) Rats (Gavage Studies).

4-Methylcyclohexanemethanol (MCHM) was the chemical involved in the 2014 Elk River Chemical Spill in West Virginia. An estimated 10,000 gallons of crude MCHM leaked into the river, contaminated the municipal water supply, and likely led to human exposure. This prenatal developmental toxicity study resulted from concern for women of childbearing potential and developing embryos/fetuses, and provided an opportunity to evaluate the adequacy of the 1 part per million advisory level set forth by the Centers for Disease Control and Prevention (CDC) and the Agency for Toxic Substances and Disease Registry (ATSDR) for MCHM in drinking water.

The dose range-finding study tested doses of 0, 150, 300, 600, and $900 \mathrm{mg} / \mathrm{kg} / \mathrm{day}$ in groups of 10 time-mated female rats each and examined maternal and fetal endpoints. In this study, exposure to 600 and $900 \mathrm{mg} / \mathrm{kg} /$ day resulted in dose-related mortality and clinical observations of toxicity. These results informed the selection of doses of $0,50,100,200$, and $400 \mathrm{mg} / \mathrm{kg} / \mathrm{day}$ for the main study in 25 time-mated female rats per group. Main study findings included:

- Reduced maternal serum total protein and globulin at doses $\geq 100 \mathrm{mg} / \mathrm{kg} / \mathrm{day}$

- Fetal findings at $400 \mathrm{mg} / \mathrm{kg} /$ day:

o Decreased fetal body weights (15\%) and gravid uterine weight (18\%) compared with controls

o Increased incidences of malformations of the axial skeleton

o Misshapen adrenal glands (malformation)

- No exposure-related fetal findings at doses $\leq 200 \mathrm{mg} / \mathrm{kg} / \mathrm{day}$ 
Under the conditions of this prenatal study, NTP's draft conclusion was:

- Clear evidence of developmental toxicity of MCHM in Hsd:Sprague Dawley rats at $400 \mathrm{mg} / \mathrm{kg} / \mathrm{day}$ in the absence of overt maternal toxicity based on findings of:

o Reduced fetal weight

o Malformations of the axial skeleton

o Malformations of the adrenal glands

As a follow-up to the presentation, panelists had the following clarifying questions and discussion:

\section{Topic - Malformation of the adrenal glands}

- Dr. Linda Roberts asked for a description of the criteria for classifying the adrenal glands as misshapen.

- Dr. Hoberman asked if histopathology is routinely performed when necrotic masses are observed on adrenal glands. Although this finding appeared in three fetuses from different litters, the genealogy of the litters was unknown, which may play a role in the occurrence rate. Responding to a question posed by Dr. Roberts, Dr. Hoberman stated he could not recall ever seeing a misshapen adrenal with a necrotic mass. Dr. Sutherland agreed that it was an unusual finding.

o Dr. Watson indicated that the misshapen adrenal designation was attributed to the presence of a necrotic mass on the adrenal glands.

o Dr. Watson stated that while histopathology could inform whether the occurrence of a necrotic mass on the adrenal gland represents a permanent change or would alter postnatal or subsequent development, guideline prenatal developmental toxicity studies do not routinely call for it.

\section{Topic - Clinical chemistry endpoints}

- Dr. Daston inquired if the clinical chemistry findings on glucose, triglycerides, and blood urea nitrogen levels were also observed in other subchronic MCHM studies or if the changes in the clinical chemistry endpoints were specific to the pregnancy in the rat.

o Dr. Watson noted that there was a decrease in some of the red blood cells in the repeat dose oral gavage study that was conducted by the Eastman Chemical Company. He indicated that Eastman Chemical Company did not observe the same glucose findings.

\section{Topic - Potential MCHM review article}

- Dr. Daston noted that NTP played a significant role in quickly developing information on MCHM and wondered if there will be a larger synthesis of information based on this and other recently conducted studies. He added that there would be interest in these types of summary reports from people who were exposed and who had made health decisions based on what the scientific community conveyed to them. The current report format may be difficult for the general public to understand given the dry and science-based conclusions they contain. 
o Dr. Watson indicated that NTP's website currently has summary findings, but the development of a report summarizing all MCHM-related NTP studies would be addressed in subsequent NTP discussions.

o Dr. Blystone noted that prior communications to the stakeholders were less dry and more informal.

\section{D.6.2. Peer Review Comments and Panel Discussion}

\section{D.6.2.1. First Reviewer - Dr. Mary Alice Smith}

Dr. Smith indicated that the study was designed and conducted according to accepted DART guidelines. She stated that the findings in the study, including reduced fetal weight, adrenal malformations, and increased malformations of the axial skeleton, support the conclusion of clear evidence of developmental toxicity of MCHM in the fetuses from dams exposed to $400 \mathrm{mg} / \mathrm{kg} /$ day. Dr. Smith recommended adding historical normal pregnant rat clinical chemistry ranges (as reported for human studies) to the report, which would help interpret the exposurerelated data. Adding to this comment, Dr. Daston asked if some of the qualitative statements on clinical chemistry endpoints found in the report might be expanded on to put this type of data in context. Dr. Smith recommended that the report clearly state that the dose-related changes are significantly different from the controls based on a dose-related trend or a pairwise comparison effect and to include this type of information in the conclusion statements. Finally, she requested inclusion of a 2018 human epidemiology study investigating the possible association of adverse birth defects with exposure to crude MCHM from the spill site.

- Dr. Michelle Cora, NTP Clinical Pathologist, responding to the clinical chemistry questions, noted that currently NTP does not have historical control data for pregnant rats. She added that reporting values from the study's controls are preferred over those of historical controls due to the number of uncontrolled variables (i.e., animal diet, conditions of the study, type of machine the samples were run on) that influence historical control data. She added that the range for clinical chemistry data indicated in these reports is typically the standard error. Expansion beyond qualitative statements would not be feasible.

- Dr. Watson agreed that inclusion of dose-related response in the fetal body weight conclusion would improve the comprehension of the data but was concerned that it could overcomplicate the conclusion statement. He indicated that NTP would consider implementing this recommendation if it could be done in a concise manner.

- Dr. Watson indicated that he would incorporate the 2018 study, which found no adverse birth outcomes following the spill, in the report's discussion.

\section{D.6.2.2. Second Reviewer - Dr. Cheryl Broussard}

Dr. Broussard found the study design clearly described and well conducted, and that the conclusions followed logically from the presented findings. She agreed with the draft conclusion of clear evidence of developmental toxicity. She suggested adding the rationale for why approximately $50 \%$ of the heads were examined for soft tissue alterations, as well as being more transparent about where to find the audit procedures and findings. She wondered whether the Sentinel Animal Program described in some of the other reports was relevant here also. 
- Dr. Watson replied:

o NTP would add the rationale to the methodology section of the report.

o Given the short duration of these studies, a Sentinel Animal Program is not required. The dams received by the lab underwent a full evaluation by the staff animal veterinarian before they were cleared to be included in the study. That information is included in the report.

\section{D.6.2.3. Third Reviewer - Dr. Linda Roberts}

Dr. Roberts indicated that the studies were conducted properly and agreed, with a single caveat, with the NTP conclusion. She was not as confident with a classification of "clear evidence" versus "some or equivocal" evidence based on the absence of statistical significance in misshapen adrenal glands in the historical controls. The strongest evidence for developmental toxicity was the reduction in fetal body weight. To clarify Dr. Roberts' comments, Dr. Daston asked her to confirm that she thought there was clear evidence that MCHM causes developmental effects based on fetal weight and skeletal malformations, but not changes in adrenal malformation. Dr. Roberts confirmed that this was a correct interpretation of her thoughts.

Dr. Roberts also expressed appreciation that the fetal no-observed-effect level (NOEL) was included in the report and noted that the maternal NOEL of $50 \mathrm{mg} / \mathrm{kg} /$ day was based on the clinical chemistry endpoints. She stated that although there was statistical significance in these endpoints, she was less confident that there was biological significance.

- Dr. Watson agreed that additional information discriminating between structural malformations and alterations that might affect postnatal development would be useful to help understand the significance of the effect. It was difficult to confirm whether there was a pairwise significant difference in the highest dose group for this finding due to the very low incidences. Dr. Watson noted that NTP takes litter incidence into account. The fact that the findings occurred in three single fetuses from three separate litters support the conclusion that the adrenal malformation was a treatment-related effect.

\section{D.6.2.4. Panel Discussion}

Dr. Kimberley Treinen questioned the choice of reporting NOEL for maternal toxicity rather than the no-observed-adverse-effect level (NOAEL). She mentioned that the entire call was characterized as being "in the absence of overt maternal toxicity," by which she assumes to be a NOAEL. Dr. Treinen also recommended adding a line to the summary table correcting for uterine weight. She noted that the study reported high non-pregnancy rates, along with a high rate of misshapen aortic valves. She would like to have seen a lower background rate, given concern about cardiovascular malformations in the controls. The relatively large increase in the axial skeletal malformations with limited variations in other endpoints was an unusual finding. Dr. Treinen recommended that further elaboration is needed in the report to describe the misshapen adrenal glands, perhaps by providing images, given that this is an unusual finding. Dr. Daston agreed that this issue needs more attention in the report. 
- Dr. Watson indicated that NTP avoided distinguishing between adverse and nonadverse effects. Using the NOEL designation avoided some of the close calls that would have been generated by using NOAEL.

- Dr. Vicki Sutherland noted:

o NTP would consider adding language to the tables as recommended.

o At the time of the study, there was a concern about successful pregnancy rates, which has since improved with increased training, suggesting this was not a strain-related effect. NTP uses the same strain across all its studies.

o NTP will consider directing the lab to follow up with histopathology in the future if this finding is present. NTP will also ascertain if this finding is specific to this strain of rat.

Dr. Daston noted that the significant decrease in dam body weight with a significant increase in food consumption was a remarkable finding that, combined with the findings on blood glucose, suggests something interesting going on beyond general maternal toxicity—something that may yield an indication of a mechanism of action. The phenomenon deserved more treatment in the report.

- Dr. Watson said that data from a MCHM toxicogenomics study suggested that fatty acid metabolism may be involved as a mechanism of action. He indicated that NTP would add a discussion to the report.

- Dr. Cora remarked that although she thought the change in blood glucose levels was real, the rats would not be considered hypoglycemic, and the mild decrease is seen with some frequency. She said the triglycerides were affected by what the dams were eating and when they had last ingested food.

\section{D.6.3. Vote on NTP Conclusion}

Dr. Daston called for a motion to accept the conclusion as written, understanding that there would be information added to the report on the adrenal malformations. Dr. Roberts said she would prefer that the reference to adrenal gland malformations be removed from the conclusion. Dr. Smith moved to accept the conclusion as written and Dr. Broussard seconded. The panel passed the motion (4 yes, 1 no, 0 abstentions). Dr. Roberts voted no, citing her discomfort with including the adrenal malformations as the reason for her vote.

\section{D.7. Prenatal Developmental Toxicity Studies of Vinpocetine}

\section{D.7.1. Presentation and Clarifying Questions}

Dr. Sutherland summarized the studies and conclusions reported in the draft NTP Developmental and Reproductive Toxicity Technical Report on the Prenatal Developmental Toxicity Studies of Vinpocetine (CASRN 42971-09-5) in Sprague Dawley (Hsd:Sprague Dawley ${ }^{\circledR} S D^{\circledR}$ ) Rats and New Zealand White (Hra:NZW SPF) Rabbits (Gavage Studies).

Vinpocetine is marketed as a dietary supplement for cognitive enhancement. It is also a semisynthetic/synthetic pharmaceutical agent for treatment of cerebrovascular and cognitive disorders. NTP chose to study vinpocetine due to concerns of consumer exposure through dietary 
supplement use, signals of developmental toxicity in the literature, and lack of adequate toxicity data.

The rat dose range-finding study used doses of $0,20,40,80,160$, or $320 \mathrm{mg} / \mathrm{kg} /$ day via gavage, with 10 time-mated female rats per group. A dose-related decrease in maternal body weight correlated with fetal loss at the higher two doses in this study. These results informed the selection of doses of $0,5,20$, and $60 \mathrm{mg} / \mathrm{kg} /$ day for the main study in 25 time-mated female rats per group. Findings from the main study included:

- Dose-related increase in the incidence of vaginal discharge (20 and $60 \mathrm{mg} / \mathrm{kg} / \mathrm{day}$ )

- Decreased maternal body weight

- Exposure-related increases in postimplantation loss (83\% at $60 \mathrm{mg} / \mathrm{kg} /$ day)

- Fetal examination findings such as:

o Increased incidences of fetuses with ventral septal defect (malformation)

o Increased incidences of incomplete ossification of the thoracic centra (variation) and full thoracolumbar ribs (malformation)

The above findings provided sufficient concern to examine the effects of vinpocetine in a second species, the rabbit. The dosages chosen for the rabbit study were $0,25,75,150$, and $300 \mathrm{mg} / \mathrm{kg} / \mathrm{day}$, administered via gavage to eight time-mated female animals per group. The main rabbit study findings revealed:

- Decreased maternal body weight gains at 150 and $300 \mathrm{mg} / \mathrm{kg} / \mathrm{day}$

- Exposure-related effect on embryo-fetal survival at $300 \mathrm{mg} / \mathrm{kg} / \mathrm{day}$

Data from the rabbit study supported the findings observed in the rat dose range-finding study and rat prenatal developmental toxicity studies.

Under the conditions of the rat prenatal study, NTP's draft conclusion was:

- Clear evidence of developmental toxicity of vinpocetine in Hsd:Sprague Dawley rats in the absence of overt maternal toxicity based on findings of:

o Increased postimplantation loss

o Increased incidences of ventricular septum defects

o Increased incidences of thoracolumbar ribs (full)

o Increased incidences of incomplete ossification of the thoracic centrum

As a follow-up to the presentation, participants had the following clarifying question and discussion:

Topic - No-observed-effect levels

- Dr. Roberts noted that the study did not include NOEL values and asked whether that was intentional.

o Dr. Sutherland responded that NTP had internal discussion about the language; if the panel feels that NOELs should be included in all the reports, the team will consider modifying the text. 


\section{D.7.2. Peer Review Comments and Panel Discussion}

\section{D.7.2.1. First Reviewer - Dr. Alan Hoberman}

Dr. Hoberman expressed appreciation to NTP for completing the study of this dietary supplement, approved performing the studies in both the rat and rabbit, and overall agreed with the conclusion. He recommended that individual animal data be made available for this report and all other studies and thought that including the onset and duration for clinical signs, such as vaginal discharge, could be informative. Recognizing that the studies were hazard assessments and not risk assessments, Dr. Hoberman also thought it would be beneficial to report how the animal doses in the study compared with human doses.

Dr. Sutherland responded:

- The individual data are available online and indicated that NTP would consider how to make access more apparent in the reports.

- The vaginal discharge data did not directly correlate with embryonic loss.

- NTP considered risk assessment information outside the scope of this report.

\section{D.7.2.2. Second Reviewer - Dr. Linda Roberts}

Dr. Roberts commented that the study was well conducted and appreciated that a second species was included. She said that the body weight gain seen did not meet the criteria for overt maternal toxicity. She agreed with the clear evidence conclusion as written.

\section{D.7.2.3. Third Reviewer - Dr. Kimberley Treinen}

Dr. Treinen recommended that an additional line be added to the summary table with corrected numbers for maternal body weight. She noted that there was a comment made in the rabbit study that food consumption might have contributed to the body weight decrement, but it appeared that it was more attributable to the decrease in implants.

In response to Dr. Treinen's comments, Dr. Sutherland indicated:

- NTP would consider adding corrected body weight in the text and tables if that would add clarity.

- The food consumption was not directly correlated to embryonic loss.

\section{D.7.2.4. Other Comments}

Dr. Gonçalo Gamboa, FDA, thanked NTP for keeping the FDA apprised as to the results. He noted that FDA released a statement cautioning women of childbearing ages from consuming this chemical. He appreciated the good communication.

\section{D.7.3. Vote on NTP Conclusion}

Dr. Daston asked for a motion and second from the panel to approve the conclusion as written. Dr. Roberts so moved and Dr. Hoberman seconded the motion. The panel voted unanimously (5 yes, 0 no, 0 abstentions) to approve the conclusion as written. 


\section{D.8. Prenatal Developmental Toxicity Studies of Dimethylaminoethanol Bitartrate}

\section{D.8.1. Presentation and Clarifying Questions}

Dr. Sutherland summarized the studies and conclusions reported in the draft NTP Developmental and Reproductive Toxicity Technical Report on the Prenatal Developmental Toxicity Studies of Dimethylaminoethanol Bitartrate (CASRN 5988-51-2) in Sprague Dawley (Hsd:Sprague Dawley ${ }^{\circledR} S D^{\circledR}$ ) Rats (Gavage Studies).

Dimethylaminoethanol bitartrate (DMAE) is a close structural analog of the essential nutrient choline. It is marketed as a dietary supplement to improve memory and general cognitive function. NTP chose to study DMAE because of its potential for widespread human exposure through its use in industrial and consumer products and limited evidence from the literature that it may be a teratogen and reproductive toxicant.

The dose range-finding study used doses of $0,250,500$, and $1,000 \mathrm{mg} / \mathrm{kg} /$ day via gavage, with 10 time-mated female rats per group. No maternal or fetal toxicity were present at the doses used in the range-finding study. The same doses were employed in the main study, which used 25 time-mated female rats per group. Findings from the main study revealed:

- No treatment-related effects on mortality, body weights, or feed consumption o Effects were sporadic or without a dose response

- No effects on uterine or litter parameters such as implantations, litter size, live fetuses per litter, or fetal weight

- Fetal examination findings of:

o Increased incidence of short thoracolumbar ribs (a variation) at the $1,000 \mathrm{mg} / \mathrm{kg} /$ day dose

o Increased incidence in the number of supernumerary sites, or ossification sites, in the skull at the $1,000 \mathrm{mg} / \mathrm{kg} /$ day dose

Under the conditions of this prenatal study, NTP's draft conclusion was:

- Equivocal evidence of developmental toxicity of DMAE in Hsd:Sprague Dawley rats in the absence of overt maternal toxicity based on increased incidences of:

o Short thoracolumbar ribs

o Supernumerary sites in the skull

There were no clarifying questions or comments about the presentation.

\section{D.8.2. Peer Review Comments and Panel Discussion}

\section{D.8.2.1. First Reviewer - Dr. Kimberley Treinen}

Dr. Treinen commented that the study was well conducted and met the standard for this type of study. She wondered why the absent innominate artery in the high-dose group was not considered a finding, even though it was statistically different from controls and was present across multiple litters. When combined with short innominate arteries, it potentially looked like a 
dose-related effect. Dr. Hoberman commented that the absent innominate artery is a very common variation. However, he added that it and other similar variations do seem to indicate a perturbation in the system and should be investigated.

Dr. Treinen recommended breaking down the historical controls rather than lumping them together.

Dr. Sutherland noted that the absent innominate artery is an extremely common finding and therefore was not included as a potential toxicity endpoint.

\section{D.8.2.2. Second Reviewer - Dr. Mary Alice Smith}

Dr. Smith thought that the maternal death in the $1,000 \mathrm{mg} / \mathrm{kg} /$ day dose group raised a question and recommended adding more historical control data in the report. She remarked that there was not a lot of evidence for dose-related outcomes in this study. In addition, Dr. Smith cautioned against concluding that there were no brain effects and recommended qualifying the statement by indicating that there were no lesions noted in the brain because functional outcomes were not evaluated. Dr. Smith said that it should be made clear that there were no structural changes in the brain.

Dr. Sutherland responded to Dr. Smith:

- More historical control data would be helpful.

- NTP only looked for structural changes in the brain. NTP will ensure that it is clear that there were no structural changes in the brain in the revised report.

- Individual data tables were available, but NTP needs to consider how to make them easier to access.

- The primary report focused on bringing forward positive findings; therefore, negative findings were not highlighted. She mentioned that this distinction would be clarified in the report.

\section{D.8.2.3. Panel Discussion}

Dr. Roberts indicated that the innominate artery finding should have received more attention in the report. Dr. Sutherland asked if she was suggesting more detail in the discussion or an addition to the conclusion. Dr. Roberts responded both.

\section{D.8.3. Vote on NTP Conclusion}

Dr. Daston proposed adding a third bullet to the draft NTP conclusion to read "increased incidence of absent innominate artery." He called for a motion to add the bullet to the NTP conclusion. Dr. Treinen so moved and Dr. Smith seconded. Dr. Daston called for a vote on the conclusion, including the addition. The panel voted unanimously (5 yes, 0 no, 0 abstentions) to approve the conclusion with the addition.

\section{D.9. Closing Remarks on the Draft Reports}

Dr. Daston welcomed additional panel comments on the overall organization of the reports. Dr. Hoberman suggested clarifying the definition of the term "natural death" used throughout the reports. 
Dr. Sutherland noted that they would revise the term to "found dead" in the reports.

Dr. Treinen recommended that litter data, as well as individual data, be added to the reports or compiled as a stand-alone report to assist with understanding the rate of resorptions and other important fetal findings. Dr. Hoberman added that it was standard to have that type of information in a toxicology report.

Dr. Blystone remarked that NTP could explore adding some of the selected endpoints in an appendix.

Dr. Roberts appreciated having the pharmacokinetic information in the report along with its relevance to humans. She added that the value of including the NOEL eliminates the possibility of other researchers calculating their own NOEL based on the data in the report.

Closing the meeting, Dr. Maull thanked all the peer review panelists.

Dr. Daston added his thanks to NTP staff and the panel members for their efforts.

Dr. Daston adjourned the meeting at 11:22 a.m. EDT on July 31, 2019.

\section{D.10. Approval of the Peer Review Report by the Chair of the Peer Review Panel}

This peer review report has been read and approved by the chair of the July 31, 2019, Peer Review of the Draft NTP Developmental and Reproductive Toxicity Technical Reports on the Prenatal Development Studies of Tris(chloropropyl) Phosphate, 4-Methylcyclohexanemethanol, Vinpocetine, and Dimethylaminoethanol Bitartrate.

George Daston, Ph.D.

Peer Review Panel Chair

Date: July 31, 2019 


\title{
Appendix E. Supplemental Files
}

The following supplemental files are available at https://doi.org/10.22427/NTP-DATA-00203277-0000-0000-1.

\section{E.1. Prenatal Developmental Toxicity Dose Range-finding Study - Rats}

I01 - Animal Removal Summary

I03 - Growth Curve

I04 - Mean Body Weights and Survival

I04G - Mean Body Weight Gain

I05 - Clinical Observations Summary

I06 - Mean Feed Consumption

PA46 - Gross Pathology Summary

R09 - Uterine Content Summary

R10 - Fetal Defects

R11 - Fetal Defect Summary

R12 - Placental Findings

R13 - Fetal Defect Cross Reference Summary

\section{E.2. Prenatal Developmental Toxicity Dose Range-finding Individual Animal Data - Rats}

\author{
Individual Animal Body Weight Data \\ Individual Animal Clinical Observations Data \\ Individual Animal Consumption Data \\ Individual Animal Gross Pathology Data \\ Individual Animal Removal Reasons \\ Individual Animal Teratology Dam Data \\ Individual Animal Teratology Fetal Weight \\ Individual Animal Teratology Implant Findings
}




\section{E.3. Prenatal Developmental Toxicity Study - Rats}

I01 - Animal Removal Summary

I03 - Growth Curve

I04 - Mean Body Weights and Survival

I04G - Mean Body Weight Gain

I05 - Clinical Observations Summary

I06 - Mean Feed Consumption

PA46 - Gross Pathology Summary

R09 - Uterine Content Summary

R10 - Fetal Defects

R11 - Fetal Defect Summary

R12 - Placental Findings

R13 - Fetal Defect Cross Reference Summary

\section{E.4. Prenatal Developmental Toxicity Individual Animal Data - Rats}

Individual Animal Body Weight Data

Individual Animal Clinical Observations Data

Individual Animal Consumption Data

Individual Animal Gross Pathology Data

Individual Animal Removal Reasons

Individual Animal Teratology Dam Data

Individual Animal Teratology Fetal Weight

Individual Animal Teratology Implant Findings

E.5. Prenatal Developmental Toxicity Dose Range-finding Individual Animal Data - Rabbits

Individual Animal Body Weight Data

Individual Animal Clinical Observations Data

Individual Animal Consumption Data 
Individual Animal Gross Pathology Data

Individual Animal Removal Reasons

Individual Animal Teratology Dam Data

Individual Animal Teratology Fetal Weight

Individual Animal Teratology Implant Findings 


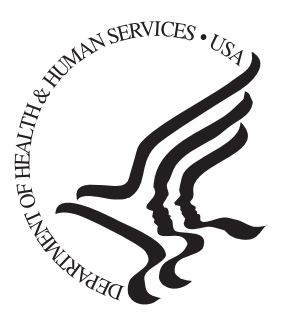

\section{National Toxicology Program}

NTP Central Data Management, MD EC-03

National Institute of Environmental Health Sciences

P.O. Box 12233

Research Triangle Park, NC 27709

http://ntp.niehs.nih.gov 